\title{
O preparo e a prática de profissionais de saúde de nível médio para o diagnóstico da tuberculose pulmonar
}

\section{Maria Cristina Mazzaia}

Tese apresentada ao Programa de Pós-Graduação em Saúde Pública da Faculdade de Saúde Pública da Universidade de São Paulo para obtenção do título de Doutor em Saúde Pública.

Área de Concentração: Serviços de Saúde Pública Orientador: Prof ${ }^{a}$ Dr $^{\mathbf{a}}$ Maria Helena Matte

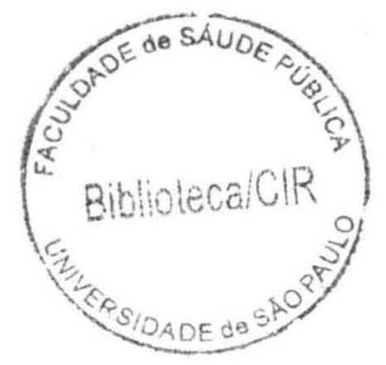

São Paulo

2005 
Autorizo, exclusivamente para fins acadêmicos e científicos, a reprodução total ou parcial desta tese, por processos fotocopiadores.

Assinatura:

Data:

$$
4623212005 \text { dre }
$$


"O medo de amar é o medo de ser livre para o que der e vier, livre para sempre estar, onde o justo estiver O medo de amar é o medo de ter de a todo momento escolher com acerto e precisão a melhor direção... O medo de amar é não arriscar esperando que façam por nós o que é nosso dever, recusar o poder..." Beto Guedes

“Nós vos pedimos com insistência: não digam nunca isso é natural! Diante dos acontecimentos de cada dia, numa época em que reina a confusão... ...em que o arbitrário tem força de lei, em que a humanidade se desumaniza, não digam nunca isso é natural!

Para que nada passe a ser imutável!

Bertold Brecht

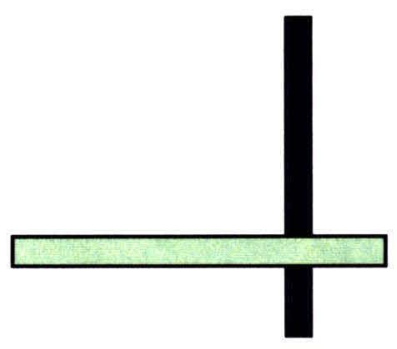




\section{Dedicatória}

A Josefa, minha mãe querida, cuja presença constante continua a tornar possível nossas vidas e sonhos

Ao Walther, meu pai querido, o mais fiel torcedor para o meu sucesso

Ao Humberto, meu marido, companheiro e amigo, compreendendo e apoiando-me sempre

Aos meus filhos Gabriela e Artur, motivos de alegria e força, que me ajudam a compreender o verdadeiro sentido do "amar"

Ao Bernardino e Mercília, meus carinhosos tios, que sempre têm uma palavra de estímulo nos momentos de maior aflição

Ao Eduardo e Erika, meus irmãos, ombros amigos e colaboradores na caminhada

\section{Valeu！}

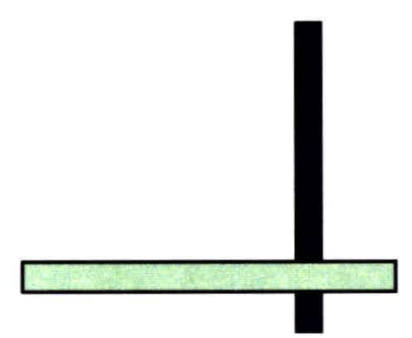




\section{Agradecimentos Especiais}

Muitos foram aqueles que direta ou indiretamente contribuíram para a realização deste sonho, porém, mesmo correndo o risco de ser injusta e não realizar todas as citações que deveria, não posso deixar de me manifestar e agradecer formalmente pessoas e instituições sem as quais a finalização deste trabalho não seria possível.

A Deus, de todo meu coração, pela vida e pela força para persistir.

A Maria Helena, amiga e orientadora que durante nossa trajetória neste momento de aprendizagem dividiu comigo incertezas, mudanças e aflições, apoiando e valorizando sempre, ousando e possibilitando, o meu mais sincero obrigada !

À pessoa do Dr Roberto Tozze, Médico Socorrista do Instituto da Criança do HCFMUSP que, atendendo meu filho prontamente e de forma extremamente humana $e$ competente, proporcionou a manutenção de minhas capacidades para a finalização deste trabalho. Muito obrigada!

Aos profissionais de saúde do Instituto da Criança do HCFMUSP que com atenção e desvelo nos atenderam e nos ajudaram a vislumbrar novas possibilidades, sendo uma delas este trabalho!

Às professoras Dr ${ }^{\mathrm{a}}$ Margarida Maria Mattos Brito de Almeida, Dr ${ }^{\mathrm{a}}$ Marcia Faria Westphal, Dr ${ }^{2}$ Maria Jacyra de Campos Nogueira, Dra Alice Moreira Derntl, Dra Maguida Costa Stefanelli e Coordenadora do Programa Estadual de Controle da Tuberculose Dr ${ }^{\mathrm{a}}$ Vera Maria Neder Galesi, que prontamente aceitaram contribuir no desenvolvimento deste trabalho através de participações na qualificação e pré-banca

À Dra Naomi Kawaoka Komatsu Coordenadora do Programa de Controle da Tuberculose da Secretaria de Saúde do Município de São Paulo pessoa atenciosa e comprometida com seu trabalho, valorizando as iniciativas

Aos Profissionais da Divisão de Tuberculose do Centro de Vigilância Epidemiológica "Dr Alexandre Vranjac" da Secretaria de Estado da Saúde de São Paulo, sempre prontos a colaborar estimulando os profissionais no combate à tuberculose

Às amigas Allison, Edvane e Mariângela, Coordenadoras dos Cursos de Enfermagem das Universidades de São Caetano do Sul, Paulista e Cruzeiro do Sul, respectivamente, por compreenderem minha distância e possibilitarem a concretização deste projeto de vida

À todos os meus companheiros de trabalho, Professores e Enfermeiras, por dividirem esperanças e compartilharem os mesmos valores

Às amigas Rosemary e Abuela Carmem, que tão pacientemente em nossas caminhadas, souberam ouvir e estimular 
À minha sobrinha Patrícia que colaborou não só sendo um excelente ouvido mas também colaborando como Assistente de Pesquisa neste estudo !

Aos Profissionais de Saúde dos Serviços de Saúde e laboratórios da Secretaria de Saúde do Município de São Paulo e aos Usuários dos serviços de saúde visitados que cordialmente aceitaram participar da pesquisa e muito contribuíram

Ao CECOVISA/USP - Centro Colaborador em Vigilância Sanitária/FSP. Convênio CA n ${ }^{\circ}$ 06/99 -44-ANVS/MS - processo $n^{\circ}$ 2001.1.1048.6.9. pesquisa

A HCG Equipamentos Ltda pela colaboração nas atividades de impressão desta

Às Secretárias e Bibliotecárias do Centro de Informação e Referência da Faculdade de Saúde Pública da USP pela atenção a auxílio exato na hora exata

Aos Profissionais da CPG da Faculdade de Saúde Pública da USP pela orientação, apoio e contribuição nas dificuldades burocráticas

Muito, muito obrigada !!!! 


\section{Resumo}

Mazzaia MC. O preparo e a prática de profissionais de saúde de nível médio para o diagnóstico da tuberculose pulmonar. São Paulo; 2004 [Tese de Doutorado Faculdade de Saúde Pública da USP].

O Programa Nacional de Controle da Tuberculose recomenda a baciloscopia do escarro para o diagnóstico e controle de tratamento da tuberculose. Para assegurar a qualidade necessária na análise das amostras de escarro é importante a colheita adequada de amostras de escarro, do paciente do PNCT, e garantir a segurança dos profissionais de saúde e da comunidade a respeito da transmissão da tuberculose. $O$ principal objetivo deste estudo foi conhecer o preparo e a prática dos profissionais de saúde que contribuem para a obtenção adequada da amostra de escarro.Foi realizada uma investigação qualitativa em serviços públicos de saúde, um estudo de caso na cidade de São Paulo. Os dados foram coletados através de entrevistas com profissionais de saúde e com o usuário do PNCT a respeito da percepção da tuberculose e sobre a aquisição da amostra de escarro, a rotina da prática dos profissionais de saúde também foi observada. Os resultados mostraram um aumento na participação de enfermeiros no processo de requisição de baciloscopia de escarro; uma diminuição no tempo necessário para o retorno dos resultados; um aumento na participação de profissionais de saúde em treinamentos. Além disso, a falta de conhecimento dos profissionais de saúde sobre a importância da baciloscopia para o controle de tratamento da tuberculose, e a falta de orientação de instruções fundamentais para usuário do PNCT para colheita das amostras de escarro foram observados. O relacionamento dos profissionais de saúde e os usuários do PNCT foi entendido como fundamental para o alcance dos objetivos do programa; as normas de biossegurança não foram incorporadas nos serviços de saúde estudados; somente 12 dos 27 serviços de saúde tinham o manual para a colheita das amostras de escarro; os usuários do PNCT demonstraram atitude positiva em relação à aquisição de amostra de escarro; o acondicionamento das amostras de escarro assim como o transporte e qualidade das mesmas melhorou, entretanto uma melhora no processo de requisição de baciloscopia é necessária. Projetos educativos e materiais de consulta são essenciais para assegurar que os profissionais de saúde observem as normas do PNCT, e, ainda importância do relacionamento entre usuários do PNCT e profissionais de 
saúde deve ser inserido em ambos. É necessário criar um banco de dados sobre os profissionais de saúde treinados, e também deve ser adotado não somente métodos quantitativos, mas qualitativos de acompanhamento e avaliação de programas de saúde.

Palavras chave: Tuberculose, projeto educativo, serviços de saúde, baciloscopia de escarro, biossegurança. 


\section{Summary}

Mazzaia, MC. O preparo e a prática de profissionais de saúde de nível médio para o diagnóstico da tuberculose pulmonar [The training and practice of the standard level health personnel to the diagnosis of pulmonary tuberculosis]. São Paulo (BR); 2005. [Tese de Doutorado - Faculdade de Saúde Pública da Universidade de São Paulo].

The National Program for Tuberculosis Control (NPTC) recommends the baciloscopy of sputum for diagnosis and control of treatment of tuberculosis. To assure the necessary quality in the sample analysis it is important to properly collect sputum specimens from patients, and guaranty the biosafety of the technical personnel and the community regarding tuberculosis transmission. The main objective of this study was to observe training and practices of the health personnel that contributes to an appropriate acquisition of sputum specimens. A qualitative investigation was carried out in public health services, a study the case of São Paulo. Data was collected by interviewing health personnel, and the NPTC users about perception on tuberculosis and sample acquisition, the routine practices of the health personnel was also observed. The results showed an increase in the participation of Nurses in the requisition process for baciloscopy of sputum; a decrease in time needed for results return; an increase in participation of health personnel on trainings. Moreover, the lack of knowledge of health personnel about the importance of baciloscopy to the control of treatment in tuberculosis, and the lack of fundamentally oriented instructions to PNTC user on sample collection were observed. The personal and NPTC users relationship was understand as fundamental to achieve the program objectives; biosafety rules were not incorporated in health services studied; only 12 of the 27 health services visited had the Manual for sputum sample acquisition; the NPTC users demonstrated positive attitude toward the sample acquisition; the preparation of the samples as much as it's transport and quality, improved however an improvement in requisition process for baciloscopy is needed. Educational projects and material are essential to assure health personnel to observe NPTC's guidelines, and the importance of the relationship among users and health personnel must to be introduced in the material. It is necessary to create a database on personnel training, and also to adopt not only quantitative but qualitative methods to monitor and evaluate the health programs.

Key words: tuberculosis, educational programs, health services, baciloscopy of sputum, biosafety. 


\section{Índice}

Introdução

$\begin{array}{ll}\text { O problema } & 7\end{array}$

$\begin{array}{ll}\text { Descrevendo projetos educativos } & 10\end{array}$

$\begin{array}{ll}\text { Referencial do Estudo } & 24\end{array}$

$\begin{array}{ll}\text { Objetivos } & 34\end{array}$

$\begin{array}{ll}\text { Metodologia } & 37\end{array}$

$\begin{array}{ll}\text { Resultados e Discussão } & 48\end{array}$

Caracterização dos Serviços de Saúde $\quad 49$

Sobre as práticas de formação de profissionais de saúde

$\begin{array}{ll}\text { Perfil e preparo dos profissionais de saúde } & 51\end{array}$

$\begin{array}{ll}\text { Opinião sobre o Manual de Orientação } & 61\end{array}$

$\begin{array}{ll}\text { Conhecimento dos profissionais de saúde } & 64\end{array}$

Sobre a prática de atendimento dos profissionais e realidade dos serviços de saúde

$\begin{array}{ll}\text { Questões de biossegurança } & 67\end{array}$

$\begin{array}{ll}\text { Prática referida pelos profissionais de saúde } & 82\end{array}$

$\begin{array}{ll}\text { Observação da prática dos profissionais de saúde } & 91\end{array}$

$\begin{array}{ll}\text { Percepção dos profissionais sobre participação } & 97\end{array}$

Sobre o resultado dos processos de capacitação na prática dos profissionais de saúde 


\section{Lista de tabelas}

Tabela 1: Número de profissionais de saúde segundo idade nos diferentes serviços de saúde estudados. São Paulo, 2004.

Tabela 2: Número de profissionais de saúde entrevistados segundo grau de escolaridade referido. São Paulo, 2004.

Tabela 3: Número de profissionais entrevistados segundo tempo de formação como profissional de saúde. São Paulo, 2004.

Tabela 4: Número de profissionais segundo tempo de trabalho no PNCT, São Paulo, 2004.

Tabela 5: Profissionais de saúde que conhecem o Manual de Orientação segundo tempo de trabalho no PNCT e participação em treinamentos. São Paulo, 2004.

Tabela 5a: Profissionais de saúde que não conhecem o Manual de Orientação segundo tempo de trabalho no PNCT e participação em treinamentos. São Paulo, 2004.

Tabela 6: Tempo decorrido do último treinamento sobre tuberculose em relação ao número de profissionais que conheciam ou não o Manual de Orientação. São Paulo, 2004.

Tabela 7: Conhecimento dos profissionais de saúde sobre a baciloscopia de escarro e sua importância no diagnóstico e controle de tratamento da tuberculose pulmonar. São Paulo, 2004.

Tabela 8: Conhecimento dos profissionais de saúde que referiram conhecer o Manual de Orientação sobre a definição e importância da baciloscopia de escarro relacionado à participação em treinamentos. São Paulo, 2004. 
Tabela 9: Conhecimento dos profissionais de saúde que referiram não conhecer o Manual de Orientação sobre a definição e importância da baciloscopia de escarro relacionado à participação em treinamentos. São Paulo, 2004.

Tabela 10: Classificação dos locais de atendimento aos usuários do PNCT nos serviços de saúde visitados quanto à adequação às normas de biossegurança. São Paulo, 2004.

Tabela 11: Local de coleta da amostra de escarro citados pelos profissionais nos serviços de saúde visitados. São Paulo, 2004.

Tabela 12: Tipos de serviços de saúde relacionado à categoria profissional responsável pelo preenchimento da solicitação de baciloscopias. São Paulo, 2004.

Tabela 13: Tempo de espera pelos resultados das baciloscopias de escarro solicitadas pelos serviços de saúde. São Paulo, 2004

Tabela 14: Número de profissionais de saúde que conhecem o Manual de Orientação segundo sua participação em treinamentos relacionado ao uso de luvas no recebimento das amostras de escarro. São Paulo, 2004

Tabela 15: Número de profissionais de saúde que desconheciam o Manual de Orientação segundo sua participação em treinamentos relacionado ao uso de luvas no recebimento das amostras de escarro. São Paulo, 2004.

Tabela 16: Uso de luvas pelos profissionais de saúde que conheciam o Manual de Orientação relacionado ao tipo de serviço de saúde. São Paulo, 2004.

Tabela 17: Uso de luvas pelos profissionais de saúde que desconheciam o Manual de Orientação relacionado ao tipo de serviço de saúde. São Paulo, 2004.

Tabela 18: Número de profissionais e o uso de luvas na recepção das amostras de escarro. São Paulo, 2004.

Tabela 19: Número de usuários do serviço de saúde entrevistado em relação a idade citada. São Paulo, 2004.

Tabela 20: Número de usuários do serviço de saúde entrevistados em relação ao grau de escolaridade citado. São Paulo, 2004. 
Tabela 21: Número de usuários conforme o tipo de citação sobre o exame de escarro. São Paulo, 2004.

Tabela 22: Profissionais de saúde dos serviços onde ocorreu entrevista de usuários do PNCT relacionados à participação em treinamentos $\mathrm{e}$ conhecimento do Manual de Orientação. São Paulo, 2004.

\section{Lista de Quadros}

Quadro 1: Resumo das variáveis e a forma de coleta dos dados

Quadro 2: Temas discutidos durante treinamento na FSP USP em Nov. 2002 referidos pelos profissionais de saúde. São Paulo, 2004.

Quadro 3: Percepção dos profissionais de saúde sobre a participação no treinamento realizado na FSP USP em Novembro de 2002. São Paulo, 2004

Quadro 4: Opinião dos profissionais de saúde sobre o Manual de Orientação para Coleta de Amostras de Escarro e Outros Materiais para Baciloscopia e Cultura para Diagnóstico da Tuberculose. São Paulo, 2004.

Quadro 5: Temas citados como orientação realizada aos usuários do PNCT de acordo com frequência nos relatos dos profissionais que referiram não conhecer o manual de orientação e a participação ou não em treinamentos. São Paulo, 2004.

Quadro 6: Temas citados como orientação realizada aos usuários do PNCT de acordo com frequência nos relatos dos profissionais que referiram conhecer o manual de orientação e a participação ou não em treinamentos

Quadro 7: Temas citados pelos profissionais de saúde, que não conheciam o Manual de Orientação, como orientação realizada aos usuários do PNCT para conservação e transporte das amostras de escarro, relacionado a participação em treinamentos. São Paulo, 2004.

Quadro 8: Temas citados pelos profissionais de saúde, que conheciam o Manual de Orientação, como orientação realizada aos usuários do PNCT para conservação e transporte das amostras de escarro, relacionado a participação em treinamentos. São Paulo, 2004.

Quadro 9: Número de observações sobre a comunicação dos profissionais de saúde durante a orientação do usuário do PNCT sobre a colheita da amostra de escarro. São Paulo, 2004. 
Quadro 10: Frequência dos itens nas orientações para a colheita de amostras de escarro realizadas por profissionais de saúde relacionado a participação dos profissionais em treinamentos e o conhecimento sobre o Manual de Orientação. São Paulo, 2004.

Quadro 11: Frequência dos temas citados como percepção dos profissionais de saúde quanto à sua participação na colheita de amostra de escarro, de acordo com o conhecimento ou não do Manual de Orientação. São Paulo, 2004.

Quadro 12: Frequência de temas citados pelos usuários do PNCT sobre a importância e utilidade do exame de escarro. São Paulo, 2004.

Quadro 13: Opinião dos usuários do PNCT entrevistados sobre a colheita da amostra de escarro. São Paulo, 2004.

Quadro 14: Frequência das formas relatadas como orientação recebida dos profissionais de saúde para colher a amostra de escarro. São Paulo, 2004.

Quadro 15: Adequação das amostras de escarro de acordo com acondicionamento, transporte, qualidade da amostra e solicitação de exame, segundo avaliação dos profissionais de laboratórios da rede pública. São Paulo, 2004.

Quadro 16: Número de baciloscopias realizadas e sintomáticos respiratórios examinados no Município de São Paulo nos quatro trimestres de 2003 e no primeiro trimestre de 2004. São Paulo, 2004.

\section{Anexos}

Anexo 1 pré e pós-teste aplicado no treinamento na FSP USP em Novembro de 2002

Anexo 2 questionário aplicado no treinamento na FSP USP em Novembro de 2002

Anexo 3 Entrevista para profissionais de saúde que atendem usuários do PNCT

Anexo 4 Entrevista com profissionais do laboratório

Anexo 5 Entrevista com usuários do PNCT

Anexo 6 Roteiro de Observação da prática dos profissionais de saúde

Anexo 7 Termo de Consentimento Livre e Esclarecido 


\section{INTRODUÇÃO}


A tuberculose caracteriza-se por ser uma doença infecto-contagiosa causada por um bacilo, uma micobactéria denominada $M$. tuberculosis, este tem como principal reservatório o homem, localizando-se preferencialmente nos pulmões forma pulmonar da tuberculose - e é transmitido através de vias aéreas, ou seja, é transmitido através da fala, do espirro e especialmente da tosse, quando o indivíduo elimina no ambiente grande quantidade de partículas cujo núcleo seco contendo 1 ou 2 bacilos - Núcleo de Wells - com diâmetro de até $5 \mu$. Os Núcleos de Wells, pelo tamanho diminuto, têm maior facilidade de atingir bronquíolos e alvéolos. Os bacilos que alcançam os bronquíolos e alvéolos, podem iniciar sua multiplicação e desenvolver a infecção (BRASIL 2002, 2002c, 2002d).

A fonte de infecção da tuberculose, então, são os indivíduos doentes capazes de transmitir o $M$. tuberculosis para o meio, geralmente é o indivíduo portador de tuberculose pulmonar, também denominado bacilífero, já que possui bacilos e os elimina através de suas secreções naso-faríngeas. Presume-se que no período de um ano, um indivíduo doente e bacilífero pode infectar em torno de 15 a 20 pessoas com quem manteve contato, e isto vai depender da quantidade de bacilos eliminada e também das condições do indivíduo susceptível. Enquanto o indivíduo não iniciar o tratamento para a tuberculose permanecerá eliminando bactérias para o meio, se for portador da tuberculose pulmonar (BRASIL 2002, 2002c, 2002d).

Todos os indivíduos apresentam chances de cura quando tratados de forma adequada obedecendo os princípios da moderna quimioterapia que compreende 6 tipos de drogas em 4 esquemas de tratamento padronizados, diminuindo assim a chance de eliminação do bacilo para o meio ambiente (BRASIL 2002, 2002c).

A tuberculose permanece como um problema de saúde pública atingindo indistintamente países em todo o mundo, agravado com o advento da Síndrome da Imunodeficiência Adquirida (SIDA/AIDS), quando a partir de 1981, observou-se o aumento de notificação de casos da doença, principalmente em indivíduos portadores do vírus HIV, característica esta notória nos países desenvolvidos onde as taxas relativas à tuberculose vinham diminuindo (BRASIL 2002d).

A princípio, este aumento do número de notificações nos países desenvolvidos foi imputado ao empobrecimento da população principalmente nos grandes centros 
urbanos e à epidemia de HIV, porém, após estudo dos casos notificados nos Estados Unidos observou-se que as notificações de casos novos eram entre imigrantes recémchegados de países em desenvolvimento (RAVAGLIONE 2003). Além disso, um aumento dos casos de tuberculose multi-resistente (TMR) em portadores do vírus HIV em Nova York e após surgimento de casos de TMR em pacientes nunca antes tratados mostrou que mudanças urgentes deveriam ser implementadas na política de atendimento às pessoas com tuberculose não só nos países desenvolvidos mas também, e principalmente nos países em desenvolvimento, dado à facilidade de trânsito da população no mundo devido ao fenômeno da globalização (RAVAGLIONE 2003).

Em 1994 a Organização Mundial da Saúde (OMS) lança Bases para o Efetivo Controle da Tuberculose, descrevendo os elementos básicos para um programa ou política de atendimento, hoje mundialmente aceitos: um comitê governamental para sustentação do controle da tuberculose, o diagnóstico através da baciloscopia do escarro principalmente entre sintomáticos respiratórios que procuram os serviços de saúde, a implementação do tratamento de curta duração em condições de monitoramento incluindo a observação direta da ingestão do medicamento, a implantação de um sistema de suprimento de medicamentos e, levantamento e divulgação dos resultados obtidos com resultados dos tratamentos. Em 1995 este programa passou a ser designado DOTS (directly observed therapy - short-course) (RAVAGLIONE 2003, WAIYEW 1999, RUFFINO-NETO 2001).

Na segunda metade dos anos 90 foi estabelecida a vigilância e monitoramento global do sistema de atendimento à tuberculose no mundo pela OMS, sendo divulgado o primeiro relatório em 1997 que demonstrou que as metas para o ano 2000 estavam comprometidas, foi pequena a adesão entre os 22 países em desenvolvimento prioritários para a adoção das medidas DOTS e responsáveis por $80 \%$ da incidência de tuberculose mundial (RAVAGLIONE 2003).

De acordo com estimativas da Organização Mundial da Saúde (OMS), aproximadamente 8 milhões de casos e 2,9 milhões de mortes por tuberculose ocorreram no mundo na década de 90 , sendo que $95 \%$ destes casos ocorreram em países em desenvolvimento; 100 milhões de pessoas são infectadas por tuberculose a cada ano e, nos países em desenvolvimento, entre $30 \%$ e $60 \%$ dos adultos estão 
infectados. Dos infectados, de 8 a 10 milhões desenvolverão a doença e, cerca da metade destes - 5 milhões de pessoas - apresentarão a doença em sua forma contagiante, ou seja, pulmonar. São 3 milhões de óbitos conhecidos e determinados por tuberculose ao ano. Os grupos populacionais mais afetados nos países desenvolvidos são idosos, minorias étnicas e imigrantes estrangeiros (BRASIL 2002c, 2002d).

Nos países em desenvolvimento a tuberculose atinge todas as faixas etárias, com predomínio de ocorrência em indivíduos economicamente ativos, ou seja entre 20 e 50 anos (BRASIL 2002).

Segundo a OMS, são 22 países responsáveis por $80 \%$ da incidência mundial de tuberculose e o Brasil está entre eles, sendo que, de acordo com estimativas do Ministério da Saúde, ainda ocorrem no Brasil em torno de 15 a $20 \%$ de subnotificação de casos novos de tuberculose (RAVAGLIONE 2003, WHO 2003).

No Brasil espera-se a ocorrência de 130 mil casos novos por ano com uma estimativa de prevalência de 50 milhões de infectados (BRASIL 2002, 2002c).

A tuberculose no Brasil mata anualmente em torno de 6 mil pessoas, o que a torna uma doença muito significativa considerando que pode ser curada se diagnosticada e tratada conforme recomendações do Programa Nacional de Controle da Tuberculose (PNCT) e OMS (CAPUANO 2001, BRASIL 2002, 2002c, 2002d).

A identificação de indivíduos bacilíferos e o tratamento dos mesmos tornamse então ações fundamentais para o controle da tuberculose, e desta forma é possível perceber a importância de ações conjuntas e união de esforços, tanto de serviços de saúde como da comunidade, para o controle desta doença que apresenta forma de contágio facilitada se levado em consideração a situação sócio-econômica da maioria da população brasileira, principalmente da população moradora na periferia das grandes cidades somada, conforme Guia de Vigilância Epidemiológica para Tuberculose (BRASIL 2002c) às "fraquezas de organização do sistema de saúde e às deficiências de gestão" que inibem "a queda sustentada de doenças marcadas pelo contexto social".

Em 1998 um comitê formado pela OMS identificou os 6 maiores obstáculos à implantação da estratégia DOTS em países em desenvolvimento: inexistência de 
pessoal qualificado, escasso seguimento e avaliação de casos, infraestrutura insuficiente, debilidade dos serviços de laboratório, baixa adesão de médicos de serviços privados e outros profissionais da saúde pública e a descentralização incompleta do atendimento à saúde (RAVAGLIONE 2003, WHO 2003).

Considerando as avaliações e recomendações da OMS, em 1999 o Ministério da Saúde definiu a tuberculose como prioridade entre as políticas governamentais de saúde. Em 2001, a então Secretaria de Políticas de Saúde através do Departamento de Atenção Básica, firmou parceria com as Secretarias Estaduais e Municipais de Saúde, depois de estabelecer 382 municípios prioritários para a reorganização do atendimento do PNCT. Estes municípios compreendem $80 \%$ das notificações de tuberculose registradas no Ministério da Saúde (BRASIL 2002b, 2002c, 2004).

Desta forma, o Ministério da Saúde lança o Plano Nacional de Mobilização para Intensificação das ações de Controle da Tuberculose, com estratégias que acompanharam o processo de reorganização da atenção básica do país e, mediante as quais, seria possível controlar a tuberculose, com a intenção de instituir o acesso universal da população às ações do PNCT (BRASIL 2002b, 2002c, 2004).

A grande concentração de população e as precárias condições sócioeconômicas e sanitárias entretanto, são um agravante para a disseminação da tuberculose nas cidades brasileiras, como é o caso da cidade de São Paulo.

O município de São Paulo foi classificado como prioritário para a reorganização e intensificação do PNCT, apresentando um coeficiente de incidência de aproximadamente 70/100.000 em 2002 e 63/100.000 em 2003, com o coeficiente de incidência para casos de tuberculose pulmonar bacilífera de aproximadamente $39 / 100.000$ em 2002 e 38/100.000 em 2003, índices estes maiores do que os dados referentes ao Estado de São Paulo que em 2002 apresentou uma incidência de 47,15/100.000 habitantes com 17.999 casos e, em 2003 a taxa foi de 45,62/100.000 habitantes com 17.659 casos (SECRETARIA DA SAÚDE DO MUNICÍPIO DE SP 2004, DATASUS 2004).

O coeficiente de mortalidade no município de São Paulo em 2003 foi de aproximadamente $4,3 / 100.000$, com uma porcentagem de cura de $55 \%$ para casos novos e $38 \%$ para retratamento (CDC SSMSP, 2204). Apesar da perspectiva de reorganização da atenção básica incorporando as atividades do PNCT, no Município 
de São Paulo, o diagnóstico da doença ainda se dá, em sua maioria, em serviços hospitalares e de emergência, perfazendo $60 \%$ dos casos diagnosticados, contra $35 \%$ de casos diagnosticados em serviços ambulatoriais.

Incorporando as recomendações da OMS, o PNCT, então, compreende um conjunto de ações integradas e desenvolvidas pelos diferentes níveis de governo, com a participação da comunidade, visando reduzir a mortalidade, a morbidade e atenuar o sofrimento humano causado pela doença, tem como principal estratégia a localização de fontes de infecção e seu tratamento, portanto a procura de casos de tuberculose, estratégia esta tida como medida de maior impacto epidemiológico (BRASIL 2002, 2002c, 2002d; NIERO 1977).

A procura de casos, ou busca ativa, é uma atividade programática para a localização das fontes de infecção de tuberculose o que compreende ações e recursos técnicos necessários para operacionalizar o diagnóstico da tuberculose, envolvendo então, os serviços de saúde e a própria comunidade. Estas ações estão voltadas para os grupos populacionais com maior probabilidade de contrair a tuberculose como sintomáticos respiratórios (indivíduos com queixa de tosse e expectoração por pelo menos três semanas), contatos de casos de tuberculose, suspeitos radiológicos e pessoas em condições de saúde ou condição social que predisponham `a tuberculose (BRASIL 2002c).

Para a localização das fontes de infecção é necessário ocorrer a suspeita diagnóstica, ou seja, é necessário que alguém - conhecedor da doença identifique os indivíduos sintomáticos respiratórios, encaminhe-os para a realização da baciloscopia do escarro - um dos métodos bacteriológicos - que é a pesquisa da presença do bacilo da tuberculose - M. tuberculosis - no escarro do indivíduo suspeito, e, sendo positivo o resultado, encaminhar o indivíduo para tratamento. O procedimento descrito é a forma de reduzir a possibilidade de transmissão da doença, já que o indivíduo elimina bacilos para o meio ambiente enquanto não tratado. É importante lembrar que quanto antes a doença for diagnosticada menor será a chance de transmissão e a gravidade da doença (SES 2002).

O Ministério da Saúde preconiza que o diagnóstico da tuberculose pulmonar esteja fundamentado no exame bacteriológico - baciloscopia do escarro - (exame microscópico direto e cultura), e que o método bacteriológico 
preenche totalmente condições de ordem epidemiológica, econômica, social e técnica exigidas pelo PNCT e deve ser considerado como medida diagnóstica prioritária (NIERO 1977, BRASIL 2002).

Das ações programáticas estabelecidas para as Us.S. (Unidades de Saúde) brasileiras, a baciloscopia de escarro tem sido a mais amplamente difundida e prioritariamente utilizada como uma das estratégias de Atenção Primária à Saúde (APS) (BRASIL 2002, 2002c, NIERO 1977, 1996).

\section{O Problema}

A realização do exame bacteriológico então, envolve a colheita da amostra de escarro e o processamento desta amostra pelos profissionais do laboratório, portanto, uma fase externa e outra interna ao laboratório, ambas as fases necessitam de medidas de controle objetivando a qualidade das atividades.

O controle de qualidade externo ao laboratório de micobactéria é entendido como o processo de vigilância das ações do PNCT, particularmente aquelas que visam a assegurar a qualidade das amostras de escarro que chegam ao laboratório. Desta forma, a vigilância das ações vai desde a recepção do cliente, primeira instrução quanto à colheita de amostra de escarro realizada, o recebimento da amostra de escarro, o acondicionamento e o transporte do material biológico, até o exame e remessa de resultados, assim como ações de referência e contra-referência entre Us.S. e laboratórios. A dinâmica do processo deve ser objeto de avaliações contínuas, a partir do confronto com os padrões de normas e procedimentos estabelecidos para estas ações (NIERO e DERNTL 1993, NIERO e col. 1996).

Baseados nestas premissas, NIERO e DERNTL (1996) realizaram estudos voltados à qualidade externa ao laboratório e, no primeiro destes estudos, identificaram que $3 \%$, ou seja, 1180 de 44.479 amostras de escarro foram recusadas pelo laboratório de micobactéria da Faculdade de Saúde Pública (FSP) da USP. Se for considerado, segundo SMITH (1994) que um indivíduo bacilífero, eliminando o bacilo da tuberculose no meio ambiente, pode contaminar de 15 a 20 outras pessoas antes do início do seu tratamento, percebe-se a gravidade da demora no estabelecimento do diagnóstico. NIERO e DERNTL (1996) investigaram os motivos que levavam à recusa das amostras de escarro sendo que, quatro destes motivos chamaram mais a atenção: amostra insuficiente (31\%), formulário de pedido enviado 
sem o material biológico (22\%), pote sem o formulário $(11,9 \%)$ e pote sem identificação $(10,6 \%)$. Estes estudos sugerem algumas hipóteses cujas falhas estariam centradas, basicamente, em assuntos referentes aos recursos humanos como: falta de treinamento e supervisão, insatisfação no trabalho, alta rotatividade funcional, desvio de função e baixos salários.

Diante destes resultados NIERO e DERNTL (1993) elaboraram um novo modelo de formulário de pedido de exame e informe de resultado para exame microscópico numa tentativa de minimizar as causas de rejeição de amostras de escarro e, principalmente, para servir como instrumento de análise de desempenho de profissionais de enfermagem na realização de procedimentos do PNCT, visando a qualidade das amostras de escarro para baciloscopia, já que na unidade de saúde onde o estudo foi realizado, as atividades de orientação dos indivíduos para a colheita da amostra de escarro, recepção e encaminhamento da amostra, ficavam a cargo do pessoal de enfermagem (NIERO e DERNTL 1989 a).

Este formulário serviu para a realização de dois estudos posteriores realizado pelos mesmos autores, onde o primeiro ressaltou que somente $27,5 \%$ dos usuários foram atendidos corretamente conforme o PNCT na atividade "colheita de amostras" ; no segundo estudo, com a finalidade de aprofundar as hipóteses levantadas na primeira pesquisa, foi verificado que apenas $4,7 \%$ dos usuários foram atendidos sem qualquer falha que mencionasse problemas de identificação, número incorreto de amostras, intervalos incorretos de solicitações ou falta de alguma informação na via de solicitação do exame (NIERO e DERNTL 1989a).

Finalmente, um último estudo realizado pelos mesmos autores levantou as dificuldades identificadas por profissionais de saúde na realização de procedimentos estabelecidos no PNCT para o exame microscópico de escarro, onde foram apontadas, dentre outras, questões de ordem pessoal e interpessoal na relação entre usuários e equipe de saúde (NIERO e col 1996).

Com respeito à qualidade de amostras de escarro para a baciloscopia, para que o usuário retorne às Us.S. com o material colhido na forma preconizada pelos padrões de qualidade externos ao laboratório, implícita está a necessidade de orientação, efetuada pelos profissionais de saúde e a compreensão do usuário (PIOVESAN 1970, NIERO e col. 1993, NIERO e col. 1996). Do exposto, é possível 
observar que, independentemente da existência de normas e manuais de procedimentos no PNCT, as ações poderão ou não virem a ser concretizadas

Para a execução do PNCT estão envolvidos profissionais de várias categorias, desta forma faz-se necessário preparo de profissionais que atendam a demanda diária de uma unidade de saúde sensibilizados para a identificação e posterior orientação de um indivíduo sintomático respiratório e seus possíveis encaminhamentos. A implantação do PNCT exige recursos não só humanos, como materiais e econômicos, sendo de extrema importância o envolvimento do profissional, já que depende dele as orientações que serão realizadas aos usuários do serviço (BRASIL 2002, 2002c, NIERO 1977, NIERO e col 1996, RUFFINO-NETO 2001).

Destacando a importância de recursos humanos capacitados para a execução do PNCT, em 1998, um comitê formado pela OMS identificou os 6 maiores obstáculos à implantação da estratégia DOTS em países em desenvolvimento: inexistência de pessoal qualificado, escasso seguimento e avaliação de casos, infraestrutura insuficiente, debilidade dos serviços de laboratório, baixa adesão de médicos de serviços privados e outros profissionais da saúde pública e a descentralização incompleta do atendimento à saúde (RAVAGLIONE 2003, WHO 2003).

Habilitação do pessoal, programas de educação continuada, supervisão e coordenação do trabalho realizado, então, são estratégias em Recursos Humanos que possibilitam o encaminhamento das atividades da unidade de saúde na consecução dos objetivos almejados por um programa de controle de doenças pois, conforme relatório da OMS, pode tornar-se um impedimento no alcance de metas (WHO 2002, 2003).

Dependendo da organização dos serviços de saúde, fica a cargo dos profissionais de nível médio a orientação dos usuários do serviço para a colheita da amostra de escarro, conferência do pedido de exames, recebimento do escarro colhido pelo cliente e muitas vezes recebimento do resultado de exame e posterior transcrição do resultado em livros de controle, orientação do usuário quanto ao uso adequado dos medicamentos e encaminhamentos, além das anotações de enfermagem em prontuários ou fichas de controle. 


\section{Descrevendo duas iniciativas de projetos educativos no preparo de}

\section{profissionais para a busca de casos e diagnóstico da tuberculose pulmonar}

Nos resultados dos fóruns de saúde mundiais, em que se privilegia a ampliação do sentido e da expressão de cidadania, como na I Conferência Internacional sobre a Promoção da Saúde - Ottawa em 1987, foram retomadas as discussões sobre temas ainda não atendidos e trazidos a público em Alma Ata. Destacou-se a importância do desenvolvimento de habilidades pessoais, o que significa transferir para a esfera individual a prerrogativa do cuidar e do controlar a saúde e, a necessidade de reorientação dos serviços de saúde, contemplando não só as políticas públicas como também a capacidade profissional para a efetivação destas políticas (DECLARAÇÃO DE OTTAWA 1987, DECLARAÇÃO DE ALMA ATA 1976).

Percebe-se o quanto é emergente a necessidade de organização de programas educativos. Estes programas educativos devem sensibilizar os profissionais de saúde e também oferecer a estes, instrumentos para que possam questionar e modificar sua realidade de trabalho, adequando suas atividades, onde os mesmos possam envolverse e desta forma realmente atender às necessidades da população (DECLARAÇÃO DE OTTAWA 1987, DECLARAÇÃO DE ALMA ATA 1976).

A capacitação de equipes de saúde para o atendimento do PNCT é tida como uma das principais ações do Plano de Eliminação da Hanseníase e Controle da Tuberculose em Municípios Prioritários Através da Atenção Básica (RUFFINONETTO, 2001)

Nesta perspectiva, a Divisão de Tuberculose (DT) do Centro de Vigilância Epidemiológica (CVE) da Secretaria de Estado da Saúde do Estado de São Paulo (SES), realizou em Novembro do ano 2000 uma Campanha de Busca Ativa de Casos de Tuberculose no Estado de São Paulo e como preparativo para a mesma ocorreu um Treinamento de Multiplicadores da Campanha de Busca Ativa de Casos de Tuberculose em Outubro do mesmo ano. A Divisão de Tuberculose tinha como perspectiva implementar ações de fortalecimento da política de atendimento do PNCT no Estado de São Paulo. 
Neste treinamento foram veiculadas informações para profissionais de saúde do PNCT das várias regiões do Estado de São Paulo, estes futuros multiplicadores, em sua maioria, ocupavam posições de expressão dentro da organização do sistema de saúde local, de onde se originavam. As informações apresentadas durante o treinamento versaram sobre a situação atual do PNCT no Estado, os problemas enfrentados e a sensibilização de profissionais de referência dentro do programa sobre a importância do diagnóstico da tuberculose pulmonar baseado na baciloscopia de escarro, a forma humanizada de atendimento do usuário do programa, bem como a necessidade de fornecer-lhes orientações sobre o procedimento a ser realizado para a colheita da amostra de escarro (CAMPINAS 1999, MAZZAIA 2000).

O conteúdo do treinamento para a Campanha do Sintomático Respiratório foi desenvolvido através de aulas expositivas sobre os temas já citados, com a participação ativa dos funcionários na resolução de suas dúvidas, entretanto em tempo bastante limitado, pois o tempo era curto para o atendimento de dúvidas de dois grupos distintos, um no período da manhã e outro a tarde.

A DT do CVE da SES na época do treinamento para a Campanha do Sintomático Respiratório, teve uma preocupação quanto à necessidade de tornar público para a rede de atendimento do PNCT a inadequação das orientações que estavam sendo realizadas ao cliente sobre a colheita da amostra de escarro e que estas orientações não estavam de acordo com o que era preconizado no PNCT. Ainda almejava veicular a informação sobre a necessidade de observação sobre a forma como o usuário do PNCT era atendido nas unidades de saúde, além de divulgar a necessidade da atenção dos trabalhadores da saúde sobre o sintomático respiratório e seu imediato encaminhamento para a colheita da amostra de escarro para elucidação diagnóstica, tratamento e eliminação de fonte de infecção, diminuindo a possibilidade de propagação da doença.

Assim, durante a Campanha de Busca Ativa de Sintomáticos Respiratórios em Novembro de 2000 foram interrogadas 2.411 .661 pessoas, $7 \%$ da população do estado e destas, 81.797 foram identificadas como sintomáticos respiratórios, 46.377 baciloscopias de escarro foram realizadas e 548 resultaram em baciloscopias positivas (GALESE e col. 2001). 
Após este trabalho, no ano de 2001, o Estado de São Paulo apresentou 20.125 casos notificados de tuberculose, sendo 9.848 (48,93\%) casos de tuberculose pulmonar em maiores de 15 anos com baciloscopia positiva, $2.555(12,7 \%)$ casos de tuberculose pulmonar em maiores de 15 anos com baciloscopia não realizada e 3523 $(17,5 \%)$ casos de tuberculose pulmonar com baciloscopias negativas (SES 2002).

Quando da observação destes números e procurando compreender a realidade de atendimento das unidades de saúde espalhadas pelo Estado de São Paulo, a seguinte pergunta foi formulada:

\section{Será que realmente as baciloscopias de escarro identificadas como negativas o}

são, considerando a técnica adequada para a colheita da amostra, acondicionamento e transporte da mesma até o laboratório ?

A necessidade de revisão da situação do desenvolvimento das baciloscopias de escarro nas várias regiões do país se intensifica com a publicação da portaria $\mathrm{n}^{\circ}$ 1474 de 19/8/02 do BRASIL (2002b), que versa sobre o Incentivo para o Controle da Tuberculose na Atenção Básica de Saúde, que seria o pagamento de procedimentos relativos ao atendimento de portadores de tuberculose, mediante o cumprimento de critérios que envolvem a realização da baciloscopia de escarro a saber:

- Notificação do caso novo de tuberculose com diagnóstico realizado por meio de baciloscopia direta do escarro ou cultura;

- Notificação da alta por cura da tuberculose mediante o resultado negativo da baciloscopia do escarro de controle de tratamento até o quarto mês para usuários em esquema I de tratamento e até o sétimo mês para usuários no esquema III de tratamento.

O controle do tratamento da tuberculose pulmonar com baciloscopias de escarro não foi uma prática estabelecida na região do grande $\mathrm{ABC}$, conforme achados de MAZZAIA (2000), apesar das orientações do PNCT (BRASIL 2002, 2002c) nem tampouco a solicitação de baciloscopias para a comprovação de resultados negativos na pesquisa de BAAR (bacilo álcool-ácido resistentes).

Preocupados com as questões que envolviam a baciloscopia do escarro, a Divisão de Tuberculose do CVE, pensou em um novo programa educativo para os profissionais de saúde, e desta vez, tinham a expectativa de alcançar os profissionais 
que realmente atendiam ao usuário do PNCT, e os orientavam para a colheita das amostras de escarro.

O programa educativo idealizado foi um treinamento pontual (SOUZA 1991) onde foram contemplados conteúdos que de forma direta ou indireta interferem na qualidade das amostras de escarro para os exames microscópicos, considerando a obtenção da amostra como atividade de atenção primária prioritária das unidades de saúde dentro do PNCT (SES 2002).

Com o objetivo de sensibilizar os profissionais para a importância da baciloscopia de escarro para o diagnóstico e controle de tratamento da tuberculose pulmonar, o treinamento foi intitulado "Treinamento para Coleta de Material para Baciloscopia e Cultura para Diagnóstico e Controle de Tratamento de Tuberculose Pulmonar".

A Divisão de Tuberculose do CVE convidou profissionais envolvidos com pesquisa relativas a qualidade externa ao laboratório em tuberculose para formar um grupo que foi composto por Enfermeiras, Médicos, Biólogos do Instituto Adolfo Lutz e uma Fisioterapeuta, que deveriam planejar o conteúdo a ser desenvolvido durante o treinamento. Este grupo passou a ser identificado como equipe de trabalho.

Durante os encontros da equipe de trabalho ocorreram várias discussões sobre as possibilidades reais que este grupo teria para proporcionar espaços de discussão sobre o conteúdo já citado acima.

As pessoas que formaram a equipe de trabalho entenderam que o treinamento deveria ser suficientemente abrangente, tentando alcançar as diversas realidades que se apresentariam durante o processo, pois, os profissionais que ali estariam seriam provenientes de diversas categorias e também de diversas realidades políticas considerando que grande parte dos serviços de saúde convidados a participar do treinamento são municipalizados, o que significa que acompanham as políticas de saúde instituídas pelo município e não mais somente as recomendações da Secretaria de Estado da Saúde.

A equipe de trabalho conviveu com uma situação limitante importante- o tempo - pois o desejo da Divisão de Tuberculose, com a intenção de socializar as informações para todo o Estado de São Paulo, programou encontros de no máximo 4 horas de duração. Assim, para que todo o conteúdo discutido durante o treinamento 
pudesse ser revisto pelos profissionais em caso de dúvidas, um material de consulta foi elaborado pela equipe de trabalho e equipe da Divisão de Tuberculose do CVE para ser utilizado durante o período de treinamento e posterior consulta dos profissionais nos seus locais de atuação. O material de consulta foi elaborado com o cuidado de utilizar textos de fácil assimilação pelos profissionais de saúde e foi denominado "Manual de Orientação para Coleta de Amostras de Escarro e outros Materiais para Baciloscopia e Cultura para Diagnóstico e Controle da Tuberculose" Manual de Orientação (SES 2002). O conteúdo do Manual de Orientação foi baseado no PNCT (BRASIL 2002, 2002C), GALESI e col (2001) e estudos de CAMPINAS (1999) e MAZZAIA (2000) e tinha como objetivo "orientar e auxiliar na capacitação de profissionais das equipes de saúde envolvidas no PNCT a colher amostras adequadas de material para exame bacteriológico de escarro, diminuindo o tempo necessário para o diagnóstico da tuberculose” (SES 2002).

A equipe concordava com DIAZ (1995) que ressalta a capacidade da educação em promover a renovação de valores nas pessoas bem como facilitar a percepção de problemas, desenvolvendo consciência e um compromisso que podem propiciar mudanças, desde pequenas atitudes, até a participação e envolvimento na resolução dos problemas.

A expectativa da equipe foi de através das discussões dos temas durante o treinamento, sensibilizar os profíssionais e iniciar um processo de mudança, começando pela mudança de atitude com relação a amostra de escarro, já que a mesma traz embutido em seu conceito uma importância vital para o PNCT e a manutenção da saúde da população. Acreditava-se que após o início deste processo algumas mudanças locais ocorreriam, não só com relação ao aumento no número de diagnósticos e controle de tratamentos baseados em baciloscopias, mas também com o envolvimento dos profissionais de saúde quanto aos aspectos relacionais no atendimento do usuário do serviço de saúde.

Entendendo o ser humano como um sujeito que se constitui social e historicamente, ou melhor dizendo, parafraseando FREIRE (2000) "natureza de homens e mulheres entendida como social e historicamente constituindo-se", a equipe de trabalho almejou o desenvolvimento de um trabalho que pudesse, apesar do tempo muito limitado, possibilitar a reflexão e discussão de situações de trabalho 
e que, os profissionais participantes pudessem vislumbrar uma forma de trabalho adequando às ações preconizadas pelo PNCT, ao seu local de atuação e suas possibilidades de atividades locais.

O que se pretendeu foi desenvolver um conteúdo que fornecesse instrumentos ao pessoal de saúde das unidades de saúde para as atividades com os pacientes do PNCT visando, não só a adequada orientação dos mesmos para a colheita da amostra de escarro mas também que durante a orientação do usuário fosse realizado de um atendimento humanizado em que ao cliente fosse oferecida a oportunidade de verbalizar dúvidas e de ser ouvido sobre suas dificuldades e impressões.

Entender o trabalho como uma possibilidade de produzir capacidades, e não de esvaziá-las, e no que se refere ao tema, capacidade de ajudar o indivíduo, possível portador de tuberculose pulmonar, a obter informações sobre seu estado de saúde, não só com relação ao diagnóstico, mas também ao processo de tratamento e cura, foi o horizonte que permeou o trabalho do grupo:

"A teoria é a construção dessa forma ideal que colocamos como o objetivo; a prática é o esforço que procura aproximar o objetivo do modelo" (MOYSÉS e col 2002).

Existiu portanto, uma preocupação da equipe de trabalho de coerência entre métodos e estratégias utilizadas durante o treinamento e os resultados esperados na prática dos profissionais que participaram do treinamento.

KURCGANT e col. (1994), referindo-se ao contexto hospitalar, apontam que a gestão de recursos humanos não apresenta preocupação com as pessoas, com a realização intelectual, criativa e social destas; acrescenta que o trabalho é organizado segundo métodos e processos repetitivos e normatizados, sem dar oportunidade ao trabalhador de usar sua energia criadora ou tomar decisões quando capacitado à fazêlo, o que resulta em processos educativos automáticos, pouco preocupados com a realização das pessoas como indivíduo, voltados para o atendimento do poder dominante, que por sua vez têm como consequência formação de profissionais pouco reflexivos e críticos, com dificuldades de operar mudanças no processo de trabalho, 
sem interesse no desenvolvimento profissional e sem compromisso com os resultados do trabalho.

A realidade hospitalar não difere da realidade dos serviços de atenção básica à saúde, e a equipe de trabalho entendeu que a forma como o treinamento fosse desenvolvido seria determinante na perpetuação ou mudança do quadro citado acima, pelo menos no que diz respeito ao atendimento do usuário do PNCT.

Embora o título escolhido "treinamento" não fosse o adequado, segundo SOUZA (1991) pois, não houve tempo para atividades práticas dos participantes do treinamento, entendia-se que seria o mais facilmente compreendido pela população esperada para participar do evento. Ainda sobre o termo treinamento, a equipe de trabalho percebeu a denominação muito próxima da questão do adestramento e não foi esta a intenção primeira do trabalho, pelo contrário, o que se pretendeu foi uma sensibilização e uma aproximação da necessidade de mudanças nos locais de trabalho.

A equipe de trabalho também entendeu que seria necessário que os profissionais de saúde participantes do treinamento, enquanto formandos, que vivenciam um processo de formação, conforme FREIRE (2000), e baseados em sua experiência de trabalho, se convencessem que participar de um trabalho de atualização não é receber conteúdo ou conhecimento transmitido por pessoal técnico, é sim participar, criando possibilidades para a produção ou a construção de seu próprio conhecimento. FREIRE (2000) acrescenta que é preciso compreender que "quem forma se forma e re-forma ao formar e quem é formado forma-se e forma ao ser formado".

O roteiro de trabalho da equipe levou em consideração o contexto sócioeconômico-cultural e político dos profissionais de saúde que compareceram ao treinamento, entendendo que estes profissionais só passariam a ser sujeitos de sua práxis através da reflexão sobre o seu ambiente e trabalho, e acreditavam que quanto mais estes sujeitos refletissem sobre sua realidade, comparando-a aos temas propostos durante o treinamento, mais se tornariam progressiva e gradualmente conscientes, comprometidos a intervir na realidade para mudá-la (MIZUKAMI 1986, FREIRE 2000). 
Considerou-se os preceitos de ROSA (2000) citando que a aprendizagem é interacionista quando reconhece o conhecimento como resultante das interações do sujeito — com todas as suas características hereditárias - com o meio - com todos os seus condicionantes sociais e culturais. A mesma autora acrescenta que na perspectiva construtivista, o indivíduo que vive o processo de formação "é o centro do pólo de aprendizagem, pois deve estar constantemente mobilizado para pensar e construir o seu próprio conhecimento" e o profissional que conduz o trabalho de formação "é o centro do processo de ensino", cabendo ao mesmo a direção, a definição dos objetivos e o controle dos rumos da ação pedagógica.

"Discutir o como não é mesmo fácil. Isso pela enorme distância entre fornecer/perder as regras de uma técnica e saber a lógica em que se fundam essas mesmas regras. Para aplicá-las com sabedoria, isto é, para descobrir nas situações suas propensões, flexibilizando, inovando e criando estratégias de acordo com as situações concretas, é necessário saber, ter constituído seu próprio conhecimento com a sensibilidade para enxergar e respeitar o outro, com todas as suas diferenças. Tem de haver a sabedoria de saber fazer. Aí, teoria e prática não mais competem entre si, exibem-se inseparáveis" (MOYSÉS e col. 2002).

"Discutir os comos não é dar receitas, mas questionar evidências tão caras que delas próprias não nos apercebemos: é pôr sob suspeição conhecimentos, saberes, seus modos de produção e circulação" (MOYSÉS e col. 2002).

A Divisão de Tuberculose do CVE comunicou a todos os municípios o seu programa, abrindo vagas para inscrições dos participantes interessados sendo 40 participantes por período de quatro horas de treinamento. Aos representantes das instituições de saúde do interior do Estado de São Paulo foi instruído que após participarem do treinamento teriam de reproduzi-lo para suas regiões em datas já estipuladas pela Divisão de Tuberculose do CVE.

O treinamento foi então realizado num período de 4 horas para cada turma de participantes, numa primeira etapa para representantes enviados pelas instituições de 
saúde do Interior do Estado de São Paulo, no dia 7 de Novembro de 2002 e estes representantes reproduziram as informações que receberam para a sua região no período de 26 a 28 de Novembro de 2002. Este primeiro momento foi importante para a equipe de trabalho pois promoveu subsídios para mudanças importantes na forma de desenvolvimento do treinamento, e, será justamente sobre este segundo momento que este estudo passará a se reportar agora.

No período de 25 a 29 de Novembro de 2002 deu-se o segundo momento do treinamento onde a equipe de trabalho realizou a atividade com oito turmas de profissionais de saúde do município de São Paulo e duas turmas de profissionais de saúde da região metropolitana de São Paulo, isto, dado ao fato da quantidade de serviços de saúde referentes a estes municípios, à facilidade de acesso ao local do treinamento e também ao fato de alguns dos municípios da região citada terem sido classificados como prioritários para a intensificação do PNCT, como é o caso do Município de São Paulo.

Após receber os participantes do treinamento em sala própria, a equipe de trabalho apresentou-se, dando aos demais um breve histórico sobre a mesma, tornaram público a importância da participação de todos naquele encontro e solicitou o preenchimento de um pré-teste (ANEXO 1 ), explicando o objetivo do mesmo. Entregaram também um questionário com 5 questões abertas (ANEXO 2) que tinham como objetivo conhecer a realidade dos serviços de saúde sobre temas relacionados à biossegurança como: quais profissionais preenchem a requisição de baciloscopias; em que local o usuário é orientado colher a amostra; se algum profissional do serviço participou de treinamento sobre colheita de amostra de escarro; se ocorre rodízio de profissionais para o atendimento dos usuários do PNCT e qual o tempo de espera pelo resultado das baciloscopias solicitadas.

O pré e pós-teste ANEXO 1) compostos pelas mesmas 9 questões objetivas, de múltipla escolha sobre o conteúdo do processo educativo, foi elaborado pela equipe de trabalho com base no Manual de Orientação (SES 2002), manual este apresentado e distribuído aos participantes após o preenchimento do pré-teste.

Depois de receber o pré-teste respondido, a equipe de trabalho iniciou a sensibilização do grupo para a importância do conteúdo do treinamento justificando a necessidade do mesmo através da apresentação de resultados dos estudos de 
CAMPINAS (1999) e MAZZAIA (2000) e os resultados da Campanha dos Sintomáticos Respiratórios realizada em 2000, apresentando o objetivo do encontro, ou seja, o objetivo do treinamento:

"Sensibilizar os profissionais para a importância da baciloscopia do escarro para o diagnóstico e controle de tratamento da tuberculose pulmonar".

Durante o período do treinamento, a equipe de trabalho procurou manter-se o mais acessível possível, sempre mostrando a importância do trabalho de cada indivíduo para a realização e sucesso de um programa de saúde, de acordo com o demonstrado por DÍAZ (1995) afirmando que, se existe a intenção de mudanças nos sistemas, elas iniciam-se nas pessoas, e portanto estão intimamente ligadas aos valores de cada um que por sua vez estão intimamente ligados a auto-estima e ao auto-conceito.

Foi necessário estimular o envolvimento de cada participante para deflagrar o processo de atenção à auto-estima e auto-conceito na expectativa de alcançar as mudanças necessárias no atendimento ao paciente do PNCT no que diz respeito a baciloscopia do escarro, embora fosse conhecimento da equipe de trabalho que tal processo poderia influenciar outros aspectos do trabalho dentro do PNCT ou mesmo de um outro programa de saúde qualquer.

No desenvolvimento dos temas, e respeitando as discussões da equipe de trabalho, que optou por utilizar recursos pedagógicos de abordagem interacionista, foram utilizados os debates em pequenos grupos.

Para que o objetivo do programa fosse alcançado, alguns temas foram discutidos por estarem diretamente ligados à qualidade das amostras de escarro, como:

1) Discussão sobre o material necessário para a realização da orientação do cliente para a colheita da amostra de escarro;

2) Discussão da técnica de colheita do escarro para a obtenção de uma boa amostra de escarro;

3) Discussão de técnicas de estímulo à tosse para a obtenção de uma boa amostra de escarro;

4) As questões de biossegurança com relação a colheita de amostras de escarro nas unidades de saúde; 
5) As implicações da conservação e do transporte das amostras de escarro nos resultados da baciloscopia.

Em cada turma de participantes, então, foram formados cinco grupos que discutiram um dos cinco temas citados acima.

O Manual de Orientação (SES 2002) foi utilizado como recurso na estratégia de atividades em pequenos grupos. Cada grupo discutiu e pesquisou no Manual de Orientação entregue o seu tema. Além de apresentarem ao grupo a sua realidade de trabalho, os participantes também discutiam as possibilidades de adequação de suas atividades ao que estava sendo apresentado pelo Manual de Orientação .

Conhecer o Manual de Orientação para que pudesse ser discutido e posteriormente modificado se assim fosse avaliado pelo grupo de participantes e equipe de trabalho, também foi uma das propostas de trabalho durante a realização do treinamento já que, como já citado, a divulgação do Manual de Orientação foi deflagrada no treinamento e havia intenção que o mesmo passasse a ser material de consulta dos profissionais de saúde, diferente do que ocorre com outros manuais onde constam os programas de saúde instituídos, que na maioria das vezes são desconhecidos da equipe de saúde, podendo, desta forma, ser inviabilizado o desenvolvimento de um programa.

Os temas discutidos em pequenos grupos foram apresentados pelo próprio grupo aos demais participantes, de forma livre, ou seja, o grupo escolheu a forma de apresentação, e durante a apresentação ou mesmo depois, dependendo da demanda dos participantes, os temas foram acrescidos pela equipe de trabalho ou demais participantes quando necessário.

Além dos temas discutidos em pequenos grupos, foram realizadas orientações através de aulas expositivas pelos profissionais do Instituto Adolfo Lutz, sobre a técnica de realização da baciloscopia do escarro, justificando a necessidade de uma boa amostra. A apresentação de técnicas de estímulo à tosse e explicações sobre as dificuldades de fluência da secreção pela árvore brônquica, no caso da utilização de técnicas não indicadas, também foi tema apresentado através de aula expositiva pelo Fisioterapeuta da equipe. Estas apresentações foram realizadas após as apresentações dos temas pelos pequenos grupos. 
O conteúdo desenvolvido pela própria equipe de trabalho foi apresentado utilizando-se projetor de slides, uma vez que o conteúdo era composto de textos e figuras.

Após o término das apresentações, um espaço para discussões de dúvidas remanescentes foi aberto e sanadas as dúvidas, foi solicitado o preenchimento do pós-teste aos participantes.

Ressalta-se que participaram do treinamento várias categorias profissionais de vários tipos de instituições públicas como: farmacêuticos, médicos, enfermeiros, auxiliares de enfermagem, técnico de enfermagem, agentes penitenciários, profissionais de laboratórios de análises clínicas entre outros, categorias profissionais estas que foram identificadas no momento da apresentação das discussões dos temas discutidos em pequenos grupos.

A avaliação dos questionários e testes contribuiu com o trabalho da equipe que pode salientar alguns temas baseados nas respostas obtidas.

A equipe de trabalho obteve 481 pré-testes e 562 pós-testes (diferença de $14,4 \%$ de incremento) respondidos.

Analisando as porcentagens de acertos nos resultados de pré e pós-testes, considerando a média de participações no preenchimento dos mesmos, foi observado um acréscimo nas porcentagens de acertos em todas as questões com exceção da questão sobre possíveis fontes de infecção, onde ocorreu uma diminuição da porcentagem de acertos de $7,5 \%$. Na questão citada, a opção sintomáticos respiratórios foi a resposta mais frequente como fonte de infecção. Acreditamos que um dos motivos para este resultado foi o foco de atenção do treinamento: a importância das amostras de escarro no PNCT, que leva à imediata associação ao sintomático respiratório em detrimento de comunicantes de tuberculose e outras possíveis fontes de infecção (MAZZAIA e col 2002).

Foram devolvidos à equipe de trabalho, 482 questionários respondidos. Os resultados cumulativos obtidos são expostos abaixo em forma de porcentagem, ressaltando que alguns participantes do treinamento optaram por mais de uma resposta ou deixaram de responder alguns itens, já que se tratou de um questionário com questões abertas que versavam sobre a prática dos serviços de saúde relacionadas às medidas de biossegurança preconizadas no controle da tuberculose. 
Com relação ao tema participação em treinamentos para a colheita das amostras de escarro, dos 482 questionários respondidos em 29 (6\%) a resposta foi positiva e $345(71,6 \%)$ negaram a participação em treinamentos ou reciclagens. Do total de questionários respondidos, $131(27,2 \%)$ apresentaram resposta afirmativa sobre a possibilidade de outro profissional de seu serviço de saúde ter participado de algum treinamento sobre o referido tema; $121(25,1 \%)$ negaram a possibilidade e 230 $(47,7 \%)$ não responderam a questão (MAZZAIA e col 2002b).

$\mathrm{O}$ número de profissionais que se manifestaram positivamente sobre a possibilidade de outro colega de trabalho ter participado de treinamento foi substancialmente maior do que a afirmativa da própria participação, quase a mesma porcentagem negou a participação de outro colega em treinamentos. No entanto, quase a metade dos participantes não se manifestou sobre a questão.

Durante a realização do treinamento, principalmente durante a apresentação das discussões dos pequenos grupos que foram realizadas, os profissionais colocaram-se como agradecidos pela possibilidade de participação em um processo educativo como o que estava sendo realizado, referindo que há muito não vivenciavam tal experiência voltada para suas atividades diárias. Talvez, pela própria dificuldade de se organizar um evento semelhante, tentando abranger todos os serviços de saúde da cidade de São Paulo, com a expectativa de universalizar informações e condutas, as respostas apresentadas tenham sido de tal monta negativas.

A respeito dos profissionais que solicitavam as baciloscopias e preenchiam a solicitações dos exames, dos 482 questionário analisados, 269 (53,9\%) dos participantes citaram o Enfermeiro, 209 (43,3\%) citaram o Médico, 177 (36,7\%) citaram o Auxiliar de Enfermagem e 31 (6,4\%) outros profissionais. É importante lembrar que as categorias profissionais foram citadas concomitantemente em alguns questionários e portanto os dados apresentados são apenas relativos ao número de questionários respondidos (MAZZAIA e col 2002b).

Quanto ao local orientado para a colheita do escarro no serviço de saúde, do total de questionários $98(20,3 \%)$ dos participantes referiram que não orientam a colheita da amostra no serviço e sim na residência do usuário, $75(15,6 \%)$ citaram a orientação da colheita no banheiro do serviço, $67(13,9 \%)$ dos profissionais orientam 
setores internos da instituição para a colheita, 54 (11,2\%) indicam área livre do serviço de saúde e $22(4,6 \%)$ dos profissionais utilizaram a terminologia de local reservado como indicado para realizar a colheita do escarro. Foram classificadas como áreas internas dos serviços citações como: consultórios, laboratórios, salas de pré e pós-consultas, sala de inalação, sala de enfermagem, sala de procedimentos, sala de exames, recepção e salas de atendimento. Somente $11,2 \%$ dos profissionais mencionaram a área adequada para a colheita do escarro que seria área aberta e ventilada (MAZZAIA e col 2002b, BRASIL 2002, 2002c, SES 2003).

A resposta "local reservado" encontrada nos questionários foi assim apresentada pois não foi possível identificar se os profissionais se referiam à áreas livres ou à áreas fechadas e reservadas, como o sanitário ou qualquer outra sala do serviço de saúde por exemplo, então teríamos mais $4,6 \%$ de citações para considerarmos em uma ou outra categoria.

Sobre a informação se existia ou não um rodízio dos profissionais de saúde no atendimento aos usuários do PNCT, 202 (41,9\%) dos profissionais responderam que sim e $170(35,2 \%)$ dos profissionais referiram que não, com $110(22,8 \%)$ dos questionários sem resposta sobre o item (MAZZAIA e col 2002b).

Quanto ao tempo de espera para receber o resultado da baciloscopia 58 (12\%) participantes responderam esperar até 4 dias, 64 (13,3\%) até 10 dias, $119(24,7 \%)$ até 20dias e 99 (20,5\%) citaram 20 dias e mais (MAZZAIA e col 2002b).

Pelos resultados obtidos percebe-se a importância da realização de encontros de atualização para a adequação e padronização de ações do PNCT, principalmente para enfatizar a necessidade de revisão das formas de organização do trabalho nas unidades de saúde, com o objetivo de prestar uma assistência à saúde atualizada $\mathrm{e}$ segura para o seu cliente, comunidade e profissionais de saúde.

É oportuno acrescentar que em absoluto acredita-se que um programa educativo seja a resposta para todos os problemas e dificuldades apresentadas na efetivação de um programa de saúde, pois compreende-se a interdependência e os múltiplos fatores que interferem nestas questões.

Alguns destes fatores citados estão no âmbito da organização do trabalho como as políticas de saúde, as normas, os objetivos do serviço que muitas vezes são estabelecidos por outros profissionais que desconhecem as atividades do PNCT e 
veêm os profissionais destas áreas apenas como um meio de efetivar o programa $\mathrm{e}$ não sujeitos das ações do mesmo (BERTOLOZZI 1998).

Outro fator que pode ser citado é de ordem pessoal como as crenças, valores, habilidades técnicas, interpessoais ou intelectuais dos profissionais de saúde. Ainda pode-se citar como um fator a forma como o PNCT tem sido operacionalizado nas unidades de saúde, muitas vezes como uma imposição das chefias que em função de só realizar administração burocrática do PNCT, acompanhando boletins e números, valorizam mais a documentação do programa que sua implementação.

Inúmeros fatores poderiam ser citados influenciando o desenvolvimento do PNCT, porém, de acordo com a experiência de BOWMAN (1986), um programa educacional estruturado foi benéfico para o desenvolvimento de atitudes positivas de enfermeiros para com o processo de enfermagem, a autora afirma "o ensino eleva as expectativas, e quando está em harmonia com a prática, cria um clima de autenticidade".

A realização de um programa educativo com as proporções dos eventos descritos demandam esforço e investimentos e tem suas repercussões na rede de saúde, assim, a equipe de trabalho, incluindo a pesquisadora, desejou conhecer a realidade dos serviços de saúde com atendimento tipo ambulatorial, no Município de São Paulo, investigando o preparo e a prática de profissionais de saúde destes serviços quanto às ações relacionadas a colheita das amostras de escarro no que diz respeito ao relacionamento que se estabelece entre profissionais e usuários e medidas de biossegurança adotadas.

\section{O Referencial do Estudo}

\section{Implicações do Relacionamento Interpessoal}

O relacionamento estabelecido com o cliente no atendimento, pode determinar ou não o envolvimento do cliente com as ações esperadas e necessárias para o desenvolvimento do PNCT. Para a adequada comunicação entre funcionários e usuários, faz-se necessário educação continuada dos envolvidos nessa dinâmica e deve ser tratada como estratégia educacional específica, pautada na análise crítica da 
realidade do cotidiano dos serviços de saúde, identificando as necessidades e falhas de atuação existentes ao longo do processo, com vistas a construir novas formas de desempenho desses profissionais.

Os fatores envolvidos no processo de comunicação e de educação extrapolam as questões meramente técnicas, pois refletem dados subjetivos como as crenças, os valores, as expectativas e as aspirações dos diversos atores sociais envolvidos técnicos e usuários, interferindo então nas relações que se produzem, permeando o atendimento, desde a chegada do usuário sintomático respiratório às Us.S. incluindo a resposta do usuário às intervenções realizadas (SILVA 1996).

CAMPINAS (1999) em estudo sobre a apreensão da orientação da população usuária a respeito da forma de colher a amostra de escarro, encontrou os seguintes resultados: dos 78 pacientes entrevistados, 93,6\% referiram ter sido orientados sobre o procedimento para colher a amostra de escarro, 66,7\% afirmaram ser a orientação recebida adequada e, apenas $15,4 \%$ relataram ter dúvidas sobre a orientação recebida. No entanto, quando solicitado aos pacientes para explicarem a maneira como apreenderam a orientação, $24,3 \%$ apresentaram dúvidas e $33,4 \%$ não tinham conhecimento adequado para a colheita de amostras de escarro.

Neste estudo CAMPINAS (1999) apresentou os sentimentos de usuários do PNCT a respeito da colheita da amostra de escarro em seu trabalho, relatou que, num total de 48 pacientes, $12,5 \%$ referiram nojo e ânsia de vômito como dificuldade com relação à colheita da amostra de escarro; $31,2 \%$ destes referiram não ter escarro em jejum e $95,8 \%$ referiram ter pouca secreção. Diz ainda que alguns pacientes afirmaram ser a amostra de escarro um assunto "constrangedor", sendo que alguns pacientes referiram-se ao exame de escarro como "podre e sujo, muito nojento, escarrar é estar bichado é estar podre por dentro". Acrescenta que dos 78 pacientes, $57,7 \%$ não apresentaram condições de obter uma boa amostra de escarro, ou por não saberem repetir a orientação sobre como obtê-la, ou por apresentarem dúvidas ao tentarem repetir a orientação.

É preciso considerar que, como já foi comentado, existem fatores de interferência no processo de comunicação relacionados ao paciente, como também existem os relacionados aos profissionais de saúde que podem estar despreparados para a atividade que devem desempenhar. Este despreparo pode estar relacionado aos 
conhecimentos, neste caso, conhecimento a respeito do conteúdo do PNCT e, também, conhecimento das habilidades interpessoais.

Avaliando o panorama de recursos humanos na saúde e a importância das interações profissionais de saúde/clientes com relação à qualidade das amostras de escarro destinadas à baciloscopia para diagnóstico da tuberculose pulmonar, surgiu o interesse de saber como era realizada a orientação dos usuários dos serviços de saúde para a colheita da amostra de escarro.

MAZZAIA (2000) realizou levantamento sobre conhecimentos, atitudes e práticas do pessoal de enfermagem no momento da orientação dos indivíduos para a obtenção da amostra de escarro. Para o estudo foi utilizado um instrumento composto por uma entrevista semi-estruturada para estudar o conhecimento do pessoal de enfermagem sobre a baciloscopia de escarro e também para levantar dados sobre a percepção deste profissionais sobre sua participação na colheita da amostra de escarro. A autora utilizou também um roteiro de observação contendo itens relacionados à comunicação verbal e não-verbal do pessoal de enfermagem no momento da orientação, contemplando também fatores relacionados aos procedimentos constantes do PNCT para a orientação dos indivíduos para a colheita da amostra de escarro. A intenção do levantamento de dados através do roteiro de observação foi de estudar a prática do pessoal de enfermagem no momento da orientação do cliente.

No estudo citado foram utilizadas Escalas de Diferencial Semântico para estudar a atitude do pessoal de enfermagem quanto aos temas - amostra de escarro, paciente portador de tuberculose pulmonar e orientação do paciente portador de tuberculose pulmonar, para a colheita da amostra de escarro. A escolha dos temas se deu, também, conforme modelo para análise das relações entre atitudes e práticas usado por CANDEIAS \& MARCONDES (1979) que, revisando teorias de natureza psicossocial, consideraram o enfoque de consistência contingente entre atitudes e práticas, que interpreta esta consistência a partir da atitude do sujeito em relação ao objeto e também em relação à situação em que o objeto se encontra.

Como "atitude" a pesquisa realizada por MAZZAIA (2000), utilizou o conceito de DANIEL (1983): "estado mental, disposição interna, forma de pensar e sentir expressas por meio de modos de ser e por ações". 
A concepção de pesquisa se fundamentou nas observações de GREEN (1980) que afirma ser o comportamento determinado por fatores que o predispõem, estudando as atitudes como um destes fatores, e nas observações de LANE (1969) no estudo que refere que a técnica do Diferencial Semântico (DS) permite medir o significado psicológico ou afetivo de conceitos mostrando uma tendência dos indivíduos de atribuírem significado de valor nas suas respostas através do uso de adjetivos.

Como resultados MAZZAIA (2000) verificou que o pessoal de enfermagem não foi treinado ou recebeu orientação sobre o PNCT para desenvolver o trabalho na área. Os sete sujeitos que participaram do estudo referiram que apenas receberam orientações sobre a organização do serviço. Os sujeitos demonstraram possuir conhecimentos sobre o que é a baciloscopia de escarro, mas desconheciam sua importância no controle do tratamento. Quanto à percepção sobre a participação na colheita da amostra de escarro apenas um sujeito referiu não "ter participação", todos os outros referiram-se à necessidade de suas orientações, a necessidade de fazer mais e também ao fato de não saberem se o que fazem é o correto.

Com relação à prática, MAZZAIA (2000) observou que o paciente não era orientado a colher a amostra de escarro conforme orientação do PNCT, e que a descrição da forma como os sujeitos do estudo referiram orientar os pacientes a colher a amostra de escarro não foi confirmada na observação da prática diária.

A atitude dos sujeitos no mesmo estudo mostrou-se negativa quanto à amostra de escarro, positiva quanto ao paciente portador de tuberculose pulmonar e expressivamente positiva para a orientação do paciente portador de tuberculose pulmonar para a colheita da amostra de escarro. Numa escala que mede o conteúdo de valores variando de -45 (quarenta e cinco negativos) a valores +45 (quarenta e cinco positivos) - detectou que os sete sujeitos daquele estudo demonstraram nível de favorabilidade segundo PASQUALI (1996) com relação ao paciente portador de tuberculose pulmonar e quanto à orientação deste paciente para a colheita da amostra de escarro, ou seja apresentaram valores positivos. Não foi verificado, no entanto, este nível de favorabilidade com relação as amostras de escarro, ratificando os achados de CAMPINAS (1999), pois os escores foram negativos para os sujeitos do estudo. 
Tais resultados mostram que apesar do pessoal de enfermagem não estar preparado para o trabalho de envolvimento do paciente do PNCT quanto às ações do mesmo, demonstram, conforme o estudo, predisposição para participação em atividades de aprimoramento e atualizações, bem como em aplicar seus conhecimentos, orientando estes pacientes.

A menção feita sobre o envolvimento do cliente com as ações do PNCT é devida à crença de que se o usuário do serviço é recebido de forma a sentir-se aceito e durante todo o atendimento houver a preocupação de orientá-lo quanto ao objetivo de cada solicitação, o mesmo envolver-se-á com as atividades, qualquer que seja o programa, o que determinaria sua adesão ao tratamento e aquiescência quanto às solicitações necessárias para o concretização do mesmo. Entendemos também que esta forma de atendimento, acolhendo o indivíduo que procura o serviço de saúde, pode interferir diretamente na motivação deste indivíduo quanto as ações do programa de saúde, o que é enfatizado por ROUILLON (1972) que relaciona a motivação do paciente não tanto às palavras exatas ditas, mas ao modo como elas são ditas, quem as diz, onde e quando serão ditas.

Quanto às habilidades interpessoais necessárias para o atendimento do usuário do serviço de saúde, segundo MIRANDA e col. (1983) referem-se às habilidades entre pessoas, como àquelas que permitem um relacionamento integral e construtivo com o outro e destaca quatro grupos principais de habilidades interpessoais, formulados pelo modelo de ajuda de Carkhuff, são eles: atender, responder, personalizar e orientar. Atender define-se como comunicar de maneira não-verbal disponibilidade e interesse pelo paciente; responder seria comunicar, corporal e verbalmente, compreensão; personalizar refere-se a indicar ao paciente sua parcela de responsabilidade no problema e finalmente, orientar diz respeito a avaliar, com o paciente, as alternativas de ação possíveis e facilitar a escolha de uma delas. Cada um destes quatro grupos de habilidades divide-se em habilidades específicas. Essas habilidades são básicas em qualquer encontro entre duas pessoas, são elas que determinam a qualidade desse encontro.

MIRANDA e col. (1983) discutem ainda que o modelo de ajuda é cumulativo e que cada habilidade é pré-requisito para a seguinte, ou seja, durante todo o tempo de interação com o paciente, as habilidades deverão ser observadas e utilizadas. 
Quando avaliados os quatro grupos de habilidades, é possível perceber que o último grupo diz respeito à habilidade de orientação, ou seja, este deveria ser o último passo do trabalho na interação profissional/paciente. Levando em consideração a orientação do usuário do serviço de saúde dentro do PNCT, o momento da orientação deste sobre a colheita da amostra de escarro deveria ocorrer após um contato de aproximação inicial, ou seja, deveria existir um trabalho de sensibilização prévio, do qual poderia fazer parte um espaço para que o usuário do serviço de saúde pudesse colocar suas dúvidas sobre seu momento de vida e dentro deste contexto a orientação sobre a colheita da amostra de escarro ser incluída. Isso facilitaria o alívio da ansiedade do indivíduo - quer seja do profissional de saúde quer seja do usuário do serviço - tornando possível a atenção necessária, ou melhor a disponibilidade interna, a motivação para a compreensão da orientação a ser realizada (MIRANDA 1983, STEFANELLI 1993, MENDES 1994).

Estudos realizados sobre a atuação de profissionais de saúde mostram resultados adversos ao que foi discutido sobre a necessidade de investimentos dos profissionais de saúde no relacionamento que se estabelece com os usuários.

O que se observa é um distanciamento dos profissionais de saúde dos indivíduos necessitados de atendimento, como que defendendo-se de situações que nas avaliações destes profissionais "fugiriam de seu controle", tornando o trabalho impessoal, mecanizado, despersonalizado (MENDES 1994, MIRANDA 1983). Sabese ainda que toda esta situação é gerada também pelas formas de organização de serviços nas Us.S. bem como devido ao contexto político vigente em cada região ou até mesmo no município (MENDES 1994, TANAKA 1994).

Os profissionais de saúde devem ter conhecimentos específicos sobre as ações do PNCT bem como estar sensibilizados para a importância do relacionamento que se estabelece com o usuário do serviço de saúde no momento da orientação deste usuário para a colheita da amostra de escarro.

\section{Orientações do PNCT para a colheita da amostra de escarro}

Com relação ao PNCT, para que o usuário do serviço de saúde colha uma boa amostra de escarro e para que esta amostra chegue em condições adequadas para ser processada pelo laboratório e gerar um resultado no qual se possa confiar, os 
profissionais de saúde que recebem e orientam o cliente quanto a colheita da amostra de escarro, recebem e encaminham esta amostra de escarro para o laboratório, necessitam de conhecimentos específicos, devem, portanto, estar atualizados tendo fortalecida sua formação específica.

Os conhecimentos citados versam sobre:

- o que é baciloscopia do escarro;

- qual a importância da baciloscopia do escarro para o diagnóstico e para o controle de tratamento da tuberculose pulmonar;

- o que é uma boa amostra de escarro - o que implica saber de que região do aparelho respiratório ela deve ser retirada e qual a quantidade de escarro necessário;

- qual o material necessário para a colheita da amostra de escarro;

- qual a técnica adequada para a colheita da amostra de escarro;

- quais os cuidados relacionados à biossegurança no caso de colheita da amostra de escarro na unidade de saúde;

- qual a importância de uma solicitação de exame completamente preenchida;

- quais os cuidados no momento da recepção da amostra de escarro na unidade de saúde e

- qual a forma adequada de transporte e conservação da amostra de escarro até o laboratório.

Quando o profissional de saúde compreende o que é a baciloscopia do escarro e sua

importância não só para o diagnóstico, mas também para o controle de tratamento da tuberculose pulmonar, consegue também compreender a importância de se obter uma boa amostra o que implica em conhecer a técnica preconizada para esta colheita, destacando-se que todo processo diagnóstico laboratorial, inicia-se com a orientação do usuário para a colheita da amostra de escarro.

A técnica para a colheita de uma boa amostra de escarro que deve ser orientada ao usuário pelos profissionais de saúde, consta do Manual de Orientação (SES 2002), e está descrita a seguir:

1. Explicar a importância do exame ao usuário utilizando termos claros e de fácil entendimento. 
2. Orientar a necessidade de seguir os passos da colheita, pois o mateiral para exame de escarro deve ser proveniente da árvore brônquica e não da região da orofaringe.

3. Fornecer ao usuário a orientação e simulação da técnica de colheita, utilizando para isto o pote, aproveitando este momento para indicar a quantidade a ser colhida.

4. Orientar o cliente a inspirar profundamente, retendo por alguns instantes o ar nos pulmões.

5. Orientar o cliente a tossir e lançar o material diretamente no pote de coleta, após ter retido $\mathrm{o}$ ar nos pulmões.

6. Orientar a repetir este procedimento por 3 vezes, afim de atingir a quantidade necessária para o exame $(5 \mathrm{a} 10 \mathrm{ml})$.

7. Orientar a tomar cuidado para que o material não escorra do lato externo do pote.

8. Orientar o usuário a tampar o pote rosqueando-o firmemente.

9. Entregar o pote de colheita identificado no corpo.

10. Solicitar ao usuário que repita verbalmente as informações realizadas e simular a colheita, validando a informação recebida.

11. Indicar ao usuário o local de colheita na Unidade de Saúde (local aberto de preferência ao ar livre ou em sala bem arejada).

12. Após a colheita o usuário deve levar o pote até o profissional de saúde transportando-o com a tampa para cima evitando extravasamento do material. $\mathrm{O}$ profissional de saúde deverá verificar a quantidade e qualidade da amostra, sem abrir o pote. Caso a quantidade seja insuficiente, deve-se pedir para que o usuário repita a operação até obter uma amostra adequada.

13. Ao final, o usuário deverá ser orientado a lavar as mãos.

As orientações de número $7,8,11$ e 13 dizem respeito à medidas de biossegurança.

Segundo HOLLANDA (1986) a palavra biossegurança, no seu sentido mais

amplo significa a vida livre de perigos, desta forma, medidas de biossegurança dizem respeito à ações que objetivam a segurança da vida no dia-a-dia dos indivíduos 
(SOUZA 2000, Secretaria de Estado da Saúde - SES 1998). Assim, medidas de biossegurança envolvem todas as ações que visam prevenir riscos físicos, ergonômicos, químicos, biológicos e psicológicos ao indivíduo (SOUZA 2000, SES 2003). O risco de contrair a tuberculose classifica-se como risco biológico.

No que toca aos cuidados relacionados à biossegurança na prevenção do contágio da tuberculose destaca-se que todo o ambiente do serviço de saúde, que atende ao usuário do PNCT, deve ser levado em conta na adoção das medidas de controle (BRASIL 2002c).

As medidas de biossegurança no combate à tuberculose dividem-se em três grupos: administrativas, ambientais e de transmissão respiratória, que são diferenciadas, no caso do PNCT, de acordo com o nível de complexidade e gravidade dos diagnósticos relacionados à tuberculose e portanto à classificação dos serviços de saúde: ambulatorial, de emergência ou de internação (SES 2003, BRASIL 2002b).

As medidas de biossegurança descritas a seguir são preconizadas para os serviços de saúde tipo ambulatoriais, contemplando os serviços de saúde selecionados para serem estudados nesta pesquisa.

As medidas administrativas de biossegurança preconizadas para 0 atendimento ambulatorial de casos de tuberculose, têm como objetivo "diminuir a exposição de susceptíveis ao contágio, atingindo grande número de pessoas” (SES 2003) apresentando como ações mais importantes as providências imediatas na suspeita de um caso de tuberculose, adequação de rotinas e fluxo para agilização de prazos no diagnóstico de tuberculose, diminuição do tempo de permanência de casos suspeitos de tuberculose nas Us.S, início mais precoce possível e adesão ao tratamento (SES 2003, BRASIL 2002b).

A utilização de conhecimentos relativos à engenharia hospitalar dizem respeito às medidas de controle ambiental de biossegurança e para a prevenção de contágio na tuberculose nos serviços de saúde ambulatoriais são necessários cuidados relativos a escolha de salas adequadas com boa ventilação e iluminação natural para a instalação do atendimento aos usuários do PNCT, a preocupação de manter janelas abertas para possibilitar ventilação constante nestas salas, adequação na disposição de móveis privilegiando a localização do usuário do PNCT próximo à 
janelas, utilização de ventiladores direcionando o ar das salas de atendimento para o meio externo (SES 2003, BRASIL 2002c).

As medidas de proteção respiratória de biossegurança referem-se ao uso de máscara e no caso de serviços ambulatoriais os profissionais de saúde devem utilizar máscaras do tipo N95 (capazes de filtrar 95\% de partículas de diâmetro médio de 3 micra) para não ocorrer a inalação do $M$. Tuberculosis nas seguintes situações: quando no uso de substâncias estimulantes da tosse e no atendimento de usuários do PNCT portadores de tuberculose resistente (SES 2003). Outra medida de proteção respiratória seria a orientação dos usuários sobre o uso de lenço de papel quando nos episódios de tosse dentro dos serviços de saúde e para descarte de secreção respiratória no lixo (SES 2003).

Além das medidas já citadas, o Manual de Orientação (SES 2002), baseado na indicação e uso das precauções universais (SOUZA 2000) preconiza que o profissional de saúde receba o pote contendo a amostra de escarro utilizando luvas, verificando a qualidade da mesma e conferindo identificação do pote e solicitações de exames.

Os potes contendo as amostras de escarro devem ser transportados com a tampa para cima de forma a não extravasarem o material biológico, ou seja, devem ser calçados ou transportados em grades próprias, sob refrigeração, em caixas térmicas contendo gelo reciclável, propiciando a conservação do material (SES 2002). As caixas térmicas devem ser de material lavável, assim como as grades de proteção e contenção dos frascos com as amostras de escarro.

As solicitações de baciloscopias devem ser encaminhadas para o laboratório, de forma organizada, protegida e fora da caixa de transporte de material biológico. 


\section{OBJETIVOS}


Os objetivos desta pesquisa foram:

\section{Objetivo Geral}

- Descrever e analisar os processos de formação e a prática de profissionais de saúde de nível médio relacionados a colheita da amostra de escarro

- Identificar problemas e necessidades de capacitação dos profissionais de saúde de nível médio sobre as ações que envolvem a colheita de amostra de escarro

\section{Objetivos específicos}

\section{Sobre as práticas de formação de profissionais de saúde}

- Verificar a participação dos profissionais de saúde em programas de capacitação sobre tuberculose e a periodicidade em que têm se envolvido neles

- Verificar o número de serviços de saúde que possuem o Manual de Orientação para consulta dos profissionais

- Verificar o conhecimento dos profissionais de saúde sobre o Manual de Orientação e sobre a definição e importância da baciloscopia de escarro no diagnóstico e controle de tratamento da tuberculose pulmonar

- Conhecer a opinião dos profissionais de saúde sobre o Manual de Orientação

Sobre a prática de atendimento dos profissionais e realidade dos serviços de saúde

- Descrever e analisar a realidade dos serviços de saúde quanto a adoção de medidas de biossegurança relacionadas aos locais reservados para o atendimento dos usuários do PNCT e colheita de amostras de escarro, as categorias dos profissionais que solicitam as baciloscopias do escarro e o tempo de espera pelos resultados das baciloscopias

- Descrever e analisar a prática dos profissionais de saúde na orientação do usuário para a colheita da amostra de escarro quanto a técnica de colheita, cuidados de biossegurança e relacionamento interpessoal

- Descrever e analisar a prática dos profissionais de saúde em relação a observação dos aspectos de biossegurança no recebimento, acondicionamento e transporte das amostras de escarro 
- Relacionar a prática dos profissionais de saúde nas ações que envolvem a colheita da amostra de escarro à participação em treinamentos e conhecimento do Manual de Orientação

- Conhecer a percepção dos profissionais de saúde sobre sua participação na colheita da amostra de escarro

\section{Sobre o resultado dos processos de capacitação na prática dos profissionais de}

\section{saúde}

- Identificar a opinião e conhecimento dos usuários a respeito do exame de escarro e sua importância para diagnóstico e controle de tratamento da tuberculose

- Comparar a forma verbalizada pelos usuários sobre a técnica utilizada para a colheita da amostra de escarro e a prática dos profissionais de saúde

- Verificar a avaliação dos profissionais dos laboratórios sobre a prática dos serviços de saúde quanto ao acondicionamento, transporte, preenchimento de solicitação de exames e qualidade das amostras de escarro enviadas para análise 
3. METODOLOGIA

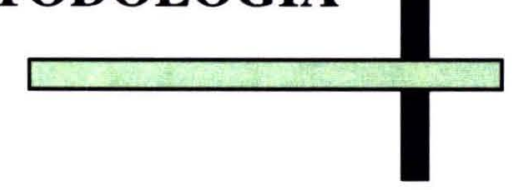


Este estudo baseou-se na premissa que o incremento de conhecimentos e de espaços para a discussão do próprio trabalho, através de projetos educativos, pode influenciar positivamente a atitude dos profissionais de saúde, entendendo atitude como "predisposição relativamente estável e organizada para reagir sob a forma de opiniões ou de atos em presença de objetos (pessoas, idéias, coisas, acontecimentos) de maneira determinada" (Minayo 1983).

Conhecer as repercussões de projetos educativos nas atividades de profissionais de saúde implica no manejo de variáveis psicossociais, que por sua vez necessitam métodos de investigação pertinentes (HEPWORTH 1997), assim, realizou-se um estudo de caso, um tipo de pesquisa qualitativa (TRIVIÑOS 1987). Para DINIZ (1999) o estudo de caso situa-se na categoria de pesquisa exploratória pois "propõe busca e não verificação de informações, com o objetivo de descoberta de idéias úteis, críticas e norteadoras de novas atitudes em relação ao mundo".

A princípio, o pesquisador tinha como planejamento visitar os serviços de saúde que possuíssem no seu quadro de profissionais indivíduos que haviam participado do treinamento organizado pela Divisão de Tuberculose do CVE e realizado na Faculdade de Saúde Pública da USP em Novembro de 2002. Estes profissionais citados deveriam ser de nível médio, por serem o maior número de profissionais na assistência direta à população e, deveriam prestar serviços nos setores de atendimento às ações do PNCT. Não foi possível a localização destes profissionais através das listas de presença em posse da Divisão de Tuberculose do CVE, então, conforme objetivo do estudo, o pesquisador optou por visitar serviços de saúde que apresentassem o maior número possíveis de solicitações de baciloscopias para o escarro.

Assim, a amostra do estudo foi intencional (TRIVIÑOS 1987) pois só poderiam ser visitados serviços de saúde que solicitavam diariamente baciloscopia de escarro, e portanto, realizavam a orientação de usuários para a colheita do escarro, o caso a ser estudado. Em Agosto de 2003, para ter acesso aos serviços descritos, foi solicitado à Divisão de Tuberculose do CVE a lista de laboratórios que realizavam a baciloscopia de escarro para os serviços de saúde do Município de São Paulo e que 
apresentavam a produção de pelo menos 1500 baciloscopias no primeiro semestre de 2003.

Foram selecionados 4 laboratórios que informaram o nome dos serviços de saúde que solicitavam o maior número de baciloscopias por mês, resultando na indicação de 39 unidades de saúde, que foram separados por subprefeituras e coordenadorias de saúde.

O número de serviços de saúde visitados ficou resumido a 27 (100\%), pois dos 39 serviços de saúde inicialmente indicados pelos laboratórios, 5 possuíam somente profissionais de nível universitário orientando os usuários do PNCT a colher a amostra de escarro, outros 5 serviços referiram não ter o PNCT instalado em suas unidades, em 1 serviço não foi autorizada a coleta de dados e em 1 serviço os dados foram perdidos por problemas no aparelho de gravação. Dos 5 serviços de saúde que referiram não ter o PNCT instalado em suas unidades, 4 foram selecionados pelos laboratórios por apresentarem uma demanda de baciloscopias devido à participação na campanha de sintomáticos respiratórios do Município de São Paulo em Março de 2003 e um deixou de atender ao PNCT na época da coleta de dados deste estudo.

Como a prática da orientação dos usuários do PNCT para a colheita da amostra de escarro não é uma atividade isolada, como já descrito, o pesquisador optou pelo uso da técnica de triangulação na coleta de dados para que as informações colhidas pudessem contribuir para "descrever, explicar e compreender" o tema do estudo (TRIVIÑOS 1987) alcançando os objetivos do mesmo.

GIL (1991) refere que os procedimentos mais comuns para a coleta de dados em estudos de caso são a análise de documentos, a observação, a entrevista e a história de vida.

Neste estudo foi utilizado a observação da prática dos profissionais, através da utilização de um roteiro de observação, e também da entrevista dos profissionais de saúde, e dos usuários do PNCT atendidos durante o período de observação, com o uso da entrevista semi-estruturada. A entrevista semi-sestruturada também foi utilizada para coleta de dados junto aos profissionais de laboratório.

A observação não participante foi escolhida como forma de obter dados sobre a prática dos profissionais de saúde no desempenho de suas funções pois segundo POLIT e HUNGLER (1995) “a observação direta do comportamento é um 
método de coleta de dados que permite a obtenção de muitas espécies de informações, como evidência da eficácia do trabalho, ou como indicação de aperfeiçoamento das práticas", acrescentam que "os métodos observacionais podem ser utilizados, de maneira proveitosa, para a reunião de uma variedade de informações que incluem as que se referem às características e condições das pessoas; comportamentos de comunicação verbal; comportamentos de comunicação não-verbal; atividades e condições ambientais". Ainda para as mesmas autoras, a observação estruturada especifica os comportamentos ou eventos em que o pesquisador se envolve, sendo que, a seleção dos eventos compõe um sistema categorial, enumerando todos os comportamentos que o pesquisador deve observar com um sistema de checagem, ou seja, utilizando-se um roteiro para registrar os fenômenos observados.

Segundo TRIVIÑOS (1987), a entrevista semi-estruturada seria um dos métodos mais adequados para a coleta de dados em estudos que utilizam também a metodologia qualitativa pois esta, ao mesmo tempo que valoriza a presença do investigador, oferece todas as perspectivas possíveis para que o informante alcance a liberdade e a espontaneidade necessárias, enriquecendo a investigação. Ainda para o mesmo autor, é essencial que o pesquisador esteja convencido da necessidade de criar as condições para que o trabalho se desenvolva em toda a sua potencialidade, desde o início da entrevista, promovendo um "clima de simpatia, confiança, lealdade e harmonia entre pesquisador e entrevistado".

Para proceder a coleta de dados nos serviços de saúde do município de São Paulo, foi realizado contato com a Coordenação do Programa de Controle da Tuberculose do Centro de Controle de Doenças da Secretaria Municipal da Saúde de São Paulo, através de telefonema e carta de apresentação, solicitando autorização para a realização do estudo.

A proposta do estudo, já avaliada e autorizada pelo comitê de Ética em Pesquisa da Faculdade de Saúde Pública da USP, foi submetida ao Comitê de Ética em Pesquisa da Secretaria da Saúde da Prefeitura do Município de São Paulo e foi aprovada em Fevereiro de 2004.

Anterior ao agendamento das visitas, os Diretores Técnicos dos serviços de saúde selecionados pelos laboratórios foram contatados por telefone e após 
concordarem com a participação do serviço no estudo, foi solicitado aos mesmos que orientassem os profissionais de saúde sobre a presença do pesquisador no período de tempo estipulado e também quanto à sua atividade de observação sobre a rotina do setor de atendimento do PNCT.

No mês de Fevereiro de 2004, após todas as exigências documentais cumpridas, as visitas aos serviços de saúde foram agendadas com os Diretores Técnicos, e, foram realizadas de Março a Julho de 2004, conforme programação dos serviços.

As visitas foram realizadas ou pelo próprio pesquisador, ou por um assistente de pesquisa devidamente treinado.

No dia agendado para a visita, o pesquisador dirigiu-se ao Diretor Técnico do serviço ou ao profissional por este designado, no horário estipulado para o início da coleta de dados. Os profissionais de saúde, então, foram orientados sobre o estudo e sobre a permanência do pesquisador por um período no setor de atendimento ao PNCT. Também foram orientados sobre a entrevista que seria realizada com o profissional de saúde que estivesse no atendimento, além de serem informados sobre a importância da participação e colaboração para o sucesso do estudo e incremento do PNCT.

A observação da atividade de orientação do paciente quanto ao procedimento para a colheita da amostra de escarro não foi destacada na orientação dos profissionais de saúde, com a intenção de diminuir interferência do fenômeno reatividade, que se caracteriza pela distorção comportamental devido à presença conhecida de um observador (POLIT e HUNGLER 1995).

Durante o período de observação o pesquisador foi apresentado aos usuários do PNCT quando também apresentou o objetivo do estudo, pois, aqueles usuários que concordaram em participar do estudo, também foram entrevistados.

Com a preocupação de aproximar o pesquisador dos profissionais de saúde e, como o funcionamento da unidade não era do domínio do pesquisador, antes de iniciar o trabalho de observação e, após as apresentações formais e informações sobre o fato de que os dados obtidos fariam parte de uma pesquisa para pósgraduação nível doutorado, foi solicitado aos profissionais de saúde que foram entrevistados, informações sobre a rotina da área, inclusive para saber se a unidade 
poderia ser incluída no estudo. Estas primeiras informações resultaram num levantamento das características dos serviços de saúde, onde também foi realizada observação da estrutura física do local reservado para o atendimento do PNCT.

Enquanto o profissional de saúde realizava a orientação do usuário para a colheita da amostra de escarro, o pesquisador preenchia o roteiro de observação da prática dos profissionais de saúde. Para tanto, o pesquisador permaneceu um período de 4 horas em cada serviço de saúde. A observação e preenchimento do roteiro de observação foram realizados de forma discreta, evitando constrangimentos por parte dos profissionais de saúde e usuários do PNCT.

No final de cada período de observação, quando já não havia mais usuários a serem atendidos, os profissionais observados foram convidados a dirigirem-se para um local tranqüilo, onde não houvesse interferências. Neste local, realizou-se a entrevista semi-estruturada que foi gravada com a anuência do sujeito do estudo.

Os usuários do PNCT também foram convidados a participar do estudo e responder às questões da entrevista quando preparavam-se para deixar o serviço de saúde.

Não foi possível observar a orientação dos usuários do PNCT para colher a amostra de escarro em todos os serviços pois, infelizmente, estas orientações não ocorreram durante o período de observação, mesmo assim, os usuários que compareceram ao serviço e concordaram em participar do estudo foram entrevistados.

Em dois serviços de saúde foi necessário solicitar ao Enfermeiro da unidade que não interferisse nas entrevistas que estavam sendo realizadas, o que não garante a solicitação pois sabe-se que a presença de outro profissional do próprio serviço interfere na qualidade das respostas e dados coletados (POLIT e HUNGLER 1995).

Os profissionais dos laboratórios, responsáveis pela realização das baciloscopias de escarro, foram solícitos à abordagem do pesquisador, atendendo prontamente no momento da entrevista e informando sobre as questões relacionadas ao acondicionamento, transporte, preenchimento de requisições de baciloscopias e qualidade das amostras de escarro. A abordagem foi em forma de entrevista por telefone, de acordo com a solicitação dos próprios profissionais de laboratório que referiram que, realizar um acompanhamento das amostras de escarro encaminhadas 
ao laboratório, preenchendo impressos diários, seria inviável devido volume de trabalho do setor, que, segundo os mesmos, aumentou no último ano. A intenção primeira deste estudo foi de solicitar aos profissionais de laboratório o acompanhamento das condições de acondicionamento, transporte e qualidade das amostras de escarro bem como do preenchimento de solicitações de baciloscopias através de impressos que discriminariam as condições descritas, de cada amostra de escarro, durante um mês.

Todos os participantes foram assegurados sobre o anonimato e sigilo quanto à identidade dos mesmos, bem como quanto à identificação dos serviços de saúde. Também foram informados sobre o respeito `a liberdade de retirar seu consentimento em qualquer momento antes da divulgação dos dados (FORTES 1998).

O termo de consentimento livre e esclarecido foi assinado pelos profissionais de saúde e alguns usuários do PNCT pois, alguns destes últimos preferiram não assinar o termo, já que concordaram com a gravação da entrevista.

As questões abertas das entrevistas foram transcritas, analisadas, na busca de temas que foram selecionados de acordo com a questão norteadora. Após a seleção dos temas, os mesmos foram analisados e agrupados para a composição de tabelas e quadros, de forma descritiva. Utilizou-se o recurso da porcentagem para determinar a frequência da citação dos temas.

Parte dos dados foram descritos conforme relato dos sujeitos entrevistados e observação do pesquisador.

Os dados objetivos foram citados no desenvolvimento do texto de apresentação dos resultados e em forma de tabelas, sendo discriminadas as porcentagens das frequências obtidas dos mesmos.

\section{Instrumentos para Coleta de Dados}

\section{Entrevistas para Profissionais de Saúde dos Serviços de Saúde}

A avaliação do conhecimento dos profissionais de saúde, da realidade dos serviços de saúde no atendimento do PNCT e da prática dos profissionais de saúde, foi realizada através de entrevista semi-estruturada, com questões fechadas e abertas (ANEXO 3), onde os entrevistados foram abordados sobre:

a) Função; 
b) tempo de trabalho na função;

b) tempo de trabalho em atividades relacionadas ao PNCT;

c) participação em treinamento relacionado a colheita da amostra de escarro;

d) opinião sobre o processo educativo vivenciado;

e) opinião sobre o desempenho da equipe de trabalho durante o treinamento;

f) opinião sobre o Manual de Orientação para Coleta de Amostras de Escarro e outros Materiais para Baciloscopia e Cultura para Diagnóstico e Controle da Tuberculose distribuído (SES 2002);

g) conhecimento sobre a definição de baciloscopia de escarro;

h) conhecimento sobre importância da baciloscopia de escarro também no controle de tratamento;

i) conhecimento sobre procedimentos preconizados pelo PNCT para a obtenção da amostra de escarro inclusive questões de biossegurança como orientação do usuário do PNCT para a lavagem das mãos após a colheita da amostra de escarro, uso de luvas na manipulação dos frascos de coleta no recebimento das amostras de escarro;

j) percepção sobre participação na colheita da amostra de escarro.

Para cada questão aberta, a resposta foi gravada e transcrita para posterior análise.

A pergunta elaborada para abordar a questão da entrevista quanto à definição da baciloscopia de escarro foi realizada com alternativas de nomenclatura, ou seja, sob três formas diferentes, para tornar a linguagem acessível a cada entrevistado. Esta iniciativa se deu pela necessidade de adequação da terminologia utilizada entre pesquisador e entrevistados (MAZZAIA 2000).

Para a avaliação dos resultados quanto ao conhecimento dos entrevistados, utilizou-se os seguintes critérios (MAZZAIA 2000):

a) satisfatório para a resposta "pesquisa do bacilo da tuberculose no escarro" ou forma similar de se expressar, na questão sobre a definição do baciloscopia de escarro;

b) satisfatório para a resposta "tratamento e controle de tratamento" ou forma similar de se expressar, na questão sobre a importância deste exame; 
c) “de acordo com o PNCT", quando a resposta sobre procedimentos preconizados foi coerente com os procedimentos descritos no manual didático do BRASIL $(2002,2002 c)$ e Manual de Orientação para Coleta de Amostras de Escarro e outros Materiais para Baciloscopia e Cultura para Diagnóstico e Controle da Tuberculose (SES 2002).

Ainda no item relacionado aos conhecimentos dos componentes das equipes de enfermagem, confrontou-se a forma como o entrevistado afirmou orientar o usuário para a colheita da amostra de escarro com a observação do pesquisador e, foi considerada como - "confere com o observado" - quando ambas foram congruentes.

Também foi realizada uma questão com a finalidade de estudar a percepção do profissional de saúde quanto a importância do seu trabalho no que diz respeito à qualidade das amostras de escarro para o diagnóstico da tuberculose pulmonar; fazendo a interface entre a dependência das relações estabelecidas com o usuário do serviço para a efetividade do trabalho.

\section{Entrevistas para Profissionais de Laboratório}

Os profissionais do laboratório responsáveis pela realização das baciloscopias de serviços de saúde do Município de São Paulo responderam a questões abertas da entrevista sobre: acondicionamento, transporte, impressos de solicitação de baciloscopias e qualidade da amostra, conforme ANEXO 4, sendo que, o conteúdo obtido também foi utilizado para o estudo da prática dos profissionais de saúde entrevistados nos serviços de saúde.

\section{Entrevistas para Usuários do PNCT}

Para estudar a opinião dos usuários do PNCT sobre a colheita do escarro, da técnica utilizada para a colheita e o conhecimento dos usuários sobre a importância do exame para diagnóstico e controle de tratamento foi realizada entrevista com questões abertas (ANEXO 5), comparando os resultados aos procedimentos preconizados no Manual de Orientação (SES 2002) e a opinião do usuário sobre o exame realizado. As entrevistas foram gravadas, quando autorizado, após o usuário receber a orientação sobre o estudo. A prática dos profissionais de saúde também foi 
estudada a partir das respostas obtidas nas entrevistas realizadas com os usuários do PNCT.

\section{Roteiro de Observação da Prática dos Profissionais de Saúde}

Para a observação da prática dos profissionais de saúde no momento da orientação sobre como colher a amostra de escarro realizada com o usuário do PNCT, foi utilizado o roteiro de observação da prática (ANEXO 6) de MAZZAIA (2000), que compreendeu à observação estruturada com ítens classificados nas seguintes categorias:

a)comunicação;

b)orientação do procedimento de colheita da amostra de escarro para diagnóstico da tuberculose pulmonar ;

c)orientação do procedimento de colheita da amostra de escarro para clientes em controle de tratamento.

Os ítens da categoria - orientação do procedimento para a colheita da amostra de escarro para diagnóstico da tuberculose pulmonar e para controle de tratamento - foram definidos com base no material didático do Ministério da Saúde (Brasil 2002, 2002c, 2002d), no Manual de Orientação para Coleta de Amostras de Escarro e outros Materiais para Baciloscopia e Cultura para Diagnóstico e Controle da Tuberculose (SES 2002) e na publicação Tuberculose: Recomendações para redução do risco de transmissão em serviço de saúde (SES 2003).

Os ítens da categoria - comunicação - foram baseados nos estudos de STEFANELLI (1993), SILVA (1996) e MIRANDA (1983), e também na experiência de trabalho do pesquisador na área de enfermagem no PNCT.

Os instrumentos utilizados na coleta dos dados foram pré-testados no estudo de MAZZAIA (2000) e novamente, com as adaptações, em serviços de saúde que não fizeram parte do estudo, sendo considerados satisfatórios para o alcance dos objetivos do estudo. 
Quadro 1: Resumo das variáveis e a forma de coleta dos dados

\begin{tabular}{|c|c|}
\hline Variáveis & Fonte de Dados \\
\hline $\begin{array}{l}\text { Conhecimento sobre a baciloscopia do } \\
\text { escarro e importância }\end{array}$ & Entrevista com profissionais de saúde \\
\hline $\begin{array}{l}\text { Percepção do pessoal de enfermagem da } \\
\text { importância do seu trabalho para o sucesso } \\
\text { do PNCT }\end{array}$ & Entrevista com profissionais de saúde \\
\hline $\begin{array}{l}\text { Devolução da técnica preconizada pelo } \\
\text { PNCT e Manual de Orientação para a } \\
\text { colheita da amostra de escarro }\end{array}$ & $\begin{array}{l}\text { Entrevista com } \\
\text { atendimento pário do PNCT após } \\
\text { enfermagem }\end{array}$ \\
\hline $\begin{array}{l}\text { Reconhecimento do usuário do PNCT da } \\
\text { importância da amostra de escarro para } \\
\text { diagnóstico e controle de tratamento }\end{array}$ & $\begin{array}{l}\text { Entrevista com } \text { usuário do PNCT após } \\
\text { atendimento pelo pessoal de } \\
\text { enfermagem }\end{array}$ \\
\hline $\begin{array}{l}\text { Prática de orientação do paciente do PNCT } \\
\text { de acordo com o preconizado no citado } \\
\text { programa }\end{array}$ & $\begin{array}{l}\text { Roteiro de observação constante no } \\
\text { instrumento de coleta de dados adaptado } \\
\text { de MAZZAIA (2000) }\end{array}$ \\
\hline $\begin{array}{l}\text { Adequação do local para a colheita das } \\
\text { amostras de escarro, diminuição na espera } \\
\text { pelo resultado das baciloscopias e cuidados } \\
\text { de biossegurança }\end{array}$ & $\begin{array}{l}\text { Entrevista com profissionais de saúde e } \\
\text { observação do pesquisador }\end{array}$ \\
\hline $\begin{array}{l}\text { Afirmação sobre a melhora da qualidade das } \\
\text { amostras de escarro encaminhadas para } \\
\text { serem processados por profissionais do } \\
\text { laboratório de bacteriologia }\end{array}$ & $\begin{array}{llr}\text { Entrevista } & \text { com profissionais } & \text { do } \\
\text { laboratório } & \text { responsáveis } & \text { pelas } \\
\text { baciloscopias de escarro } & \end{array}$ \\
\hline
\end{tabular}


4. RESULTADOS E DISCUSSÃO

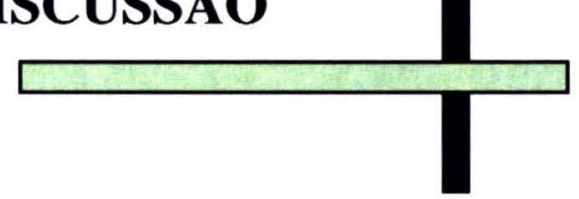




\section{Caracterização dos Serviços de Saúde Visitados}

Os $27(100 \%)$ serviços de saúde visitados foram identificados por Subprefeituras discriminadas a seguir:

- 2 serviços de saúde na Subprefeitura de Santo Amaro $(7,4 \%)$,

- 4 serviços de saúde na Subprefeitura da Capela do Socorro/Grajaú $(14,8 \%)$,

- 1 serviço de saúde na Subprefeitura do Jardim Angela (3,7\%),

- 6 serviços de saúde na Subprefeitura de CampoLimo/CapãoRedondo $(22,2 \%)$,

- 2 serviços de saúde na Subprefeitura do Jardim São Luiz $(7,4 \%)$,

- 3 serviços de saúde na Subprefeitura de Cidade Ahemar $(11,1 \%)$,

- 1 serviço de saúde na Subprefeitura da Sé $(3,7 \%)$,

- 2 serviços de saúde na Subprefeitura de Santana (7,4\%),

- 2 serviços de saúde na Subprefeitura de Vila Prudente/Sapopemba $(7,4 \%)$,

- 1 serviço de saúde na Subprefeitura de Ermelino Matarazzo (3,7\%),

- 1 serviço de saúde na Subprefeitura de Cidade Líder/Itaquera (3,7\%),

- 2 serviços de saúde na Subprefeitura de Freguesia do Ó/Brasilândia $(7,4 \%)$.

Quanto ao tipo de atendimento prestado foram encontradas 5 (18,5\%) Unidades Básicas de Saúde (UBS); 6 (22,2\%) Unidades de Saúde da Família (USF); $5(18,5 \%)$ Unidades Mistas de Saúde (UM) - que funcionam com os modelos de atendimento ambulatorial (UBS), programa de saúde da família (PSF) e programa do agente comunitário de saúde (PCAS) conjuntamente; 5 (18,5\%) Ambulatórios de Especialidades (AE) e 6 (22,2\%) Ambulatórios de DST/AIDS (DST/AIDS).

A Coordenação do Programa de Controle da Tuberculose da Secretaria Municipal de Saúde de São Paulo informou que possui 549 serviços de saúde que atendem aos usuários do PNCT, sendo 338 UBS (onde estão incluídas as Unidades Mistas), 179 USF e 32 ambulatórios, portanto foram visitados 2,95\% das UBS, 3,35\% das USF e 34,4\% dos ambulatórios.

Os serviços de saúde visitados são municipais ou municipalizados e os 27 (100\%) serviços de saúde referiram possuir profissionais de saúde contratados pela 
Prefeitura do Município de São Paulo, 9 (33,3\%) serviços possuíam também profissionais de saúde municipalizados, ou seja, contratados pela Secretaria de Estado da Saúde de São Paulo à disposição da Secretaria Múnicipal de Saúde e 6 $(22,2 \%)$ serviços de saúde possuíam profissionais contratados por Organizações Sociais, Instituições Filantrópicas, Fundações, instituições estas que celebram parcerias com a Prefeitura do Município de São Paulo, através da Secretaria Municipal de Saúde.

Dos serviços visitados, $22(81,5 \%)$ referiram realizar o tratamento supervisionado para tuberculose, sendo observado pelo pesquisador que o tratamento não foi realizado diariamente para todos os usuários. Os profissionais entrevistados relataram que existe grande resistência dos usuários em colaborar com a supervisão direta do tratamento, portanto, realizam a supervisão duas ou três vezes na semana. Acrescentaram que alguns usuários, por demonstrar interesse no próprio tratamento ou por dificuldade de locomoção, recebem a medicação para utilizarem no domicílio. Dos 27 serviços visitados, em $5(18,5 \%)$ foi observado pelo pesquisador o tratamento supervisionado diário para todos os usuários do PNCT no serviço de saúde.

A respeito do Manual de Orientação, dos 27 serviços de saúde visitados, 12 $(44,4 \%)$ possuíam o Manual de Orientação; $13(48,2 \%)$ não possuíam e $2(7,4 \%)$ serviços não souberam informar.

A expectativa da Coordenação do Programa de Controle da Tuberculose e da Divisão de Tuberculose do CVE era de que houvesse ampla divulgação do Manual de Orientação para os serviços de saúde, principalmente das áreas classificadas como prioritárias para o município de São Paulo, que são as subprefeituras da Sé, Itaquera, Campo Limpo, M’Boi Mirim e Freguesia d Ó/Brasilândia, nesta ordem, por possuírem as maiores incidências de tuberculose do município (SECRETARIA MUNICIPAL DE SAÚDE DE SÃO PAULO, 2004), mas não foi o encontrado. Ainda mais da metade dos serviços visitados, 55,6\% encontravam-se sem o Manual de Orientação disponível para consulta.

Embora a Coordenação do Programa de Controle de Tuberculose da SMSSP cite as 5 subprefeituras acima discriminadas como as detentoras da maior incidência de tuberculose no município, durante a coleta de dados, somente 10 serviços de saúde foram visitados nestas subprefeituras, conforme apresentado a seguir: 
- $1(3,4 \%)$ serviço de saúde na Subprefeitura da Sé

- $1(3,4 \%)$ serviço de saúde na Subprefeitura de Cidade Líder/Itaquera

- $2(7,8 \%)$ serviços de saúde na Subprefeitura Freguesia do Ó/Brasilândia e

- $6(22,2 \%)$ serviços de saúde na Subprefeitura de Campo Limpo/Capão Redondo.

Pelos dados observa-se que os serviços de saúde da Subprefeitura de Campo Limpo/Capão Redondo somam 22,2\% das unidades visitadas e portanto parecem investir no atendimento dos procedimentos do PNCT investigando sintomáticos respiratórios e solicitando baciloscopias de escarro.

Dos $12(100 \%)$ serviços de saúde que possuíam o Manual de Orientação temos:

- 2 serviços $(16,6 \%)$ Subprefeitura Cidade Adhemar

- 4 serviços (33\%) Subprefeitura Campo Limpo/Capão Redondo

- 1 Serviço $(8,4 \%)$ Subprefeitura Jardim Angela

- 1 Serviço $(8,4 \%)$ Subprefeitura Freguesia do Ó/Brasilândia

- 1 Serviço $(8,4 \%)$ Subprefeitura Santana

- 1 Serviço $(8,4 \%)$ Subprefeitura Capela do Socorro/Grajaú

- 1 Serviço $(8,4 \%)$ Subprefeitura Cidade Adhemar e

- 1 Serviço $(8,4 \%)$ Subprefeitura Sé.

A Subprefeitura de Campo Limpo/Capão Redondo, representam então 33\% dos serviços de saúde visitados neste estudo que possuem o Manual de Orientação, o que é avaliado como promissor visto ter esta Subprefeitura uma alta incidência de tuberculose de acordo com a Coordenação do Programa de Controle da Tuberculose da SSMSP, necessitando investimentos na busca ativa de casos (SECRETARIA MUNICIPAL DE SAÚDE DE SÃO PAULO, 2004).

\section{Sobre as práticas de formação de profissionais de saúde: perfil e preparo dos profissionais de saúde entrevistados}

Foram entrevistados 28 profissionais de saúde nos 27 serviços de saúde visitados sendo, $27(96,4 \%)$ do sexo feminino e $1(3,6 \%)$ do sexo masculino, com 
idade, função, tempo de formação e tempo de trabalho no PNCT conforme dados a seguir:

Tabela 1: Número de profissionais de saúde segundo idade nos diferentes serviços de saúde estudados. São Paulo, 2004.

\begin{tabular}{l|cc}
\hline $\begin{array}{c}\text { Faixa Etária em } \\
\text { anos }\end{array}$ & Número de Profissionais & \% acumulada \\
\hline De 20 a 29 & $1(3,6 \%)$ & 3,6 \\
De 30 a 39 & $4(14,3 \%)$ & 17,9 \\
De 40 a 49 & $13(46,4 \%)$ & 64,3 \\
50 anos e mais & $10(35,7 \%)$ & 100,0 \\
\hline Total & $\mathbf{2 8 ( 1 0 0 \% )}$ & $\mathbf{1 0 0 \%}$ \\
\hline
\end{tabular}

De acordo com o observado na tabela 1 foi possível notar que os profissionais com 40 anos ou mais somam $82,1 \%$ da amostra, sugerindo maior tempo de trabalho na rede de serviços de saúde.

Com relação às funções dos profissionais de saúde foram entrevistados 24 $(85,7 \%)$ auxiliares de enfermagem, $2(7,1 \%)$ atendentes de enfermagem, $1(3,6 \%)$ técnico de laboratório e $1(3,6 \%)$ auxiliar de laboratório no atendimento dos usuários do PNCT para a orientação da técnica da colheita da amostra de escarro.

O grau de escolaridade dos profissionais de saúde entrevistados são apresentados na tabela 2, a seguir:

Tabela 2: Número de profissionais de saúde entrevistados segundo grau de escolaridade referido. São Paulo, 2004.

\begin{tabular}{l|c|c}
\hline Grau de Escolaridade & Número de Profissionais & \% acumulada \\
\hline I Grau Completo & $5(17,8 \%)$ & 17,8 \\
II Grau Incompleto & $1(3,6 \%)$ & 21,4 \\
II Grau Completo & $10(35,7 \%)$ & 57,1 \\
III Grau Completo & $4(14,3 \%)$ & 71,4 \\
III Grau Incompleto & $8(28,6 \%)$ & 100,0 \\
\hline Total & $\mathbf{2 8 ( 1 0 0 \% )}$ & $\mathbf{1 0 0 \%}$ \\
\hline
\end{tabular}

As informações quanto ao grau de escolaridade dos profissionais de saúde revelam que embora os Auxiliares de Enfermagem sejam a maioria da amostra e, para tal função legalmente o que se obriga é possuir o I Grau completo (BRASIL 1986), constata-se que $35,7 \%$ da amostra possui II Grau concluído e $28,6 \%$ da 
amostra com III Grau completo. Percebe-se um preparo superior ao exigido o que poderia não ser somente um fator positivo, pois a capacidade superior às atividades desenvolvidas no trabalho pode tornar-se um fator de agravo à saúde (COX e col. 2000, MARTIN e col. 1997, ILO 1986) considerando a satisfação do trabalhador com as exigências para o desempenho de suas atividades, além de interferir no envolvimento do mesmo com a realização do seu trabalho.

Na tabela 3 são apresentados os dados sobre o tempo de formação dos profissionais de saúde.

É possível observar que $71,4 \%$ dos profissionais entrevistados apresentam mais de 10 anos de formação. Os profissionais referiram estar em atividade desde que terminaram o curso profissionalizante.

Tabela 3: Número de profissionais entrevistados segundo tempo de formação como profissional de saúde. São Paulo, 2004.

\begin{tabular}{l|cc}
\hline Tempo de Formação em anos & $\begin{array}{c}\text { Número de } \\
\text { Profissionais }\end{array}$ & \% acumulada \\
\hline De 0 a 5 & $1(3,6 \%)$ & 3,6 \\
De 5 a 9 & $7(25 \%)$ & 28,6 \\
De 10 a 14 & $5(17,8 \%)$ & 46,4 \\
De 15 a 19 & $6(21,5 \%)$ & 67,9 \\
20 anos e mais & $9(32,1 \%)$ & 100,0 \\
\hline Total & $\mathbf{2 8 ( 1 0 0 \% )}$ & $\mathbf{1 0 0 \%}$ \\
\hline
\end{tabular}

Tabela 4: Número de profissionais segundo tempo de trabalho no PNCT, São Paulo 2004

\begin{tabular}{l|cc}
\hline \multicolumn{1}{c|}{$\begin{array}{c}\text { Tempo de trabalho no } \\
\text { PNCT em anos }\end{array}$} & Número de Profissionais & \% acumulada \\
\hline De 0 a & $5(17,9 \%)$ & 17,9 \\
De 2 a 3 & $6(21,4 \%)$ & 39,3 \\
De 4 a 5 & $4(14,3 \%)$ & 53,6 \\
De 6 a 7 & $2(7,1 \%)$ & 60,7 \\
De 8 a 9 & $1(3,6 \%)$ & 64,3 \\
10 anos e mais & $10(35,7 \%)$ & 100 \\
\hline Total & $\mathbf{2 8 ( 1 0 0 \% )}$ & $\mathbf{1 0 0 \%}$ \\
\hline
\end{tabular}

Analisando os dados referentes ao tempo de trabalho dos profissionais de saúde no PNCT foi observado que 57,1\% da amostra trabalha no PNCT de 2 a 3 anos e 10 anos e mais, sendo que somam $61 \%$ os profissionais que trabalham no 
PNCT há mais de 4 anos. Os dados nos levam a refletir sobre o preparo destes profissionais, pois, pelo tempo de trabalho na área, já deveriam ter participado de treinamentos e apresentarem preparo para tal.

Quanto ao conhecimento do Manual de Orientação por parte dos 28 profissionais de saúde entrevistados, $12(42,8 \%)$ referiram conhecer o Manual de Orientação, $15(53,6 \%)$ profissionais relataram não conhecer o Manual de Orientação e um profissional $(3,6 \%)$ não soube informar, e portanto passou a ser classificado como não conhecedor do Manual de Orientação, mudando o montante de não conhecedores do Manual de Orientação para 16 e portanto, 57,2\% do total de profissionais de saúde.

Dos 12 profissionais que relataram conhecer o Manual de Orientação, 2 $(7,1 \%)$ referiram conhecer o Manual de Orientação mas não terem lido com atenção. Ainda $16(57,2 \%)$ dos serviços citados pelos laboratórios entre aqueles que mais solicitam baciloscopias, possuíam profissionais atendendo ao usuário do PNCT sem conhecer o Manual de Orientação. A coordenação do programa de controle da tuberculose da Secretaria de Saúde do Município de São Paulo foi notificada sobre os mesmos para que providenciasse o material de consulta. Alguns serviços já receberam o Manual de Orientação das mãos do próprio pesquisador após a coleta de dados.

Ressalta-se que coincide o número de profissionais de saúde que relataram conhecer o Manual de Orientação e o número de serviços de saúde onde foi encontrado o Manual de Orientação.

Quanto à participação em treinamentos, dos 28 (100\%) profissionais entrevistados, $16(57,1 \%)$ referiram ter participado de treinamentos sobre tuberculose em que foi visto o tema colheita de amostra de escarro, $8(28,6 \%)$ referiram esta participação há menos de um ano e, $3(10,7 \%)$ referiram participação no treinamento realizado na Faculdade de Saúde Pública em Novembro de 2002 (MAZZAIA e col.2002b).

Existiu a preocupação de destacar os profissionais de saúde entrevistados que participaram do treinamento realizado em Novembro de 2002 na Faculdade de Saúde Pública da USP pois, foram abordados sobre sua opinião a respeito do treinamento citado, já que foi um projeto educativo conhecido. 
Foi possível observar que houve uma elevação no percentual de profissionais de saúde que referiram ter participado de treinamentos uma vez que, 6\% dos 482 profissionais de saúde que responderam ao questionário aplicado em 2002 no treinamento realizado na FSP USP, haviam participado de treinamento semelhante e, durante a coleta de dados nos serviços de saúde foi observado que $57,1 \%$ de 28 profissionais também haviam participado de treinamento semelhante, desde 2002 (MAZZAIA e col 2002b). Embora sejam amostras bastantes distintas, a porcentagem de profissionais que citaram participação em treinamentos, comparados aos dados colhidos em 2002, foi expressiva.

Estes valores demonstram a existência de esforços no aprimoramento das ações do PNCT que se mantiveram após a iniciativa da Divisão de Tuberculose do CVE da Secretaria de Estado da Saúde, não só da Coordenação do Programa de Controle de Tuberculose do Centro de Controle de Doenças da Secretaria Municipal de Saúde de São Paulo como também das Coordenadorias de Saúde das Subprefeituras, como citado pelos próprios entrevistados.

Com relação ao preparo dos profissionais entrevistados, surgiu a curiosidade de conhecer especificamente o tempo de trabalho destes no PNCT e quando participaram de eventos de atualização com relação ao mesmo programa, pois acredita-se que a aquisição de conhecimentos, como já citado, possa não só aumentar expectativas quanto ao trabalho desenvolvido (BOWMAN 1986) mas principalmente incrementar as habilidades dos profissionais, decorrendo na valorização do próprio trabalho, o que determina a percepção de si próprio no mesmo. Para tanto a tabela 5 apresenta os dados quanto ao tempo de trabalho e o conhecimento do Manual de Orientação, bem como da participação em treinamentos pelos profissionais entrevistados.

Percebe-se que a maioria dos profissionais desenvolvem atividades dentro do PNCT há 10 anos e mais, tanto entre aqueles que conhecem o Manual de Orientação como aqueles que referiram desconhecê-lo, e, observa-se um maior número de profissionais há menos de 3 anos trabalhando no PNCT entre aqueles que desconhecem o Manual de Orientação, sendo que somente metade destes referem já ter participado de treinamentos ou atualizações. Infelizmente, profissionais sem o devido preparo são encaminhados para setores de trabalho, que, por sua importância, 
necessitariam de receber profissionais preparados para as atividades a serem desenvolvidas.

Tabela 5: Profissionais de saúde que conhecem o Manual de Orientação segundo tempo de trabalho no PNCT e participação em treinamentos. São Paulo, 2004.

\begin{tabular}{|c|c|c|c|}
\hline $\begin{array}{c}\text { Tempo no PNCT } \\
\text { em anos }\end{array}$ & $\begin{array}{c}\text { Participação eI } \\
\text { Sim }\end{array}$ & $\begin{array}{l}\text { einamentos } \\
\text { Não }\end{array}$ & Total \\
\hline 0 a 1 & $1(8,3 \%)$ & - & $1(8,3 \%)$ \\
\hline 2 a 3 & $1(8,3 \%)$ & $1(8,3 \%)$ & $2(16,7 \%)$ \\
\hline 4 a 5 & $2(16,7 \%)$ & - & $2(16,7 \%)$ \\
\hline 6 a 7 & $1(8,3 \%)$ & - & $1(8,3 \%)$ \\
\hline 8 a 9 & - & $1(8,3 \%)$ & $1(8,3 \%)$ \\
\hline $10 \operatorname{anos} e+$ & $4(33,5 \%)$ & $1(8,3 \%)$ & $5(41,7 \%)$ \\
\hline Total & $9(75,1 \%)$ & $3(24,9 \%)$ & $12(100 \%)$ \\
\hline
\end{tabular}

Tabela 5a: Profissionais de saúde que não conhecem o Manual de Orientação segundo tempo de trabalho no PNCT e participação em treinamentos. São Paulo, 2004.

\begin{tabular}{c|cc|c}
\hline $\begin{array}{c}\text { Tempo no PNCT } \\
\text { em anos }\end{array}$ & \multicolumn{2}{|c|}{ Participação em treinamentos } & Notal \\
\hline Sim a & $2(12,5 \%)$ & $2(12,5 \%)$ & $4(25 \%)$ \\
2 a 3 & $2(12,5 \%)$ & $2(12,5 \%)$ & $4(25 \%)$ \\
4 a 5 & - & $2(12,5 \%)$ & $2(12,5 \%)$ \\
6 a 7 & $1(6,25 \%)$ & - & $1(6,25 \%)$ \\
8 a 9 & - & - & - \\
10 anos e + & $2(12,5 \%)$ & $3(18,75 \%)$ & $5(31,25 \%)$ \\
\hline Total & $\mathbf{7 ( 4 3 , 7 5 \% )}$ & $\mathbf{9 ( 5 6 , 2 5 \% )}$ & $\mathbf{1 6 ( 1 0 0 \% )}$ \\
\hline
\end{tabular}

Durante a coleta de dados da pesquisa, foram observados profissionais que trabalham atendendo aos usuários do PNCT referindo:

“...falta investir no envolvimento do profissional.."

“..a maioria tem necessidade, uma perda familiar ou de emprego $e$ o profissional tem que estar pronto, com desejo de observar esses pequenos detalhes. Ele tem que estar motivado porque tratar tuberculose é muito difícil, muito difícil mesmo..." 
“...precisa estar sendo incentivado, não só os pacientes, mas os profissionais também, porque se o profissional não acredita, dificilmente ele vai passar essa credibilidade para o paciente."

No conteúdo destas falas, que foram literalmente transcritas, encontra-se referência ao envolvimento do profissional através, também, do preparo do mesmo para suas atividades, além de referirem-se à motivação, corroborando o trabalho de BERTOLOZZI (1998), MENDES (1994) e DIÁZ (1995).

Aos profissionais entrevistados foi solicitado saber quanto tempo já havia decorrido do último treinamento até os dias atuais. Os resultados obtidos estão dispostos na tabela 6.

Dos 16 profissionais entrevistados que referiram não conhecer o Manual de Orientação, 7 (43,8\%) afirmaram ter participado de treinamentos ou palestras sobre tuberculose, sendo que destes, 3 profissionais $(18,7 \%)$ referem ter participado dos treinamentos há um ano, um profissional $(6,3 \%)$ há 2 anos, dois profissionais $(12,5 \%)$ há mais de 10 anos e um $(6,3 \%)$ referiu não se recordar do período decorrido entre a participação no treinamento até os dias atuais, o que pode sugerir que este treinamento pode ter ocorrido a tempo suficiente para ser esquecido a época em que foi realizado.

Tabela 6: Tempo decorrido do último treinamento sobre tuberculose em relação ao número de profissionais que conheciam ou não o Manual de Orientação. São Paulo, 2004.

\begin{tabular}{c|c|c|c}
\hline $\begin{array}{l}\text { Tempo decorrido do último } \\
\text { treinamento em anos }\end{array}$ & $\begin{array}{l}\text { Conhece } \\
\text { manual }\end{array}$ & $\begin{array}{c}\text { Não conhece o } \\
\text { manual }\end{array}$ & Total \\
\hline 0 a 1 & $5(31,1 \%)$ & $3(18,7 \%)$ & $8(50,0 \%)$ \\
2 a 3 & $1(6,3 \%)$ & $1(6,3 \%)$ & $2(12,5 \%)$ \\
4 a 5 & - & - & - \\
6 a 7 & $1(6,3 \%)$ & - & $1(6,3 \%)$ \\
8 a 9 & - & - & - \\
10 anos e mais & - & $2(12,5 \%)$ & $2(12,5 \%)$ \\
Não lembra & $2(12,5 \%)$ & $1(6,3 \%)$ & $3(18,7 \%)$ \\
\hline Total & $\mathbf{9 ( 5 6 , 2 \% )}$ & $\mathbf{7 ( 4 3 , 8 \% )}$ & $\mathbf{1 6 ( 1 0 0 \% )}$ \\
\hline
\end{tabular}

Daqueles 12 profissionais de saúde que referiram conhecer o Manual de Orientação, $9(56,2 \%)$ relatam ter participado de treinamentos sendo que $5(31,1 \%)$ destes últimos referiram participação há um ano, um (6,3\%) referiu participação há 2 
anos, um (6,3\%) há 7 anos e dois (12,5\%) referiram não se lembrar do tempo decorrido. Cabe lembrar que destes 9 profissionais, $3(18,7 \%)$ são profissionais que participaram do treinamento realizado na Faculdade de Saúde Pública em Nov. 2002.

No total, dos 16 profissionais que referiram ter participado de treinamentos, 8 $(50,0 \%)$ frequentaram os mesmos há um ano; $2(12,4 \%)$ entre dois e três anos; 1 $(6,2 \%)$ entre seis e sete anos; $2(12,4 \%)$ há mais de dez anos e ainda $3(18,8 \%)$ que referem não se lembrar do período em que participaram de treinamentos.

O menor espaço de tempo entre os treinamentos frequientados e os dias atuais está no grupo de profissionais que referiu conhecer o Manual de Orientação.

Alguns profissionais entrevistados referiram não ter participado de treinamentos mas serem orientados por profissionais de saúde dos serviços.

Dos $27(100 \%)$ serviços, $6(22,2 \%)$ possuem profissionais que repassam ou preparam outros profissionais para as atividades do PNCT sendo o médico citado por dois profissionais de serviços de saúde distintos, e o enfermeiro citado por 4 outros profissionais.

Somente um profissional de uma Unidade Mista referiu ter participado de treinamentos e também receber orientações do Enfermeiro do serviço, dos outros 5 profissionais que referiram não participar de treinamentos e serem orientados por profissionais do serviço de saúde, um conhecia o Manual de Orientação.

Aos profissionais que relataram ter participado do treinamento na Faculdade de Saúde Pública em Novembro de 2002, foi solicitado responder à questão sobre o conteúdo que havia sido discutido durante o treinamento com a intenção de investigar que informações são prontamente evocadas.

Percebe-se que a técnica de como colher o escarro foi citada pelos 3 participantes e refere-se a necessidade de solicitar ao paciente que inspire profundamente, mantenha o ar nos pulmões alguns segundos e após tussa uma só vez com força, de boca aberta sobre o pote de coleta aberto, tentando retirar a secreção proveniente das vias aéreas inferiores, e não a saliva ou secreção da região dos seios paranasais, conforme o Manual de Orientação (SES 2002). 
Quadro 2: Temas discutidos durante treinamento na FSP USP em Nov. 2002 referidos pelos profissionais de saúde. São Paulo, 2004.

\begin{tabular}{|c|l|}
\hline Sujeitos & \multicolumn{1}{c|}{ Informações recebidas citadas } \\
\hline 1 & $\begin{array}{l}\text { Como colher a amostra, colher amostra pela manhã, colher na } \\
\text { unidade em área livre, se paciente com bastante secreção não falar } \\
\text { do exercício, usar o chuveiro em casa para ajudar, embaçar o } \\
\text { espelho. }\end{array}$ \\
\hline 2 & $\begin{array}{l}\text { Qual é o pote para cultura, que pode guardar o escarro sob } \\
\text { refrigeração até 7 dias, técnica de como colher o escarro... até 3 } \\
\text { vezes no pote, não sabia que exercício podia ajudar, aprimorei } \\
\text { minha técnica }\end{array}$ \\
\hline 3 & $\begin{array}{l}\text { Como fazer a coleta, como orientar o paciente que não tem } \\
\text { escarro, como guardar a amostra, como receber o paciente, como } \\
\text { agir com dedicação, amor, não manifestar "coitadinho", orientar } \\
\text { quanto ao tratamento, como tem feito, tomar 15 dias direitinho } \\
\text { senão transmite, 2 amostras de primeira vez, uma à noite e uma de } \\
\text { manhã. }\end{array}$ \\
\hline
\end{tabular}

O exercício orientado para estimular a tosse e contribuir para que o paciente colha uma amostra de boa qualidade, foi citado por 2 participantes, esta técnica, chamada de Técnica de Expiração Forçada - Huffing, baseia-se no conceito fisiológico de igual pressão (PIP) e tem como objetivo "ajudar na mobilização das secreções através da manipulação das pressões torácicas e da dinâmica das vias aéreas com menor probabilidade de colapso bronquiolar" (dificuldade de eliminação da secreção pela formação de bolhas de ar nas vias aéreas). Ao paciente é solicitado realizar inspirações curtas "e em seguida um grande esforço expiratório com a boca aberta, permanecendo a glote aberta e os músculos abdominais contraídos, como se a pessoa estivesse tentando embaçar um vidro ou espelho. A técnica descrita, foi apresentada através do Manual de Orientação, entregue durante o treinamento na FSP USP em Novembro de 2002 (SES 2002).

Observa-se que somente um dos participantes citou algum cuidado atendendo as normas de biossegurança, referindo-se à necessidade de orientar o cliente dirigirse para uma área reservada, porém ao ar livre, para a colheita da amostra de escarro na unidade de saúde.

Durante o treinamento descrito na introdução deste estudo, o tema biossegurança foi um dos escolhidos para ser discutido em pequenos grupos 
conforme já citado, e no Manual de Orientação, os itens relativos ao local da coleta, técnica de coleta, recepção das amostras no serviço de saúde e transporte das amostras para o laboratório, são destacados como atividades que implicam em algum risco e necessitam de atenção para o controle da transmissão da tuberculose.

O tema relacionamento profissional de saúde e paciente só foi citado por um sujeito, e no entanto, foi o tema com o qual a equipe de monitores deu início ao treinamento na FSP USP em 2002, tema este que foi escolhido para sensibilizar os participantes e abrir as discussões sobre a colheita das amostras de escarro que, indubitavelmente, inicia-se com a relação interpessoal estabelecida entre profissional de saúde e usuário do PNCT.

Também foi solicitado aos profissionais de saúde que participaram do treinamento realizado na FSP USP em Novembro de 2002 que relatassem a sua percepção sobre a participação no projeto educativo citado.

No quadro 3, observa-se que os três participantes reportaram-se à aquisição de conhecimentos, à utilidade das informações veiculadas e principalmente ao preparo para as atividades. Um dos participantes, especificamente, referiu-se à necessidade da manutenção de atividades educativas que permitam aos profissionais de saúde organizar o seu trabalho de forma a atender a um protocolo, no nosso caso o Programa Nacional de Controle da Tuberculose, protocolo este que não só define normas como define formas de atendimento aos usuários dos serviços de saúde, o que muitas vezes não acontece como pode ser constatado nos estudos de CAMPINAS (1999) e MAZZAIA (2000).

Quadro 3: Percepção dos profissionais de saúde sobre a participação no treinamento realizado na FSP USP em Novembro de 2002. São Paulo, 2004

\begin{tabular}{|c|l|}
\hline Sujeitos & \multicolumn{1}{|c|}{ Percepção sobre a participação no treinamento } \\
\hline 1 & "Foi útil para mim." \\
\hline 2 & $\begin{array}{l}\text { "Foi ótimo... sempre tem algo novo, sempre aprende algo, agente se } \\
\text { sente muito isolado, deveríamos falar a mesma linguagem e não é } \\
\text { isso que rola, seria mais fácil se todo mundo tivesse o mesmo fluxo, } \\
\text { cada unidade é uma unidade, o respaldo da UVES é muito fraco." }\end{array}$ \\
\hline 3 & Foi bom pois não tinha idéia de nada, não sabia nada. \\
\hline
\end{tabular}


O profissional de saúde que referiu "não ter idéia de nada , não saber nada" trabalha como auxiliar de enfermagem há 6 anos e está no atendimento dos usuários do PNCT há 2 anos.

\section{Opinião dos profissionais de saúde sobre o Manual de Orientação}

Foi investigada a opinião dos profissionais de saúde sobre o Manual de Orientação já que uma das propostas para o mesmo foi de torná-lo material de consulta no atendimento dos usuários do PNCT, dando subsídios aos profissionais de saúde com o intuito de adequar as atividades para a obtenção de uma boa amostra de escarro, cujos dados estão citados no quadro 4.

A avaliação do Manual de Orientação foi positiva e nenhum dos sujeitos que participaram do treinamento na FSP USP em Novembro de 2002 o modificaria, dois destes sujeitos referiram-se ao Manual de Orientação como objeto de consulta para esclarecimentos e um dos sujeitos reportou-se ao mesmo como instrumento que fundamentou cientificamente uma prática estabelecida.

Os profissionais de saúde que conheceram o Manual de Orientação nos serviços de saúde também avaliaram de forma positiva o Manual de Orientação. Observa-se que três sujeitos não manifestaram opinião sobre o Manual de Orientação o que nos faz pensar na possibilidade de os mesmos não terem manuseado o material. Esta é uma grande dificuldade: a socialização do conhecimento para a rede de serviços, nem sempre aquilo que foi discutido durante um processo educativo é divulgado a contento.

Em um dos serviços visitados, solicitando saber do Enfermeiro sobre a existência ou não do Manual de Orientação no serviço, informaram que não possuíam o Manual de Orientação pois dois Auxiliares de Enfermagem da instituição participaram do treinamento na Faculdade de Saúde Pública, porém, um deles está afastado e um outro foi transferido e provavelmente o Manual de Orientação deva estar de posse destes. 
Quadro 4: Opinião dos profissionais de saúde sobre o Manual de Orientação para Coleta de Amostras de Escarro e Outros Materiais para Baciloscopia e Cultura para Diagnóstico da Tuberculose. São Paulo, 2004.

\begin{tabular}{|c|c|}
\hline Sujeitos & $\begin{array}{l}\text { Opinião sobre Manual de Orientação para Coleta de Amostras de } \\
\text { Escarro e Outros Materiais para Baciloscopia e Cultura para } \\
\text { Diagnóstico da Tuberculose }\end{array}$ \\
\hline 1 & "Ajudou muito e tirou dúvidas". Não mudaria. \\
\hline 2 & $\begin{array}{l}\text { "O manual é muito importante , mostra os modos de colher e a } \\
\text { importância, né?". Não mudaria. }\end{array}$ \\
\hline 3 & Referiu que conhece o manual enviado pela UVIS mas não tem opinião. \\
\hline 4 & $\begin{array}{l}\text { Conheço e não li totalmente. Achei bom, ele até em palestras aqui ele é } \\
\text { usado por mim, pela médica, já usei para tirar dúvida da coleta de } \\
\text { escarro, para dar uma recordada. Não mudaria. }\end{array}$ \\
\hline 5 & Conheço mas não li com atenção, não tenho opinião sobre ele. \\
\hline 6 & $\begin{array}{l}\text { Interessante, foi através dele que aprendi para dar orientação, apesar da } \\
\text { Enfermeira orientar, dá uma boa base para conseguir conversar com o } \\
\text { paciente. Linguagem acessível, fácil de aprender. Não mudaria. }\end{array}$ \\
\hline 7 & $\begin{array}{l}\text { Eu acho ele viável. Tem bastante coisa... Eu gostei muito deste material, } \\
\text { é muito interessante. }\end{array}$ \\
\hline 8 & $\begin{array}{l}\text { Referiu que conhecia mas não emitiu parecer e que não tem na unidade } \\
\text { pois deu para os pacientes. }\end{array}$ \\
\hline 9 & $\begin{array}{l}\text { Eu acho o material importante... (falou sobre o que sabe de TB e a } \\
\text { necessidade de envolvimento dos profissionais) }\end{array}$ \\
\hline $10^{*}$ & $\begin{array}{l}\text { "Excelente, atualizou o atendimento e adequou à teoria". "Eu não } \\
\text { modificaria". }\end{array}$ \\
\hline $11 *$ & $\begin{array}{l}\text { "Técnico para fazer consulta, não precisei consultar depois do } \\
\text { treinamento". "Eu não modificaria". }\end{array}$ \\
\hline $12 *$ & $\begin{array}{l}\text { "Leio alguma coisa quando tenho dúvida, interessante, ajudou, mais ou } \\
\text { menos igual ao que vi no treinamento". "Eu não modificaria". }\end{array}$ \\
\hline
\end{tabular}

\footnotetext{
2002

Profissionais que participaram do treinamento na FSP USP em Novembro de
}

O Manual de Orientação foi entregue no treinamento mas a intenção seria de divulgação para o próprio serviço de procedência do profissional, ou seja, as informações deveriam ser socializadas com toda a equipe de profissionais que atendem aos usuários do PNCT. 
Talvez devesse existir maiores investigações sobre a repercussão de capacitações, atualizações e treinamentos para profissionais da rede pública de saúde. Parece que o controle daquilo que se veicula em projetos educativos para implantação ou aprimoramento do atendimento não ocorre na medida que deveria, ou seja, a gestão dos serviços de saúde necessita instituir um mecanismo de acompanhamento das ações que são realizadas e não só apenas o controle do número de procedimentos realizados que existe hoje.

Durante a coleta de dados nos serviços de saúde foi observado muitas considerações sobre a necessidade de envolver outros profissionais nos treinamentos realizados como os médicos, por exemplo, que foram os profissionais mais citados, porém, quando nos deparamos com situações em que o Manual de Orientação existe no serviço e no entanto o profissional da área não o conhece ou não o lê, ou mesmo profissionais que participam de reciclagens e treinamentos e não são solicitados a divulgar as informações recebidas no serviço, percebemos o quanto nos falta de ações de gestão e controle, para tornar os conhecimentos adquiridos públicos e para que os profissionais sintam-se "parte" do processo, no nosso caso, no processo de controle da tuberculose no país.

Preocupando-se com uma forma de avaliação consistente, cabe deixar registrado as impressões e observações do pesquisador durante a coleta de dados.

$\mathrm{O}$ três sujeitos identificados como participantes do treinamento realizado na Faculdade de Saúde Pública em Novembro de 2002 sobre a colheita de amostras de escarro, demonstraram, durante o período de observação do pesquisador, desenvolver relacionamento afetivo e próximo com todos os usuários do serviço que atenderam, independente de pertencerem ao PNCT. Dirigiram-se aos usuários utilizando seus nomes, mantiveram contato visual com os mesmos, e na maioria das vezes, como os sujeitos 1 e 2 , foi observado o uso do toque em membros superiores dos usuários do serviço de saúde, o que demonstra que o cultivo de um relacionamento satisfatório já é estabelecido como prática, para estes profissionais citados, de acordo com MIRANDA (1983) e MENDES (1994).

A respeito dos profissionais que não participaram do treinamento e referem conhecer o Manual de Orientação, o desenvolvimento de relacionamento afetivo também foi realidade, com exceção de um profissional identificado como sujeito 5 , 
que, coincidentemente refere conhecer o Manual de Orientação e não tê-lo lido com atenção. Aqui cabem as considerações feitas acima: "Será que realmente o Manual de Orientação foi explorado ?"

\section{Conhecimento dos profissionais de saúde sobre a baciloscopia de escarro e sua importância}

Neste estudo, foi investigado o conhecimento dos profissionais de saúde sobre a baciloscopia do escarro e sua finalidade, ou seja, a procura de bacilos $M$. tuberculosis na amostra de escarro e também a importância do procedimento para o controle de tratamento no caso de tuberculose pulmonar.

Conforme o tabela 7 constata-se que a maioria dos profissionais compreende a baciloscopia determinante para o diagnóstico da tuberculose pulmonar, porém não relaciona a mesma ao controle de tratamento.

Tabela 7: Conhecimento dos profissionais de saúde sobre a baciloscopia de escarro e sua importância no diagnóstico e controle de tratamento da tuberculose pulmonar. São Paulo, 2004.

\begin{tabular}{l|cc}
\hline Conhecimentos & $\begin{array}{c}\text { Sobre baciloscopia de escarro } \\
\text { e importância no diagnóstico }\end{array}$ & $\begin{array}{l}\text { Importância da baciloscopia } \\
\text { no controle de tratamento }\end{array}$ \\
Classificação & $24(85,7 \%)$ & $4(14,3 \%)$ \\
\hline Satisfatório & $4(14,3 \%)$ & $24(85,7 \%)$ \\
Insatisfatório & $\mathbf{2 8 ( 1 0 0 \% )}$ & $\mathbf{2 8}(\mathbf{1 0 0 \% )}$ \\
Total & & \\
\hline
\end{tabular}

Somente $4(14,3 \%)$ profissionais responderam satisfatoriamente ao conceito de baciloscopia e sua importância no controle de tratamento e destes, somente 1 participou do treinamento realizado na Faculdade de Saúde Pública da USP em Novembro de 2002 e utiliza o Manual de Orientação; dos outros 3 profissionais que não participaram do treinamento na Faculdade de Saúde Pública, um conhece o Manual de Orientação e referiu que a importância do exame está também em conhecer o "grau em que a doença está" e referiu ainda utilizar o Manual de Orientação sempre que surgem dúvidas; os outros 2 referiram não conhecer o 
Manual de Orientação e também não terem participado de treinamentos e citaram o acompanhamento do tratamento de uma forma indireta como:

“para saber se está mais ou menos no tratamento do paciente?” e

“...para a procura de um remédio correto...”.

Estas duas últimas observações não demonstram segurança e sim uma certa dúvida sobre o tema em questão, ou seja, existe dúvida se a baciloscopia do escarro pode contribuir para o acompanhamento do tratamento do usuário.

Separando-se os profissionais por categorias entre os que referem conhecer o Manual de Orientação ou não e aqueles que referem ter participado de treinamentos esta distribuição fica de acordo com a tabela 8.

Tabela 8: Conhecimento dos profissionais de saúde que referiram conhecer o Manual de Orientação sobre a definição e importância da baciloscopia de escarro relacionado à participação em treinamentos. São Paulo, 2004.

\begin{tabular}{|c|c|c|c|}
\hline \multirow[t]{2}{*}{$\begin{array}{l}\text { Conhecimentos sobre definição } \\
\text { e importância da baciloscopia }\end{array}$} & \multicolumn{2}{|c|}{$\begin{array}{c}\text { Participação em } \\
\text { treinamentos }\end{array}$} & \multirow[t]{2}{*}{ Total } \\
\hline & Sim & Não & \\
\hline $\begin{array}{l}\text { Satisfatório definição } \\
\text { insatisfatório importância }\end{array}$ & $5(41,6 \%)$ & $\$(25,0 \%)$ & $8(66,6 \%)$ \\
\hline $\begin{array}{l}\text { Satisfatório definição } \\
\text { satisfatório importância }\end{array}$ & $1(8,4 \%)$ & $1(8,4 \%)$ & $2(16,6 \%)$ \\
\hline $\begin{array}{l}\text { Insatisfatório definição } \\
\text { satisfatório importância }\end{array}$ & - & - & - \\
\hline $\begin{array}{l}\text { Insatisfatório definição } \\
\text { insatisfatório importância }\end{array}$ & $2(16,6 \%)$ & - & $2(16,6 \%)$ \\
\hline Total & $8(66,6 \%)$ & $4(33,4 \%)$ & $12(100 \%)$ \\
\hline
\end{tabular}

Observa-se que $83,3 \%$ da amostra - 10 profissionais - compreendem o que é a baciloscopia do escarro, destes $6(50 \%)$ participaram de treinamentos. Dois profissionais, $16,6 \%$, compreendem o que é a baciloscopia e também sua importância para o controle de tratamento, sendo a mesma porcentagem para aqueles profissionais que não compreendem o que é e nem a importância da mesma para o 
controle de tratamento, embora estes últimos tenham declarado ter participado de treinamentos. Vale lembrar que destes 12 profissionais, 3 (25\%) participaram do treinamento da FSP USP e que um dos objetivos do mesmo foi sensibilizar os profissionais sobre a importância da baciloscopia para o controle de tratamento de tuberculose.

Da amostra, $66,6 \%$ referem ter participado de treinamentos contra $33,4 \%$ de não participação.

A porcentagem de profissionais que compreendem o que é a baciloscopia do escarro é maior do que entre os profissionais que referiram conhecer o Manual de Orientação, porém, é menor quando se busca além do conceito a importância da baciloscopia para o controle do tratamento. Somente $43,8 \%$ da amostra refere ter participado de treinamentos contra $56,3 \%$ de não participação, conforme observado na tabela 9.

Tabela 9: Conhecimento dos profissionais de saúde que referiram não conhecer o Manual de Orientação sobre a definição e importância da baciloscopia de escarro relacionado à participação em treinamentos. São Paulo, 2004.

\begin{tabular}{ll|c|c|c}
\hline \multicolumn{1}{c|}{$\begin{array}{c}\text { Conhecimentos sobre definição e } \\
\text { importância da baciloscopia }\end{array}$} & \multicolumn{2}{|c|}{$\begin{array}{c}\text { Participação em } \\
\text { treinamentos }\end{array}$} & \multirow{2}{*}{ Total } \\
\cline { 3 - 5 } & Sim & Não & \\
\hline $\begin{array}{l}\text { Satisfatório definição } \\
\text { importância }\end{array}$ & insatisfatório & $5(31,2 \%)$ & $7(43,8 \%)$ & $12(75 \%)$ \\
$\begin{array}{l}\text { Satisfatório definição } \\
\text { importância }\end{array}$ & e satisfatório & - & $2(12,5 \%)$ & $2(12,5 \%)$ \\
$\begin{array}{l}\text { Insatisfatório definição e satisfatório } \\
\text { importância }\end{array}$ & - & - & \\
$\begin{array}{l}\text { Insatisfatório definição e insatisfatório } \\
\text { importância }\end{array}$ & $2(12,5 \%)$ & - & $2(12,5 \%)$ \\
\hline \\
Total
\end{tabular}


A quantidade de respostas satisfatórias para os profissionais que referem conhecer o Manual de Orientação e participar de treinamentos é discretamente maior, o que pode demonstrar que a frequência em atividades de reciclagem e o acesso a material de consulta pode contribuir para adequar a prática às normas dos programas de saúde, porém se levarmos em conta o tempo de trabalho destes profissionais no PNCT observamos que $35,7 \%$ dos profissionais estão trabalhando há 10 anos e mais na área e 39,3\% a menos de 3 anos, quanto a isso, Santos (2003) em estudo sobre o conhecimento de Enfermeiros em temas relacionados à biossegurança descreve que os enfermeiros mais jovens e formados recentemente apresentam melhores níveis de conhecimento provavelmente por receberem, durante a graduação, informações atualizadas, o que não explica a adequação dos resultados com os profissionais entrevistados que estão trabalhando no PNCT há mais de 10 anos, porém estes últimos, têm a seu favor o acompanhamento de usuários e o aprendizado com a própria prática e se permaneceram realizando as mesmas atividades, talvez porque se identifiquem com as mesmas e sintam-se motivados a realizá-las. Além disso, precisamos levar em consideração que 55,5\% dos profissionais que referiram conhecer o Manual de Orientação e $42,8 \%$ dos que não conhecem, participaram de treinamentos há menos de 1 ano, o que pode surtir no efeito descrito por Santos (2003).

\section{Os relatos dos profissionais e as observações do pesquisador sobre os aspectos relativos às medidas de biossegurança}

Neste estudo foram observadas, principalmente, as medidas de biossegurança ambientais e administrativas, pois, durante o período de coleta de dados, só foi observado pelo pesquisador a utilização de máscara tipo N95 por um funcionário de um ambulatório de DST/AIDS, que atendia a um paciente portador de tuberculose multiresistente, que também utilizava máscara, mas do tipo cirúrgica, conduta esta adequada de acordo com as recomendações do SES (2003).

As medidas administrativas de biossegurança observadas referem-se ao tempo de espera pelos resultados das baciloscopias, a participação dos profissionais em treinamentos para o atendimento dos usuários do PNCT, a prática do rodízio de profissionais no atendimento dos usuários do PNCT e às categorias de profissionais 
que solicitam as baciloscopias de escarro nos serviços de saúde. O preparo dos profissionais de saúde para a prática já foi apresentado no item perfil dos profissionais de saúde que participaram do estudo.

Com relação as medidas ambientais de biossegurança, foram observados os ambientes reservados para o atendimento dos usuários do PNCT, bem como os ambientes reservados para a colheita das amostras de escarro nos serviços de saúde.

\section{Ambientes reservados para o atendimento dos usuários do PNCT e para a colheita das amostras de escarro}

Com relação à observação dos ambientes reservados nos serviços de saúde para o atendimento dos usuários do PNCT e para a colheita da amostra de escarro, estabeleceu-se parâmetros de classificação para estes locais baseados nas recomendações do PNCT (BRASIL 2002, BRASIL 2002c, SES 2003):

- Local adequado: com iluminação natural, janelas na altura da mesa de atendimento do profissional de saúde, ventilado, com pisos e paredes constituídos de material lavável, proporcionando privacidade ao atendimento

- Local inadequado: local que não atendeu a um dos quesitos local devidamente iluminado, com janelas na altura da mesa de atendimento do profissional de saúde, ventilado, com pisos constituídos de material lavável, proporcionando privacidade ao atendimento.

O tabela 10 apresenta os resultados da observação feito nos locais quanto a área reservada para o atendimento dos usuários do PNCT.

Foi observado que $16(59,3 \%)$ serviços de saúde, realizam o atendimento do usuário do PNCT em salas ou corredores mal ventilados, na maioria das vezes por possuir nestes locais janelas altas, próximas ao teto e do tipo vasculante, características estas de construções antigas encontradas em algumas unidades. Também foi observado serviços com piso de madeira tipo taco, grande parte solta; paredes impróprias para a lavagem por serem divisórias de madeira pintadas; atendimento no final de corredores, sem janelas, dependendo de janelas de salas que permanecem a maior parte do tempo fechadas; salas pequenas com duas a quatro mesas além de arquivos, situações estas que se agravavam por não contarem com a presença de ventiladores para criação de correntes de ar. Nenhum serviço de saúde 
foi classificado como inadequado em função somente de não atender ao quesito privacidade, todos que receberam esta classificação apresentaram problemas quanto à ventilação, iluminação ou possibilidade de higienização do espaço.

Tabela 10: Classificação dos locais de atendimento aos usuários do PNCT nos serviços de saúde visitados quanto à adequação às normas de biossegurança. São Paulo, 2004.

\begin{tabular}{l|c}
\hline Classificação dos locais & Número de serviços \\
\hline Adequado & $8(29,6 \%)$ \\
Inadequado & $16(59,3 \%)$ \\
Não tem local específico & $3(11,1 \%)$ \\
\hline \multicolumn{1}{c|}{ Total } & $\mathbf{2 7 ( 1 0 0 \% )}$ \\
\hline
\end{tabular}

Analisando as questões relacionadas à biossegurança, foi possível observar que não estão sendo considerados aspectos quanto às medidas ambientais para proteção de profissionais e usuários do serviço de acordo com as normas. Este fato desmotiva os profissionais de saúde no atendimento das orientações quanto à biossegurança, ficando implícito que os gestores de saúde não valorizam esta condição pois, não propiciam um ambiente de trabalho com condições conforme preconizado. $\mathrm{O}$ ambiente inadequado expressa sempre o questionamento: se os gestores não estão atentos a esta observação, porque o profíssional de saúde deve utilizar de tantos cuidados ? Talvez estes profissionais de saúde possam interpretar estes cuidados como demasiados...

Os dados apresentados a seguir foram comparados aos dados obtidos através de questionários aplicados durante o treinamento realizado na FSP USP em 2002, dados estes que serviram como parâmetro para a análise da realidade dos serviços de saúde no que diz respeito à implantação das medidas de biossegurança preconizadas no controle da tuberculose. 


\section{Local reservado nos serviços de saúde para a colheita da amostra de escarro}

Na coleta de dados nos serviços de saúde, o local reservado para a colheita da amostra de escarro pelo usuário do PNCT, segue conforme tabela 11 que apresenta o número de vezes que os locais discriminados foram citados pelos entrevistados.

Dos serviços de saúde visitados, $11,1 \%$ ainda não colhem uma amostra de escarro quando o usuário está em atendimento na unidade, orientado-o a colher em sua residência, contrariando as normas do PNCT (BRASIL 2002, 2002c, 2002d, SES 2002). Durante o treinamento na FSP USP em 2002, 20,3\%, 98 dos 482 questionários respondidos referiram que a colheita das amostras de escarro eram realizadas na residência dos usuários, observa-se incremento no número de serviços que iniciam a colheita na unidade de saúde, respeitando-se as proporções de entrevistas e questionários respondidos, conforme tabela 11 (MAZZAIA e col 2002b).

Tabela 11: Local de coleta da amostra de escarro citados pelos profissionais nos serviços de saúde visitados. São Paulo, 2004.

\begin{tabular}{l|cc}
\hline \multicolumn{1}{c|}{ Local citado } & $\begin{array}{c}\text { Número de } \\
\text { serviços }\end{array}$ & $\begin{array}{c}\text { Porcentagem de citações sobre } \\
\text { total dos 27 serviços }\end{array}$ \\
\hline Não colhe no serviço & 3 & $11,1 \%$ \\
Banheiro de pacientes & 10 & $37,0 \%$ \\
Parte externa do unidade & 12 & $44,4 \%$ \\
Salas internas dos serviços & 4 & $14,8 \%$ \\
\hline
\end{tabular}

Apesar dos esforços enfatizando a necessidade dos profissionais de saúde insistirem com os usuários do serviço, orientando a necessidade de reduzir a contaminação no ambiente do serviço de saúde (BRASIL 2002d), alguns serviços não conseguem convencer o usuário a colher sua amostra em área aberta, arejada. São necessários cuidados com a escolha do local para onde o usuário deve ser encaminhado para a colheita do material, pois além de arejado deve ser reservado, respeitando a privacidade do usuário, precisamos lembrar que a percepção da coleta do material biológico, por parte também dos usuários, não é positiva (CAMPINAS 
1999, MAZZAIA 2000), e se estes não se sentirem resguardados, não aceitarão a exposição.

A quantidade de citações do banheiro do paciente como local de colheita do escarro na unidade esteve presente em 10 relatos, ou seja, 37\% dos serviços visitados e 72 ou 15,6\% de citações durante o treinamento na FSP USP em 2002 (MAZZAIA e col 2002b). O dado causa preocupação considerando os cuidados necessários com o ambiente e proteção dos clientes e profissionais do serviço (BRASIL 2002, SES 2003, BOLYARD 1998) e a forma de transmissão da tuberculose, e também por ter sido tema compondo o Manual de Orientação divulgado.

Áreas internas da unidade como local de colheita das amostras de escarro foram citadas por $14,8 \%$ dos serviços visitados, ou 4 serviços de saúde sendo que, durante o treinamento na FSP USP este valor foi de $67(13,9 \%)$ citações, embora menor, mostra-se de forma muito discreta (MAZZAIA e col 2002b). Considerou-se áreas internas dos serviços de saúde citações como laboratório, sala de atendimento e sala de inalação. Se para a colheita do material estas salas não permanecerem de portas fechadas com janelas abertas na tentativa de evitar que correntes de ar sejam conduzidas para dentro dos corredores dos serviços de saúde, existe o risco de disseminar o $M$. tuberculosis no ambiente já que se transmite por via respiratória, formando aerossóis que mantêm-se em suspensão, principalmente se o ambiente não for iluminado e ventilado a contento.

Áreas externas da unidade foram citadas por $44,4 \%$ dos serviços visitados, ou 12 unidades, no entanto, durante o treinamento foi citação de apenas $54(11,2 \%)$ dos 482 questionários respondidos (MAZZAIA e col 2002b). Embora ainda existam serviços permitindo a colheita nos ambientes do serviço, um número expressivo começa a introduzir a orientação da colheita ser realizada em ambientes abertos e ventilados o que não só protege usuários e profissionais, mas principalmente, pode tornar-se instrumento importante para orientar o usuário quanto ao risco de contaminação e cuidados com ambientes, inclusive doméstico.

\section{Profissionais que solicitam baciloscopias de escarro nos serviços de saúde}

As solicitações de baciloscopias devem ser realizadas por qualquer profissional que suspeite de um possível diagnóstico de tuberculose ou que identifique um 
sintomático respiratório que atenda aos critérios do PNCT (BRASIL 2002, 2002c, SES 2002, SES 2003), o que significa agilidade nas medidas necessárias na identificação precoce das possíveis fonte de infecção e imediato encaminhamento para tratamento, medida administrativa em relação à biossegurança. Na coleta de dados nos serviços de saúde os resultados obtidos sobre esta tema estão apresentados na tabela 12.

A tabela 12 foi elaborada com a citação dos profissionais sobre que indivíduos, dentro dos serviços de saúde, eram responsáveis pela solicitação de baciloscopia e preenchimento da requisição do exame, então, as porcentagens apresentadas dizem respeito ao número de vezes que determinada categoria profissional foi citada, e não ao número de profissionais entrevistados ou serviços de saúde visitados.

Tabela 12: Tipos de serviços de saúde relacionado à categoria profissional responsável pelo preenchimento da solicitação de baciloscopias. São Paulo, 2004.

\begin{tabular}{l|cccc}
\hline \multicolumn{1}{|c|}{ Rrofissionais } & $\begin{array}{c}\text { Somente } \\
\text { Médico }\end{array}$ & Médicos & Enfermeiros & $\begin{array}{c}\text { Profissionais } \\
\text { de } \\
\text { Enfermagem }\end{array}$ \\
\hline $\begin{array}{l}\text { Ambulatórios } \\
\text { DST/AIDS }\end{array}$ & $1(3,7 \%)$ & - & $5(18,5 \%)$ & - \\
$\begin{array}{l}\text { Ambulatórios de } \\
\text { Especialidades }\end{array}$ & $4(14,8 \%)$ & - & $1(3,7 \%)$ & $1(3,7 \%)$ \\
$\begin{array}{l}\text { Unidades de Saúde } \\
\text { (USF/UBS/Mistas) }\end{array}$ & - & $16(59,2 \%)$ & $16(59,2 \%)$ & $16(59,2 \%)$ \\
\hline & $\mathbf{5 ( 1 8 , 5 \% )}$ & $\mathbf{1 6}(\mathbf{5 9 , 2 \% )}$ & $\mathbf{2 2}(\mathbf{8 1 , 5 \% )}$ & $\mathbf{1 7}(\mathbf{6 3 , 0 \%})$ \\
\hline
\end{tabular}

Todos os $27(100 \%)$ serviços de saúde visitados referiram que os médicos realizam as solicitações de baciloscopias, sendo que nas $16(59,2 \%)$ Unidades de Saúde (UBS, USF e UM) visitadas foi observado que as baciloscopias são solicitadas por médicos, enfermeiros e outros profissionais de enfermagem. No entanto, um ambulatório especializado em DST/AIDS $(3,7 \%)$ e quatro $\mathrm{AE}(14,8 \%)$ referiram que somente o médico solicita as baciloscopias, e, esta não é a recomendação da DT do CVE da Secretaria de Estado da Saúde em consonância com o PNCT (BRASIL, 
2002, 2002c, SES 2002, SES 2003). O próprio pedido de baciloscopia padronizado pela Secretaria de Estado da Saúde não possui local para identificação do profissional que preencheu a solicitação.

As solicitações de baciloscopias preenchidas exclusivamente por médicos e enfermeiros foi a citação de 5 ambulatórios especializados em DST/AIDS (18,5\%), destes, 3 auxiliares de enfermagem entrevistados, de serviços distintos, referiram que recebem orientações dos Enfermeiros para solicitarem as baciloscopias e preencherem os pedidos, mas, preferem encaminhar para que o Enfermeiro da unidade realize o procedimento.

Durante o treinamento na FSP USP em 2002 foi identificado que de 482 questionários respondidos, 209 (43,3\%) referiram ser o médico o responsável pelos pedidos de exames, $260(53,9 \%)$ referiram ser o Enfermeiro e $177(36,7 \%)$ o auxiliar de enfermagem (MAZZAIA e col 2002b). Comparando os resultados percebe-se, até então, maior envolvimento dos profissionais de enfermagem no preenchimento de solicitações, o que vem adequar-se às recomendações do PNCT e às medidas administrativas de biossegurança.

A maioria das indicações da baciloscopia e as requisições de exames são realizados pelos profissionais que estão em contato direto e permanente com o usuário do serviço, ou seja, a enfermagem que "permanece no meio de uma dupla demanda, de um lado as normas institucionais e do outro a necessidade da população" (SCOCHI 1989).

O fato de existirem serviços de saúde onde somente profissionais médicos realizam a solicitação de exames para doenças que possuem atendimento programático, demonstra que, apesar dos gestores do sistema de saúde brasileiro investirem esforços em modelos de assistência à saúde diferentes dos modelos assistenciais “medicocêntricos” (BRASIL 2001; BERTOLOZZI, 1998), permanecemos com esta característica, talvez também porque a população permaneça buscando a unidade de saúde para atendimento de uma queixa definida, e cabe ao serviço de saúde responder à solicitação, porém, não se deve perder a oportunidade de desenvolver ações educativas, ou seja, promovendo a saúde e principalmente prevenindo problemas, capacitando a população a entender o serviço de saúde como um recurso de conhecimento e defesa e não apenas de 
“procedimentos e tratamentos". Estas ações só são possíveis no trabalho em equipe, interdisciplinar.

\section{Rodízio de profissionais de saúde no atendimento do usuário do PNCT}

Sobre a informação se existia ou não um rodízio dos profissionais de saúde que trabalhavam no atendimento aos usuários do PNCT, $202(41,9 \%)$ dos profissionais que responderam aos questionários durante o treinamento na FSP USP em 2002 responderam afirmativamente e 170 (35,2\%) dos profissionais referiram que não (MAZZAIA e col 2002b). Já nos serviços de saúde visitados, 6 (22,2\%) referiram possuir rodízio de profissionais contra $21(77,8 \%)$ serviços de saúde que negaram a realização de rodízio dos profissionais.

A troca de profissionais da área é interessante para que se possa contar com outros profissionais preparados para desenvolver as atividades do setor, porém, este profissional que vem substituir no setor de atendimento do PNCT deve ser devidamente preparado, principalmente para atender às necessidades dos usuários do PNCT que são específicas. Precisamos de profissionais sensibilizados para o cuidado com todas as ações do programa para que não tenhamos riscos de abandonos e falência de tratamentos, não identificação de fontes de infecção, entre outros.

BERTOLOZZI (1998) em seu estudo revela que a mudança da equipe de saúde nos serviços é apontada como negativa pela população usuária do PNCT, "na medida em que promove o distanciamento da nova equipe, no relacionamento com o doente", fato este que pode determinar "a ruptura da relação do doente com o serviço de saúde", significando abandono, não tratamento, perpetuação de fontes de infecção.

Por outro lado é importante lembrar que no atendimento dos serviços de saúde é necessário manter profissionais capacitados para o atendimento do usuário do PNCT pois deve-se considerar o absenteísmo profissional por problemas de saúde, faltas abonadas, entre outros e no advento da necessidade, as atividades relativas ao PNCT não podem ser suspensas. Este cuidado diz respeito à observação das medidas administrativas de biossegurança necessárias no controle da disseminação da tuberculose em instituições de saúde. 
Surpreendeu o pesquisador o fato de serem encontradas Unidades de Saúde da Família atendendo aos usuários do PNCT nos serviços de saúde, inclusive para receber o tratamento supervisionado, atividades estas realizadas por profissionais específicos para os quais eram encaminhados os casos de tuberculose ou suspeita de tuberculose. Acreditava-se que cada equipe estivesse acompanhando e supervisionando seus usuários conforme princípios do atendimento do Programa de Saúde da Família.

Dos $6(22,2 \%)$ serviços de saúde que referiram manter um rodízio de profissionais atendendo ao usuário do PNCT 2 eram USF, 1 UM, 1 UBS e 2 DST/AIDS.

\section{Tempo de espera pelo resultado das baciloscopias nos serviços de saúde}

A espera pelo resultado das baciloscopias relatado pelos profissionais durante visitas aos serviços de saúde, são apresentados na tabela 13:

Tabela 13: Tempo de espera pelos resultados das baciloscopias de escarro solicitadas pelos serviços de saúde. São Paulo, 2004

\begin{tabular}{l|ccc}
\hline \multicolumn{1}{c|}{ Tempo de espera } & $\mathbf{N}^{\circ}$ Serviços & \% de serviços & \% acumulada \\
\hline No mesmo dia & 15 & $55,6 \%$ & 55,6 \\
Até 2 dias & 1 & $3,7 \%$ & 59,3 \\
Até 4 dias & 3 & $11,1 \%$ & 70,4 \\
Até 7 dias & 5 & $18,5 \%$ & 88,9 \\
Até 10 dias ou mais & 3 & $11,1 \%$ & 100,0 \\
\hline Total & $\mathbf{2 7}$ & $\mathbf{1 0 0 \%}$ & $\mathbf{1 0 0 \%}$ \\
\hline
\end{tabular}

O tempo citado como espera para os resultados das baciloscopias quando positivas, segundo às expectativas e metas da Secretaria Municipal de Saúde de São Paulo, é de 24 horas, ou seja, no mesmo dia, também é o caso para as solicitações de baciloscopias de urgência onde se preconiza o encaminhamento dos resultados em no máximo 4 horas (SECRETARIA MUNICIPAL DE SAÚDE DE SÃO PAULO, 2004). Comparando os resultados obtidos nas visitas aos serviços de saúde com as respostas obtidas no treinamento da FSP USP em 2002, identifica-se expressiva redução no tempo de espera pelos resultados de baciloscopia, pois, durante o treinamento não ocorreu nenhuma citação de resultados de baciloscopias recebidos 
no mesmo dia do encaminhamento dos exames, já durante as visitas, $15(55,6 \%)$ dos serviços afirmaram receber os resultados das baciloscopias por FAX no mesmo dia do encaminhamento das amostras de escarro para os laboratórios. Cabe lembrar que o treinamento ocorreu no final do ano 2002 e em 2003 a Coordenação do Programa de Controle da Tuberculose da SMSSP realizou a reformulação do sistema de atendimento da rede de laboratórios para atendimento do PNCT.

Em 2002 na FSP USP encontramos $119(24,7 \%)$ de 482 profissionais referindo que esperavam até 20 dias pelos resultados de baciloscopias e $99(20,5 \%)$ dos profissionais citando mais de 20 dias de espera pelos resultados. Na coleta de dados em 2004 ainda encontramos 3 profissionais citando espera de até 10 dias pelos resultados de baciloscopias, porém, perfazem apenas $11,1 \%$ do total de profissionais entrevistados (MAZZAIA e col 2002b).

A identificação das fontes de infecção e início do tratamento para a tuberculose pulmonar é estratégia primordial no controle da doença e redução do risco de infecção para a população em geral, principalmente dentro dos serviços de saúde, então, o quanto mais rápido for o trâmite de encaminhamento dos resultados das baciloscopias quando positivas, maior é a chance de eliminar a fonte de infecção, reduzindo a possibilidade de novas fontes (BRASIL 2002, 2002c; SES 2002, 2003). A reformulação do sistema de atendimento laboratorial para os serviços de saúde realizada pela SMSSP parece ter sido um diferencial na diminuição no tempo de espera pelos resultados de baciloscopia, porém, ainda existem serviços aguardando mais de 48 horas por estes resultados. É necessário que os gestores do sistema de saúde municipal estejam atentos para atender ao princípio de "capacidade de resolução" dos serviços de saúde (BRASIL 1990).

Os resultados obtidos durante as visitas aos serviços de saúde não foram compatíveis com o relato dos profissionais de laboratório entrevistados pois, como será mostrado na sequência do trabalho, relatam enviar os resultados positivos no mesmo dia por FAX para os serviços de saúde. 


\section{Cuidados na recepção da amostra de escarro nos Serviços de Saúde}

A recepção da amostra de escarro no serviço de saúde é uma atividade de destaque pois, neste momento, é realizada a verificação da qualidade da amostra recebida e portanto, o pote de colheita é manipulado pelo profissional de saúde.

A tabela 14 apresenta dados sobre como os profissionais de saúde que referiram conhecer o Manual de Orientação, recebiam as amostras de escarro nos serviços de saúde visitados.

Tabela 14: Número de profissionais de saúde que conhecem o Manual de Orientação segundo sua participação em treinamentos relacionado ao uso de luvas no recebimento das amostras de escarro. São Paulo, 2004

\begin{tabular}{l|c|c|c}
\hline $\begin{array}{l}\text { Participação } \\
\text { Treinamento }\end{array}$ & Com luva & Sem luva & $\begin{array}{c}\text { Número de } \\
\text { profissionais }\end{array}$ \\
\hline Sim & $4(33,3 \%)$ & $5(41,7 \%)$ & $9(75 \%)$ \\
Não & $3(25,0 \%)$ & - & $3(25 \%)$ \\
\hline Total & $\mathbf{7 ( 5 8 , 3 \% )}$ & $\mathbf{5 ( 4 1 , 7 \% )}$ & $\mathbf{1 2 ( 1 0 0 \% )}$ \\
\hline
\end{tabular}

Dos 12 profissionais que referiram conhecer o Manual de Orientação, 9 (75\%) referiram também terem participado de treinamentos sendo que destes, 3 (25\%) participaram do treinamento na FSP da USP. Ainda 3 (25\%) profissionais referiram não ter participado de treinamentos. Dos profissionais que participaram de treinamentos somente $4(33,3 \%)$ referiram receber as amostras com luvas conforme orientação do Manual de Orientação. Outros 5 (41,7\%) profissionais referiram receber a amostra sem luvas.

Embora o risco de contaminação com o bacilo esteja disseminado pela população em geral, o profissional de saúde está mais exposto a mesma pois encontra-se periodicamente em contato com possíveis indivíduos bacilíferos (ALA, 2003, BOLYARD 1998). HARRIES e col. (2002), durante 3 anos, realizaram pesquisa em Malawi, comparando o número de casos notificados de tuberculose pulmonar entre professores primários e profissionais de saúde e, verificaram que, o número de notificações se manteve entre os profissionais de saúde, porém foi 
significativamente maior do que as notificações obtidas entre os professores primários, mostrando o risco a que estão expostos.

A tabela 15 mostra o uso de luvas por profissionais de saúde que referiram não conhecer o Manual de Orientação.

Tabela 15: Número de profissionais de saúde que desconheciam o Manual de Orientação segundo sua participação em treinamentos relacionado ao uso de luvas no recebimento das amostras de escarro. São Paulo, 2004.

\begin{tabular}{l|c|c|c|c}
\hline $\begin{array}{l}\text { Participação } \\
\text { Treinamento }\end{array}$ & Com luva & Sem luva & $\begin{array}{l}\text { Não refere } \\
\text { luvas }\end{array}$ & $\begin{array}{l}\text { Número de } \\
\text { profissionais }\end{array}$ \\
\hline Sim & $4(25,0 \%)$ & - & $3(18,8 \%)$ & $7(43,7 \%)$ \\
Não & $5(31,2 \%)$ & $2(12,5 \%)$ & $2(12,5 \%)$ & $9(56,3 \%)$ \\
\hline Total & $\mathbf{9 ( 5 6 , 3 \% )}$ & $\mathbf{2 ( 1 2 , 5 \% )}$ & $\mathbf{5 ( 3 1 , 2 \% )}$ & $\mathbf{1 6 ( 1 0 0 \% )}$ \\
\hline
\end{tabular}

Os profissionais que referem não conhecer o Manual de Orientação apresentam uma porcentagem de 56,3\% de não participação em treinamentos e um índice de $12,5 \%$ de profissionais que recebem as amostras de escarro sem luvas, somados a $12,5 \%$ de profissionais que não se referem ao uso de luvas no momento da recepção das amostras de escarro. Se considerada a importância dos cuidados com o ambiente para a redução da disseminação do $M$. tuberculosis, evidencia-se a necessidade da citação do uso de luva para a realização do procedimento de recepção da amostra de escarro. Pode-se inferir sobre a significação do procedimento para o profissional. A não observação de cuidados com a recepção da amostra com uso de luvas e posterior lavagem das mãos pode contribuir para o aumento do risco de exposição do profissional de saúde que desempenha suas funções no PNCT (tabela 15).

Nas tabelas 16 e 17, os dados sobre o uso de luvas entre os profissionais de saúde, são distribuídos pelo tipo de atendimento dos serviços de saúde visitados. 
Tabela 16: Uso de luvas pelos profissionais de saúde que conheciam o Manual de Orientação relacionado ao tipo de serviço de saúde. São Paulo, 2004.

\begin{tabular}{c|c|c|c}
\hline Uso de luvas & Sim & Não & Total \\
\hline $\begin{array}{c}\text { Unidade Saúde } \\
\text { da Família }\end{array}$ & $3(25,0 \%)$ & - & $\mathbf{3}(\mathbf{2 5 , 0 \% )}$ \\
$\begin{array}{c}\text { Unidade Básica } \\
\text { de Saúde }\end{array}$ & $2(16,7 \%)$ & $1(8,3 \%)$ & $\mathbf{3}(\mathbf{2 5 , 0 \% )}$ \\
$\begin{array}{c}\text { Ambulatório } \\
\text { Especialidades }\end{array}$ & $1(8,30 \%)$ & $1(8,3 \%)$ & $\mathbf{2 ( 1 6 , 7 \% )}$ \\
$\begin{array}{c}\text { Ambulatório } \\
\text { DST/AIDS }\end{array}$ & $1(8,30 \%)$ & - & $\mathbf{1}(\mathbf{8 , 3 0 \% )}$ \\
$\begin{array}{c}\text { Unidade Mista } \\
\text { Total }\end{array}$ & $\mathbf{7 ( 5 8 , 3 \% )}$ & $\mathbf{5 ( 4 1 , 7 \% )}$ & $\mathbf{1 2}(\mathbf{1 0 0 \%})$ \\
\hline
\end{tabular}

Relacionando o uso de luva entre os profissionais que conheciam o Manual de Orientação, ao tipo de serviço de saúde, observa-se que o uso de luva é mais frequente nas USF e DST/AIDS, este último com 100\% de adesão ao uso de luvas, e, menos frequente nas UM, porém ainda observa-se um profissional de uma UBS e um profissional de um $\mathrm{AE}$ que citam não utilizar luvas para receber a amostra de escarro, totalizando 5 serviços, ou seja, $41,6 \%$ dos profissionais de saúde que referiram conhecer o Manual de Orientação, quase a metade dos profissionais desta classificação, sendo que, como já comentado, o uso de luvas e a lavagem das mãos após o recebimento e acondicionamento da amostra de escarro, são procedimentos descritos no Manual de Orientação (tabela 16).

Pelos dados analisados, o conhecimento do Manual de Orientação pareceu não influenciar o comportamento de utilizar ou não as luvas no momento do recebimento das amostras de escarro nos serviços de saúde.

Considerando-se o total de profissionais entrevistados em relação ao uso de luvas no momento de recepção das amostras de escarro temos os resultados apresentados na tabela 18. 
Dos 28 profissionais, 16 ou $57,1 \%$ fazem uso de luvas para receber amostras de escarro, 7 (25\%) profissionais não utilizam luvas, porém 5 profissionais, ou $17,9 \%$ do total, não se refere à prática do uso de luvas no momento da recepção da amostra em resposta à questão da entrevista, o que pode sugerir, como já discutido, que não ocorre a utilização das mesmas, o que somaria um total de $42,9 \%$ da amostra de profissionais sem utilizar luvas (tabela 18).

Tabela 17: Uso de luvas pelos profissionais de saúde que desconheciam o Manual de Orientação relacionado ao tipo de serviço de saúde. São Paulo, 2004.

\begin{tabular}{c|c|c|c|c}
\hline Uso de luvas & Sim & Não & Não refere & Total \\
\hline $\begin{array}{c}\text { Unidade Saúde } \\
\text { da Família }\end{array}$ & $1(6,25 \%)$ & $1(6,25 \%)$ & - & $\mathbf{2}(\mathbf{1 2 , 5 \% )}$ \\
$\begin{array}{c}\text { Unidade Básica } \\
\text { de Saúde }\end{array}$ & - & $1(6,25 \%)$ & $2(12,5 \%)$ & $\mathbf{3}(\mathbf{1 8 , 8 \% )}$ \\
$\begin{array}{c}\text { Ambulatório } \\
\text { Especialidades }\end{array}$ & $3(18,8 \%)$ & - & - & $\mathbf{3}(\mathbf{1 8 , 8 \% )}$ \\
$\begin{array}{c}\text { Ambulatório } \\
\text { DST/AIDS }\end{array}$ & $5(31,2 \%)$ & - & $1(6,25 \%)$ & $\mathbf{6}(\mathbf{3 7 , 5 \% )}$ \\
$\begin{array}{c}\text { Unidade Mista } \\
\text { Total }\end{array}$ & $\mathbf{9 ( 5 6 , 3 \% )}$ & $\mathbf{2 ( 1 2 , 5 \% )}$ & $\mathbf{5 ( 3 1 , 2 \% )}$ & $\mathbf{1 6 ( 1 0 0 \% )}$ \\
\hline
\end{tabular}

Entre os profissionais de saúde que referiram não conhecer o Manual de Orientação, o uso de luva também mostra-se mais frequente nos ambulatórios de DST/AIDS, talvez por ser enfatizado, nestas unidades, o uso das precauções padrão e o cuidado com secreções orgânicas. Assusta o fato de encontrarmos profissionais de 2 UBS, 2 UM e um ambulatório especializado em DST/AIDS, ou seja 31,2\% dos profissionais que referem não conhecer o Manual de Orientação, não se referindo ao uso de luvas no momento da recepção das amostras de escarro (tabela 17).

$\mathrm{Na}$ técnica para a colheita do escarro, mesmo que o usuário envolva o frasco de colheita em papel, através dos aerossóis promovidos pelo esforço de tosse, pode 
ocorrer a contaminação da parte externa do frasco, daí também ser necessário orientar o cliente a lavar as mãos após ter embrulhado o frasco de colheita em plástico, que deve ser um plástico que realmente envolva o frasco. Além disso, o profissional mesmo utilizando a luva, deve lavar suas mãos após ter terminado o procedimento de colheita e armazenamento da amostra de escarro, todos estes cuidados com vistas ao controle da disseminação do $M$. tuberculosis e outros patógenos.

Tabela 18: Número de profissionais e o uso de luvas na recepção das amostras de escarro. São Paulo, 2004.

\begin{tabular}{l|c}
\hline Uso de luvas & Profissionais de Saúde \\
\hline Sim & $16(57,1 \%)$ \\
Não & $7(25,0 \%)$ \\
Não refere & $5(17,9 \%)$ \\
Total & $\mathbf{2 8 ( 1 0 0 \% )}$ \\
\hline
\end{tabular}

JEUKENS (1997), em levantamento realizado em Hospital Público Especializado em Doenças Infecto-contagiosas identifica que os profissionais de enfermagem aceitavam as precauções padrão porém não sabiam sua definição e implementação de barreiras recomendadas para coleta de sangue, banho do paciente, aspiração de secreções respiratórias e cuidados com pacientes com tosse, estes profissionais utilizavam excesso de equipamentos de proteção individual (EPI) para o atendimento dos pacientes, justificado pelo medo de contágio, acreditando trabalharem com pacientes muito infectados. Além disso, o uso incorreto de EPI também foi devido à falta de equipamento e a alegação de perder-se muito tempo no processo de paramentação.

No caso do recebimento das amostras de escarro a crença de que não existe risco de contaminação com o bacilo da tuberculose sem o uso de luvas e o desconhecimento da contaminação por outros microorganismos podem ser os motivos que levam os profissionais a não utilizarem o EPI recomendado, ou até mesmo a necessidade de não perder tempo com o procedimento de calçar as luvas.

BREVEDELLI e CIANCIARULLO (2001) aplicaram o Modelo de Crenças em Saúde em profissionais de enfermagem de um hospital universitário para explicar a prática de reencapar agulhas antes do descarte das mesmas. Relacionaram o 
comportamento individual às crenças de susceptibilidade, severidade, benefíciosbarreiras e aos estímulos recebidos para adotar a recomendação. Como resultado encontraram $75 \%$ da amostra referindo reencapar agulhas pelo menos alguma vez. Os profissionais de enfermagem que respeitavam a recomendação de não reencapar agulhas tinham menos que 2 anos de experiência profissional pois percebiam maiores os benefícios que as barreiras. Concluíram que um treinamento informativo não é suficiente para garantir adoção do comportamento de não reencapar agulhas, é necessário espaço para que os profissionais discutam as barreiras que percebem para adoção das recomendações.

Analisando a questão do uso de luvas associado aos cuidados outros estabelecidos com relação ao local para a colheita de escarro nos serviços de saúde ou local estabelecido para o atendimento do usuário do PNCT, cuidados orientados aos usuários sobre o local adequado para a colheita da amostra de escarro no domicílio, cuidados com o transporte da amostra e cuidados relacionados à higienização das mãos após a realização de alguns procedimentos, percebe-se que, apesar de serem itens contemplados nos manuais e programas não têm sido atendidos como preconizado, promovendo maior exposição tanto dos usuários na comunidade quanto dos profissionais de saúde. Estímulos constantes como atualizações necessitariam ser deflagrados para a modificação ou o estabelecimento de cuidados relacionados às medidas de biossegurança.

\section{A prática referida pelos profissionais de saúde}

\section{Sobre a forma de orientar os usuários do PNCT a colher a amostra de escarro}

Aos profissionais de saúde foi solicitado contar com detalhes como orientavam os usuários a colher a amostra de escarro. Analisando as respostas dos 28 profissionais encontramos 21 temas citados com maior frequência que serão apresentados a seguir nos quadros 5 e 6.

Os quadros foram elaborados com parte das falas dos profissionais entrevistados para ficar claro como os mesmos se referiram e utilizavam as palavras durante a orientação do tema para o usuário de saúde. Cada um dos itens descritos foi constituído pelas formas de expressão mais citadas. 
Quadro 5: Temas citados como orientação realizada aos usuários do PNCT de acordo com frequência nos relatos dos profissionais que referiram não conhecer o manual de orientação e a participação ou não em treinamentos. São Paulo, 2004.

\begin{tabular}{|l|lc|}
\hline $\begin{array}{l}\text { Temas citados como orientação do usuário para } \\
\text { a colheita da amostra de escarro }\end{array}$ & $\begin{array}{l}\text { Participação em } \\
\text { Sim }\end{array}$ & $\begin{array}{c}\text { treinamentos } \\
\text { Não }\end{array}$ \\
\hline $\begin{array}{l}\text { Escarro e não saliva; catarro do pulmão; não do } \\
\text { nariz e boca; catarro do peito; puxar o máximo; } \\
\text { escarrar; secreção que vem de dentro }\end{array}$ & $6(37,5 \%)$ & $10(62,5 \%)$ \\
\hline Sem escovar os dentes, lavar a boca com água & $5(31,2 \%)$ & $6(37,5 \%)$ \\
\hline Jejum & $5(31,2 \%)$ & $5(31,2 \%)$ \\
\hline De manhã acumula catarro & $5(31,2 \%)$ & $4(25 \%)$ \\
\hline Colher fora de casa; local ventilado & $1(6,2 \%)$ & $1(6,2 \%)$ \\
\hline Colher no dia de vir no posto & - & $2(12,5 \%)$ \\
\hline Respirar fundo; respirar fundo 3 vezes & $2(12,5 \%)$ & $3(18,7 \%)$ \\
\hline $\begin{array}{l}\text { Inalação; tapotagem; usar o chuveiro; fazer fricção } \\
\text { na garganta }\end{array}$ & $1(6,2 \%)$ & $1(6,2 \%)$ \\
\hline Prender a respiração; segurar & $2(12,5 \%)$ & $1(6,2 \%)$ \\
\hline $\begin{array}{l}\text { Tossir, forçar a tosse, tossir 3 vezes, tossir como } \\
\text { embaçando espelho }\end{array}$ & $4(25 \%)$ & - \\
\hline $\begin{array}{l}\text { Pergunta se sabe o que é o exame; explica } \\
\text { importância para descobrir bacilo; explica sobre a } \\
\text { tuberculose }\end{array}$ & - & - \\
\hline Soltar o ar de uma vez para estimular a tosse & - & - \\
\hline $\begin{array}{l}\text { Lavar bem as mãos; não deixar vazar nas bordas; } \\
\text { envolver pote para não sujar }\end{array}$ & $1(6,2 \%)$ & $1(6,2 \%)$ \\
\hline $\begin{array}{l}\text { Pelo menos 10 ml, no mínimo 5 ml, quantidade } \\
\text { certa }\end{array}$ & - & $1(6,2 \%)$ \\
\hline Retirar a dentadura para colher & - & $1(6,2 \%)$ \\
\hline Não colocar na geladeira & - & - \\
\hline Guardar na geladeira & $2(12,5 \%)$ & - \\
\hline Colher em dias alternados & $-2 \%)$ \\
\hline $\begin{array}{l}\text { Colher o catarro da garganta; se não consegue fazer } \\
\text { RX }\end{array}$ & - & - \\
\hline Identificar o pote no corpo & $34,2 \%)$ \\
\hline Cuspir a saliva na pia da sala de atendimento & - & - \\
\hline Total & & $1(6,2 \%)$ \\
\hline
\end{tabular}

* Orientações totalmente em desacordo com o Manual de Orientação (SES 2002) e PNCT (Brasil 2002, 2002c) 
Quadro 6: Temas citados como orientação realizada aos usuários do PNCT de acordo com frequência nos relatos dos profissionais que referiram conhecer o manual de orientação e a participação ou não em treinamentos

\begin{tabular}{|c|c|c|}
\hline \multirow{2}{*}{$\begin{array}{l}\text { Temas citados como orientação do usuário } \\
\text { para a colheita da amostra de escarro }\end{array}$} & \multicolumn{2}{|c|}{ Participação em treinamentos } \\
\hline & Sim & Não \\
\hline Respirar fundo; respirar fundo 3 vezes & $8(66,7 \%)$ & $2(16,7 \%)$ \\
\hline $\begin{array}{l}\text { Tossir, forçar a tosse, tossir } 3 \text { vezes, tossir como } \\
\text { embaçando espelho }\end{array}$ & $5(41,7 \%)$ & $2(16,7 \%)$ \\
\hline $\begin{array}{l}\text { Pergunta se sabe o que é o exame; explica } \\
\text { importância para descobrir bacilo; explica sobre } \\
\text { a tuberculose }\end{array}$ & $2(16,7 \%)$ & - \\
\hline Soltar o ar de uma vez para estimular a tosse & $1(8,3 \%)$ & $1(8,3 \%)$ \\
\hline $\begin{array}{l}\text { Escarro e não saliva; catarro do pulmão; não do } \\
\text { nariz e boca; catarro do peito; puxar o máximo; } \\
\text { escarrar; secreção que vem de dentro }\end{array}$ & $6(50 \%)$ & $1(8,3 \%)$ \\
\hline Sem escovar os dentes, lavar a boca com água & $1(8,3 \%)$ & $1(8,3 \%)$ \\
\hline Jejum & $3(25 \%)$ & $1(8,3 \%)$ \\
\hline 'De manhã acumula catarro & $2(16,7 \%)$ & $2(16,7 \%)$ \\
\hline $\begin{array}{l}\text { Inalação; tapotagem; usar o chuveiro; fazer } \\
\text { fricção na garganta }\end{array}$ & $2(16,7 \%)$ & $1(8,3 \%)$ \\
\hline Prender a respiração; segurar & $2(16,7 \%)$ & $2(16,7 \%)$ \\
\hline $\begin{array}{l}\text { Lavar bem as mãos; não deixar vazar nas } \\
\text { bordas; envolver pote para não sujar }\end{array}$ & $2(16,7 \%)$ & - \\
\hline $\begin{array}{l}\text { Pelo menos } 10 \mathrm{ml} \text {, no mínimo } 5 \mathrm{ml} \text {, quantidade } \\
\text { certa }\end{array}$ & $1(8,3 \%)$ & $1(8,3 \%)$ \\
\hline Colher fora de casa; local ventilado & $1(8,3 \%)$ & $1(8,3 \%)$ \\
\hline Retirar a dentadura para colher & - & - \\
\hline Colher no dia de vir no posto & $1(8,3 \%)$ & - \\
\hline Não colocar na geladeira & $1(8,3 \%)$ & - \\
\hline Guardar na geladeira & $1(8,3 \%)$ & - \\
\hline $\begin{array}{l}\text { Colher o catarro da garganta; se não consegue } \\
\text { fazer RX }\end{array}$ & $1(8,3 \%)$ & $1(8,3 \%)$ \\
\hline Cuspir a saliva na pia da sala de atendimento & $1(8,3 \%)$ & - \\
\hline Identificar o pote no corpo & $1(8,3 \%)$ & - \\
\hline Colher em dias alternados & $1(8,3 \%)$ & 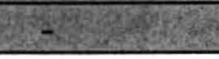 \\
\hline Total & 37 & 15 \\
\hline
\end{tabular}

- Orientações totalmente em desacordo com o Manual de Orientação (SES 2002) e PNCT (Brasil 2002, 2002c)

Com os resultados observa-se que no grupo de profissionais que referiram conhecer o Manual de Orientação existiu uma preocupação quanto à técnica de obter o escarro, principalmente no que diz respeito a encher o pulmão de ar, reter este ar, 
soltar o ar de uma vez num esforço de tosse para eliminar junto a secreção. Acreditase que com a divulgação do Manual de Orientação esta foi a novidade, a orientação do usuário para facilitar a colheita da amostra, inclusive, como já relatado, com a descrição de técnicas de estímulo da tosse. A informação sobre a necessidade de colher uma amostra de escarro e não saliva também foi encontrada com frequência expressiva neste grupo de profissionais.

Respirar fundo, aparece em 53,6\% das respostas dos participantes totais, ou seja 15 profissionais, porém, não percebe-se em alguns relatos, principalmente daqueles profissionais que não conhecem o Manual de Orientação e não participaram de treinamentos, a relação da orientação de respirar fundo com a atividade do músculo diafragma que com este procedimento pode imprimir mais força para que se consiga eliminar secreções presentes nas vias aéreas inferiores.

Já no grupo que referiu não conhecer o Manual de Orientação as maiores frequências de temas estão entre aqueles cuidados anteriores à obtenção da amostra como colher a amostra pela manhã, cuidados com higiene da boca e a obtenção da amostra livre de resíduos químicos ou alimentares, a manutenção de jejum e principalmente a ênfase à qualidade da amostra, ou seja, deve ser escarro e não saliva, talvez porque até então sempre houve a preocupação de cuidados relativos à qualidade da amostra e não quanto à sua obtenção. Para garantir a qualidade das baciloscopias realizadas, a boa amostra de escarro, proveniente da árvore brônquica (BRSIL 2002, 2002c) é primordial e portanto a ênfase dos profissionais vem contribuir para que o usuário entenda esta necessidade. De acordo com os resultados, $100 \%$ dos profissionais que referiram não conhecer o Manual de Orientação realizaram esta orientação de alguma forma contra $58,3 \%$ dos profissionais que referiram conhecer o Manual de Orientação.

O jejum foi citação de $14(50 \%)$ dos 28 profissionais, porém nos relatos não foi identificada nenhuma justificativa para que a colheita ocorresse em jejum, pareceu que a correlação da orientação estaria atrelada ao fato de colher pela manhã, livre de resíduos alimentares, e não relacionada ao incômodo que pode ser ocasionado ao usuário que realiza a colheita do escarro. Esteve mais presente no grupo que referiu não conhecer o Manual de Orientação. 
A orientação sobre manter a amostra de escarro livre de resíduos alimentares ou químicos, o que pode alterar esta amostra se a mesma não for processada em tempo hábil pelo laboratório, é realizada utilizando-se de artifícios como sugerir ao usuário lavar a boca, não escovar os dentes antes da colheita, aparece em 13 relatos ou $46,4 \%$ dos 28 entrevistados, no entanto está presente em $2(7,14 \%)$ relatos de profissionais que referiram conhecer o Manual de Orientação, cinco $(17,8 \%)$ relatos de profissionais que não conheciam Manual de Orientação mas já haviam participado de treinamentos e $6(21,4 \%)$ dos relatos entre profissionais que desconheciam o Manual de Orientação e não haviam participado de treinamentos. Ocorreu até um profissional $(3,6 \%)$ que sugere aos usuários a retirada da prótese dentária para realizar a colheita da amostra de escarro tentando garantir que a amostra esteja realmente livre de resíduos, e este profissional não conhecia o Manual de Orientação e nem havia participado de treinamentos.

Somente dois $(7,14 \%)$ profissionais, antes de realizar a orientação sobre a colheita da amostra de escarro, solicitam saber do usuário se o mesmo conhece o exame e a doença e explica sobre a doença e a importância da realização do exame. Estes profissionais conhecem o Manual de Orientação e participaram de treinamentos, sendo que um deles participou do treinamento na FSPUSP em Novembro de 2002.

Orientações relacionadas aos cuidados de biossegurança como solicitar ao usuário que lave as mãos após o término do acondicionamento da amostra, recomendar cuidado para não deixar secreção extravasar do frasco de colheita e orientar o usuário a colher a amostra em local ventilado ou fora de casa foi observada com maior frequência nos profissionais que conheciam o Manual de Orientação e haviam participado de treinamentos. A frequência de temas relacionados à biossegurnaça não apresentou diferenças quanto a participação em treinamentos ou não entre os profissionais de saúde que desconheciam o Manual de Orientação. Dos 7 profissionais de saúde que reportaram-se ao tema biossegurança nas orientações dos usuários, um trabalhava em AE, dois em DST/AIDS, três em UBS, um em USF, totalizando 7 serviços de saúde ou $25,9 \%$ do total visitado e $25 \%$ dos profissionais entrevistados. 
Chama a atenção algumas orientações que estão em destaque nos quadros 5 e 6 que foram classificadas como em desacordo com o manual de orientação (SES 2002) e o PNCT (BRASIL 2002, 2002c). O uso de terminologia, onde um dos profissionais refere não participar de treinamentos mas ser orientado por médico e conhecer o Manual de Orientação, que solicita ao usuário que faça um grande esforço e "colha o catarro da garganta", o que pode ser interpretado pelo usuário como a secreção das vias aéreas superiores mesmo que o profissional enfatize que a secreção "deve vir lá do fundo". Necessitamos da secreção proveniente da árvore brônquica. Um outro profissional, participou de treinamentos e conhece o Manual de Orientação, refere que solicita ao usuário antes de colher a amostra na própria sala de atendimento, "cuspir a saliva na pia da sala". As orientações citadas ferem princípios do PNCT e o que é grave, mostram descuido com as questões de biossegurança e as medidas de controle ambientais nele contidas. (BRASIL 2002, 2002c; SES 2003).

Outro resultado que chama a atenção é o fato de nos dois grupos de profissionais ocorrer a orientação de solicitação ao usuário para que identifique o frasco de colheita do escarro. Existe a recomendação de que este procedimento seja realizado pelo profissional que orienta o usuário visto ser de extrema importância a localização dos usuários que apresentam baciloscopias positivas, além de ser necessário a discriminação do tipo de amostra se diagnóstico ou controle de tratamento. No relato dos profissionais de laboratório será observado que o preenchimento das solicitações de baciloscopias e a identificação dos frascos de colheita permanecem como os principais problemas a serem transpostos quanto às baciloscopias.

A colheita em dias alternados também não está de acordo com o preconizado, ao usuário deve ser facilitado tanto a colheita, quanto o encaminhamento da mesma. O usuário pode ser orientado a colher amostras à noite e pela manhã e não precisar se deslocar para o serviço de saúde mais que uma vez para entregar amostras de escarro.

A forma como os profissionais referem orientar aos usuários do PNCT a colher a amostra de escarro encontra-se influenciada pelo material educativo divulgado e pelas informações veiculadas nos treinamentos. Considerando-se que $57,1 \%$ dos profissionais entrevistados participaram de treinamentos e destes, 62,5\% participou de treinamentos a menos de dois anos, fica claro os motivos pelos quais os 
profissionais que referiram não conhecer o Manual de Orientação e não participarem de treinamentos estarem mais atentos aos cuidados prévios à colheita da amostra, o contrário acontecendo com profissionais que referem conhecer o Manual de Orientação e participar de treinamentos que enfatizam a técnica de obtenção da amostra pelos motivos já descritos.

\section{Sobre a forma de orientar os usuários do PNCT a transportar a amostra de escarro \\ O transporte da amostra de escarro até o serviço de saúde é de suma} importância já que interfere não somente na qualidade da mesma para a análise do laboratório como também pode ser um facilitador para a disseminação do bacilo se não forem tomados os devidos cuidados com o fechamento e posicionamento do frasco durante o transporte. $\mathrm{O}$ frasco de colheita do escarro deve estar bem fechado e embrulhado em plástico para evitar possível derramamento da secreção durante o transporte e contaminação de pertences do usuário além da perda do material. $O$ frasco de colheita deve ser transportado até o serviço de saúde sempre com a tampa voltada para cima, ou seja, não deve ser virado, mesmo que esteja bem fechado (SES 2002).

Aos profissionais de saúde foi solicitado que descrevessem a forma como orientavam os usuários a transportar as amostras de escarro colhidas no domicílio até o serviço de saúde, o que resultou nos quadros 7 e 8 a seguir.

No grupo de profissionais que referem conhecer o Manual de Orientação e participar de treinamentos observa-se maior frequência de respostas adequadas quanto ao transporte das amostras (quadro 8).

Já no grupo de profissionais que não conheciam o Manual de Orientação a maior frequência de respostas adequadas estão entre os profissionais que referiram não ter participado de treinamentos, destes $37,5 \%$ estão trabalhando no PNCT há menos de 5 anos e são formados como profissionais de saúde, em sua maioria há mais de 10 anos (quadro 7). 
Quadro 7: Temas citados pelos profissionais de saúde, que não conheciam o Manual de Orientação, como orientação realizada aos usuários do PNCT para conservação e transporte das amostras de escarro, relacionado a participação em treinamentos. São Paulo, 2004.

\begin{tabular}{|l|lc|}
\hline $\begin{array}{c}\text { Temas citados como orientação do usuário } \\
\text { para conservação e transporte da amostra de } \\
\text { escarro }\end{array}$ & $\begin{array}{l}\text { Participação em treinamentos } \\
\text { Sim }\end{array}$ & Não \\
\hline $\begin{array}{l}\text { Trazer o frasco de coleta com a amostra num } \\
\text { saco plástico }\end{array}$ & $5(31,2 \%)$ & $6(37,5 \%)$ \\
\hline Fechar bem o pote & $4(25 \%)$ & $4(25 \%)$ \\
\hline $\begin{array}{l}\text { Trazer o frasco de coleta com a amostra } \\
\text { embrulhados em papel, evitando raios solares }\end{array}$ & $1(6,25 \%)$ & $1(6,25 \%)$ \\
\hline Deixar a amostra colhida na geladeira & - & $2(12,5 \%)$ \\
\hline $\begin{array}{l}\text { Não deixar escorrer escarro para fora do frasco } \\
\text { de coleta }\end{array}$ & $1(6,25 \%)$ & $1(6,25 \%)$ \\
\hline Trazer com a tampa sempre para cima & $2(12,5 \%)$ & - \\
\hline Não deixar amostra na geladeira & - & $2(12,5 \%)$ \\
\hline Primeiro verifico o frasco & - & - \\
\hline Trazer separado de outros exames & $1(6,25 \%)$ & - \\
\hline Identificar o frasco & $1(6,25 \%)$ & $3(18,7 \%)$ \\
\hline Trazer na embalagem do frasco de coleta & $1(6,25 \%)$ & $1(6,25 \%)$ \\
\hline $\begin{array}{l}\text { Não orienta cuidados com relação ao transporte } \\
\text { da amostra }\end{array}$ & $1(6,25 \%)$ & $1(6,25 \%)$ \\
\hline
\end{tabular}

- Orientações totalmente em desacordo com o Manual de Orientação (SES 2002) e PNCT (Brasil 2002, 2002c)

Embora a questão realizada durante a entrevista solicitasse aos profissionais que relatassem a forma como orientavam os usuários a transportar a amostra de escarro colhida até o serviço de saúde, $3(10,7 \%)$ profissionais citaram que orientavam aos usuários cuidados quanto à contaminação do frasco no momento da colheita da amostra, porém não relacionaram com a necessidade de transportar o frasco de colheita com a tampa para cima evitando extravasamento de secreção. A conservação da amostra de escarro em geladeira foi citada por 3 profissionais ou $10,7 \%$ da amostra entrevistada, o que sugere a relação da conservação da amostra e sua manutenção até seu transporte para o serviço de saúde. 
Quadro 8: Temas citados pelos profissionais de saúde, que conheciam o Manual de Orientação, como orientação realizada aos usuários do PNCT para conservação e transporte das amostras de escarro, relacionado a participação em treinamentos. São Paulo, 2004.

\begin{tabular}{|l|lc|}
\hline $\begin{array}{c}\text { Temas citados como orientação do usuário } \\
\text { para conservação e transporte da amostra de } \\
\text { escarro }\end{array}$ & $\begin{array}{l}\text { Participação em treinamentos } \\
\text { Sim }\end{array}$ & Não \\
\hline $\begin{array}{l}\text { Trazer o frasco de coleta com a amostra num } \\
\text { saco plástico }\end{array}$ & $4(33,3 \%)$ & $1(8,3 \%)$ \\
\hline Fechar bem o pote & $4(33,3 \%)$ & $2(16,6 \%)$ \\
\hline $\begin{array}{l}\text { Trazer o frasco de coleta com a amostra } \\
\text { embrulhados em papel, evitando raios solares }\end{array}$ & $5(41,6 \%)$ & $1(8,3 \%)$ \\
\hline Deixar a amostra colhida na geladeira & $1(8,3 \%)$ & - \\
\hline $\begin{array}{l}\text { Não deixar escorrer escarro para fora do frasco } \\
\text { de coleta }\end{array}$ & $1(8,3 \%)$ & - \\
\hline Trazer com a tampa sempre para cima & $1(8,3 \%)$ & - \\
\hline Não deixar amostra na geladeira & - & - \\
\hline Primeiro verifico o frasco & $2(16,6 \%)$ & - \\
\hline Trazer separado de outros exames & - & - \\
\hline Identificar o frasco & - & - \\
\hline Trazer na embalagem do frasco de coleta & - & $1(8,3 \%)$ \\
\hline $\begin{array}{l}\text { Não orienta cuidados com relação ao transporte } \\
\text { da amostra }\end{array}$ & $1(8,3 \%)$ & \\
\hline
\end{tabular}

• Orientações totalmente em desacordo com o Manual de Orientação (SES 2002) e PNCT (Brasil 2002, 2002c)

Cuidados como trazer o frasco de colheita embrulhados em saco plástico ou papel foi a maior preocupação dos profissionais sendo citado portanto por $57,1 \%$ dos entrevistados.

A preocupação com o fechamento adequado do frasco esteve presente em $50 \%$ das respostas dos entrevistados.

Chama a atenção os 3 itens destacados como em desacordo com o Manual de Orientação e PNCT. O primeiro, a identificação do frasco de colheita, que já foi discutido anteriormente e evidencia-se nas respostas às questões relativas ao transporte das amostras, em segundo lugar a orientação de trazer o frasco de colheita embrulhado na própria embalagem. A embalagem que envolve o frasco de colheita é constituída de plástico tipo celofane e insuficiente para promover a contenção da 
secreção se houver derramamento durante o transporte. A terceira observação é sobre o fato de 4 profissionais referirem que não realizam orientações ao usuário sobre o transporte da amostra. A qualidade da amostra também depende da forma como é conservada e transportada.

A presença de orientações não condizentes com o Manual de Orientação (SES 2002) e PNCT (Brasil 2002, 2002c) estão mais presentes entre os profissionais que não conhecem o Manual de Orientação e não participaram de treinamentos.

\section{Observação da prática dos profissionais de saúde na orientação do usuário para a colheita da amostra de escarro}

Serão apresentados os resultados e análise dos roteiros de observação da prática dos profissionais de saúde (ANEXO 6) preenchidos durante 9 atendimentos de usuários do PNCT onde ocorreu a orientação para a colheita da amostra de escarro. Destaca-se a participação ou não dos profissionais observados em treinamentos e o conhecimento dos mesmos sobre o Manual de Orientação.

O roteiro de observação da prática dos profissionais, como já citado, possui duas partes: uma abordando o relacionamento estabelecido entre profissional de saúde e usuário do PNCT e outra abordando o procedimento orientado ao usuário sobre como deve ser realizada a colheita, acondicionamento e transporte das amostras de escarro.

Dos 9 roteiros de observação preenchidos, 7 (77,8\%) foram realizados durante a orientação de usuários para a colheita da amostra de escarro para o controle de tratamento e $2(22,2 \%)$ para acompanhar a orientação de usuários que deveriam colher amostras para diagnóstico da tuberculose.

Com relação aos itens sobre a comunicação verbal e não-verbal dos profissionais de saúde, relativos a parte 1 do roteiro de observação, percebeu-se que existe uma preocupação de atender ao usuário, acolhendo-o, principalmente no que diz respeito a olhar para o usuário, utilizar linguagem de fácil compreensão, esperar pela manifestação do usuário e reportar-se ao usuário pelo nome, conforme quadro 9.

A frequência de observação dos itens citados demonstram a preocupação com a humanização do atendimento e respeito pelo usuário (SILVA 2002). O item 
utilização de gestos demonstra também a preocupação com a compreensão da população assistida.

Quadro 9: Número de observações sobre a comunicação dos profissionais de saúde durante a orientação do usuário do PNCT sobre a colheita da amostra de escarro. São Paulo, 2004.

\begin{tabular}{|c|c|c|c|}
\hline Comunicação com o paciente & Sim & Não & Ás vezes \\
\hline Linguagem fácil compreensão & $8(88,9 \%)$ & - & $1(11,1 \%)$ \\
\hline Olha usuário quando este responde & $7(77,8 \%)$ & $1(11,1 \%)$ & $1(11,1 \%)$ \\
\hline $\begin{array}{c}\text { Recebe usuário pelo nome } \\
\text { Espera pela resposta do usuário }\end{array}$ & $6(66,6 \%)$ & $1(11,1 \%)$ & $2(22,2 \%)$ \\
\hline $\begin{array}{c}\text { Olha usuário quando se dirige ao } \\
\text { mesmo }\end{array}$ & $5(55,5 \%)$ & - & $4(44,4 \%)$ \\
\hline $\begin{array}{c}\text { Utiliza gestos } \\
\text { Clarifica termos do usuário }\end{array}$ & $5(55,5 \%)$ & $3(33,3 \%)$ & $1(11,1 \%)$ \\
\hline Valida compreensão da mensagem & $3(33,3 \%)$ & $5(55,5 \%)$ & $1(11,1 \%)$ \\
\hline
\end{tabular}

A clarificação de termos utilizados só foi observada ocorrendo sistematicamente em 3 orientações observadas, portanto $33,3 \%$ da amostra. Os usuários, quando na observação do pesquisador, manifestarem-se pouco, assumindo posturas de ouvintes concordando com aquilo que é emitido pelos profissionais (Quadro 9). Também observou-se que nem sempre é dada a oportunidade ao usuário para se manifestar.

Infelizmente a validação da compreensão das mensagens enviadas sobre as orientações realizadas para que o usuário colha a amostra de escarro, não é uma prática instituída pois, $5(55,5 \%)$ profissionais, ou seja, mais da metade da amostra não realizou a validação da mensagem. Esta prática poderia viabilizar ao profissional de saúde identificar dificuldades de compreensão ou necessidades por parte do usuário (STEFANELLI 1993; SILVA 1996, 2002). Ao usuário não é solicitado 
repetir a orientação realizada para que seja percebido a forma como compreendeu o que foi dito pelo profissional de saúde.

Os itens relativos à clarificação de termos utilizados e à validação das mensagens enviadas contribuem para que aumente a possibilidade do alcance dos objetivos dos profissionais, que seria a compreensão do usuário da forma adequada de se obter uma boa amostra de escarro. Quando o recurso da clarificação de termos ou validação da mensagem enviada não são utilizados, a possibilidade do alcance dos objetivos do profissional fica prejudicada já que o mesmo termina por não conhecer a forma como o usuário compreendeu a mensagem enviada, e portanto, podendo culminar na colheita de uma amostra de escarro que pode gerar resultados pouco fidedignos.

A apresentação dos dados da segunda parte do roteiro de observação a respeito do procedimento orientado ao usuário sobre como deve ser realizada a colheita, acondicionamento e transporte das amostras de escarro também foi realizada dividindo-se os profissionais observados em grupos que participaram de treinamento e conheciam o Manual de Orientação, participaram de treinamentos e não conheciam o Manual de Orientação, não participaram de treinamentos e conheciam o Manual de Orientação, não o conheciam e nem participaram de treinamentos conforme quadro 10.

Pelo quadro 10 observamos que, embora só tenham sido observados 2 profissionais realizando a orientação dos usuários do PNCT em serviços de saúde, que tenham participado de treinamentos e conheçam o Manual de Orientação, o número de observações contemplando os procedimentos preconizados pelo PNCT (BRASIL 2002d) e Manual de Orientação (SES 2002) é mais presente neste grupo de profissionais. Por outro lado, o maior número de negativas quanto ao atendimento dos procedimentos do PNCT estão no grupo de profissionais que não conhecem o Manual de Orientação (SES 2002) ou que não participaram de treinamento e não conhecem o Manual de Orientação.

Constata-se também que os itens sobre a explicação da importância da baciloscopia para o usuário que colhe o exame pela primeira vez para o diagnóstico; a orientação do usuário sobre a necessidade de manter a cavidade bucal sem resíduos alimentares para a colheita do escarro e o item sobre a 
necessidade de mudar a forma de orientar e lou o vocabulário no caso de usuários demonstrarem não compreender a forma correta da colheitao, não são atendidos por todos os grupos de profissionais.

Este resultado confere com o relato dos profissionais sobre a forma como referiram orientar o usuário a colher a amostra de escarro onde as relações dos motivos pelos quais são realizadas determinados cuidados não são explicitados ao usuário, podendo interferir da colheita da amostra, já que não são oferecidos dados que justifique a realização de determinadas ações e que possam trazer conhecimento ao usuário, instrumentalizando-o para a mudança de atitude (Quadro 10).

Os itens sobre a orientação da inspiração profunda, retenção do ar nos pulmões; a necessidade de embrulhar o frasco de colheita contendo a amostra para transporte até o serviço; a orientação para a colheita da amostra de escarro no dia de encaminhá-la ao serviço de saúde e a orientação para que o usuário colha a amostra em local ventilado da casa foram observados sendo realizados nos grupos de profissionais em maior frequência, corroborando com resultados apresentados nos quadros 5 e 6 que diz respeito ao relato dos próprios profissionais.

Solicitar ao usuário do PNCT, que retorna para controle do tratamento, para explicar como vai colher a amostra de escarro, identificando inadequação da técnica e posterior esclarecimento do usuário, foi prática observada por apenas um dos dois profissionais de saúde que participaram de treinamentos e conheciam o Manual de Orientação e realizaram a orientação de usuários para a colheita de amostras de escarro no controle de tratamento.

O restante dos itens do roteiro de observação da prática dos profissionais de saúde, em sua maioria, não foram contemplados pelos profissionais, e portanto em desacordo ao preconizado pelo PNCT e Manual de Orientação.

Somente 5 observações da prática de orientar o usuário do PNCT a colher a amostra de escarro foram condizentes com a forma relatada pelos profissionais sobre como realizavam a orientação dos usuários.

A participação em treinamentos e o conhecimento sobre o Manual de Orientação foi identificado em dois $(22,2 \%)$ dos profissionais observados, um $(11,1 \%)$ profissional referiu ter participado de treinamento e não conhecer o Manual de Orientação, um $(11,1 \%)$ profissional que não participou de treinamentos e 
Quadro 10: Frequência dos itens nas orientações para a colheita de amostras de escarro realizadas por profissionais de saúde relacionado a participação dos profissionais em treinamentos e o conhecimento sobre o Manual de Orientação. São Paulo, 2004.

\begin{tabular}{|c|c|c|c|c|c|c|c|c|}
\hline \multirow{3}{*}{$\begin{array}{l}\text { Itens do Roteiro de Observação da Orientação para a colheita da } \\
\text { Amostra de Escarro }\end{array}$} & \multicolumn{8}{|c|}{\begin{tabular}{|c|} 
Participação em Treinamentos e Conhecimento do Manual \\
\end{tabular}} \\
\hline & \multicolumn{2}{|c|}{ Participou e conhece } & \multicolumn{2}{|c|}{$\begin{array}{l}\text { Participou e não } \\
\text { conhece }\end{array}$} & \multicolumn{2}{|c|}{$\begin{array}{l}\text { Não participou e } \\
\text { conhece }\end{array}$} & \multicolumn{2}{|c|}{$\begin{array}{l}\text { Não participou e } \\
\text { não conhece }\end{array}$} \\
\hline & Sim & Não & Sim & Não & Sim & Não & Sim & Não \\
\hline Procura saber do usuário como colhe a amostra & 1 & 1 & - & 1 & - & 1 & - & 4 \\
\hline No caso de procedimento incorreto informa o usuário & 1 & 1 & - & - & - & - & - & - \\
\hline Explica importância do exame para controle de tratamento ** & - & 2 & - & 1 & 1 & - & - & 3 \\
\hline Orientação da necessidade de lavar a boca com água antes de expectorar & - & 2 & - & 1 & - & 1 & - & 5 \\
\hline Orienta a inspiração profunda para esforço de tosse & 2 & - & 1 & - & - & 1 & 2 & 3 \\
\hline Orienta reter o ar por instantes & 2 & - & 1 & - & - & 1 & 2 & 3 \\
\hline Orienta usuário ao esforço de tosse após retenção do ar & 2 & - & - & 1 & - & 1 & 1 & 4 \\
\hline Demonstra com o frasco a quantidade de escarro a ser colhida & 1 & 1 & - & 1 & - & 1 & - & 5 \\
\hline Explica necessidade do escarro ser proveniente da árvore brônquica & 2 & - & - & 1 & - & 1 & 1 & 4 \\
\hline Orienta usuário repetir inspiração, retenção do ar e tosse por 3 vezes & - & 2 & - & 1 & - & 1 & 1 & 4 \\
\hline Orienta fechar bem o frasco e transportar com tampa para cima & 1 & 1 & - & 1 & 1 & - & 2 & 3 \\
\hline Orientação do paciente a embrulhar o frasco para transporte & 2 & - & - & 1 & 1 & - & 3 & 2 \\
\hline Orientação do usuário p/ lavagem das mãos após a colheita e necessidade & - & 2 & - & 1 & - & 1 & 1 & 4 \\
\hline Orientação sobre necessidade de colher em ambiente ventilado em casa & 2 & - & 1 & - & - & 1 & 2 & 3 \\
\hline Valida a compreensão do usuário sobre o procedimento de colheita & 2 & - & - & 1 & - & 1 & 2 & 3 \\
\hline Muda vocabulário quando necessário repetir orientação & - & 2 & - & - & - & - & - & 2 \\
\hline Pergunta se o paciente quer fazer perguntas & 2 & - & - & 1 & - & 1 & 1 & 4 \\
\hline Total das frequêmcias de respostas & 21 & 15 & 4 & 12 & 3 & 13 & 21 & 60 \\
\hline
\end{tabular}

* Foram realizadas somente duas observações de orientação de usuários para a colheita de amostra para diagnóstico de tuberculose

** Foram realizadas sete observações de orientação de usuários para a colheita de amostra para controle de tratamento de tuberculose 
conhecia o Manual de Orientação e cinco $(55,6 \%)$ profissionais que negaram ter participado de treinamentos e desconheciam o Manual de Orientação, totalizando 9 (100\%) profissionais de saúde. Somente $3(33,3 \%)$ profissionais de saúde observados conheciam o Manual de Orientação e também somente $3(33,3 \%)$ profissionais de saúde haviam participado de treinamentos.

Nenhuma das observações realizadas sobre a orientação do usuário a colher a amostra de escarro ou forma de relato dos profissionais, em sua totalidade, conferem com o PNCT (BRASIL 2002, 2002c) ou com o Manual de Orientação (SES 2002).

A maioria dos profissionais, em cujos serviços foi realizada a observação da prática da orientação dos usuários sobre a forma de colher a amostra de escarro, não participaram de treinamento e referiram não conhecer o Manual de Orientação, talvez este dado reflita o resultado obtido, dado o afastamento destes profissionais das atualizações pertinentes ao desempenho de sua atividade no PNCT.

\section{Percepção dos profissionais de saúde sobre sua participação na colheita}

\section{do escarro}

Quanto à questão sobre como os profissionais de saúde percebiam a sua participação na colheita da amostra de escarro, os temas presentes nas respostas foram identificados destacando-se a freqüência com que apareceram nos relatos, conforme quadro 11.

A citação da percepção da participação nas orientações gerais realizadas, sem especificação destas orientações, é maior no grupo de profissionais que mencionaram não conhecer o Manual de Orientação do que no grupo que conhecia o Manual de Orientação, porém, a quantidade de citações explicitando o tipo de orientação como, aquela realizada para que o usuário apreenda a forma de como colher a amostra de escarro, ou mesmo no destaque sobre a importância e necessidade de uma boa amostra de escarro, é maior para o grupo que referiu conhecer o Manual de Orientação.

O conteúdo das orientações, principalmente a preocupação com a técnica de colheita das amostras de escarro são citadas com maior frequência no grupo de profissionais que referiram conhecer o Manual de Orientação, mostrando que durante 
os processos educativos planejados ou elaboração de materiais educativos, talvez ocorra maior preocupação de explicitar normas e formas do que enfatizar a necessidade de aproximação do profissional de saúde ao usuário para que ocorra a real compreensão das informações que devem ser veiculadas. A preocupação com a técnica também aparece como o segundo item mais citado no grupo de profissionais que referiram não conhecer o Manual de Orientação.

Quadro 11: Frequência dos temas citados como percepção dos profissionais de saúde quanto à sua participação na colheita de amostra de escarro, de acordo com o conhecimento ou não do Manual de Orientação. São Paulo, 2004.

\begin{tabular}{|l|c|c|}
\hline $\begin{array}{l}\text { Percepção da participação na colheita } \\
\text { de amostras de escarro }\end{array}$ & Conhecem o manual & $\begin{array}{c}\text { Desconhecem o } \\
\text { manual }\end{array}$ \\
\hline Nas orientações em geral realizadas & $7(43,8 \%)$ & $3(25,0 \%)$ \\
\hline $\begin{array}{l}\text { Nas orientações de como colher a } \\
\text { amostra }\end{array}$ & $4(25,0 \%)$ & $7(58,3 \%)$ \\
\hline $\begin{array}{l}\text { Nas orientações explicitando a } \\
\text { necessidade e importância da boa } \\
\text { amostra }\end{array}$ & $1(6,3 \%)$ & $3(25,0 \%)$ \\
\hline $\begin{array}{l}\text { Colaboração na quebra da cadeia do } \\
\text { processo infeccioso, identificando } \\
\text { sintomático respiratório }\end{array}$ & $2(12,5 \%)$ & $1(8,3 \%)$ \\
\hline $\begin{array}{l}\text { No preenchimento dos pedidos de } \\
\text { exame e coleta de dados do usuário }\end{array}$ & $2(12,5 \%)$ & $1(8,3 \%)$ \\
\hline $\begin{array}{l}\text { Facilitação da comunicação reforçando } \\
\text { informações, validando mensagens }\end{array}$ & $2(12,5 \%)$ & $1(8,3 \%)$ \\
\hline $\begin{array}{l}\text { Proporcionando espaços para o usuário } \\
\text { se colocar, oferecendo apoio }\end{array}$ & $3(18,8 \%)$ & $1(8,3 \%)$ \\
\hline $\begin{array}{l}\text { Reduzir preconceitos em relação a } \\
\text { colheita do escarro }\end{array}$ & $1(6,3 \%)$ & $1(8,3 \%)$ \\
\hline $\begin{array}{l}\text { Necessidade de maior preparo para } \\
\text { realizar a atividade }\end{array}$ & $3(18,8 \%)$ & - \\
\hline $\begin{array}{l}\text { Não percebe sua participação, mais } \\
\text { uma atividade de orientação a ser } \\
\text { cumprida }\end{array}$ & $1(6,3 \%)$ & \\
\hline
\end{tabular}

Embora entenda-se que a relação estabelecida com o usuário e a comunicação estabelecida com o mesmo seja de extrema importância para o sucesso das ações de um programa de saúde (BERTOLOZZI 1998, MENDES 1994, MIRANDA 1983 e 
SILVA 1996, 2002), e está destacada com atenção especial no momento do atendimento do usuário do PNCT quando o mesmo deve ser orientado sobre a definição, importância e método de coleta das amostras, a citação sobre cuidados com a comunicação verbal e terminologia utilizada percebidas como a participação do profissional na colheita de escarro, foi preocupação de apenas um dos profissionais que referiram conhecer o Manual de Orientação e este, também participou do treinamento na FSP USP em 2002 e exerce suas atividades em uma UBS municipalizada.

Quanto aos profissionais referidos como não conhecedores do Manual de Orientação, cuidados relativos à comunicação verbal foram citados por 2 profissionais de saúde, um deles trabalha no programa há 7 anos e não se lembra quando recebeu treinamento para o atendimento em tuberculose, o outro trabalha com o programa há 17 anos e refere nunca ter sido treinado para tal; ambos são lotados em ambulatórios de atendimento especializado em DST/AIDS o que pode sugerir que ambos apresentem maior disponibilidade para o atendimento $\mathrm{e}$ relacionamento com a pessoa que procura o serviço, por serem influenciados pelas atividades educativas e modelo de atendimento relativos ao programa de atendimento e controle das DST/AIDS.

Cabe lembrar que a atitude é um dos determinantes dos comportamentos, ou seja, a predisposição para agir influenciando o comportamento. (DANIEL 1983, MINAYO 1993).

A percepção da participação através do apoio e espaço oferecidos ao usuário esteve presente em 3 respostas de 3 profissionais de saúde que referiram conhecer o Manual de Orientação e 1 resposta de 1 profíssional de saúde que referiu não conhecer o Manual de Orientação. O profissional de saúde que desconhecia o Manual de Orientação está lotado em um ambulatório de atendimento especializado em DST/AIDS, trabalha na enfermagem há 32 anos e no PNCT há 8 anos e referiu nunca ter participado de treinamento específico.

Dos três profissionais que conheciam o Manual de Orientação e citaram o relacionamento - apoio e espaço para manifestação do usuário - como sua participação na colheita da amostra, um deles está lotado em um AE municipalizado, 
trabalha na enfermagem há 20 anos e no PNCT há 3 anos, recebe orientações sobre o programa de uma médica e nunca participou de treinamentos específicos; um está lotado em uma USF, trabalha na enfermagem há 11 anos e com o PNCT há um ano e meio e havia recebido treinamento há 1 mês, e o último, está lotado em um ambulatório de DST/AIDS, trabalha como auxiliar de laboratório há 14 anos e está há três anos desenvolvendo a atividade de orientação de usuários para a colheita da amostra de escarro e havia participado de um treinamento há 3 meses.

Os dois profissionais de saúde que citaram a sua participação na colheita da amostra de escarro através do relacionamento estabelecido e do apoio oferecido, e que não participaram de treinamentos, estão lotados em $\mathrm{AE}$ e portanto convivendo com problemas de saúde , entende-se, mais complexos, exigindo dos profissionais maior envolvimento com a clientela. Não que isto seja determinante para que o relacionamento se estabeleça de forma adequada, mas, acredita-se que os profissionais necessitem investir mais no relacionamento dada a gravidade dos problemas de saúde apresentados pelos usuários.

O fato do profissional entender sua participação nas orientações e no relacionamento que se estabelece com o cliente, isto, por si só, não garante que a orientação para a colheita do escarro seja adequada, principalmente se o profissional não apresentar uma atitude positiva para o tema em questão, ou seja, para a amostra de escarro.

MAZZAIA (2000) e CAMPINAS (1999) relatam atitudes negativas dos profissionais e usuários com relação às amostras de escarro e colheita das mesmas.

Frases de profissionais de saúde referindo-se à colheita da amostra de escarro e ao escarro, foram selecionadas e transcritas conforme o relato, durante a atual coleta de dados:

"É porque é desagradável"

“...é escarrar, não é a saliva é aquela coisa nojenta que vem lá de dentro...”

"Porque a maioria dos paciente, na verdade, eles tem nojo, né? Nojo de escarrar"

"Teve caso de gente com secreção que não conseguiu colher aqui de vergonha. Existe tabu que escarrar na frente dos outros é falta de higiene" 
“...não é nada agradável o paciente estar escarrando, em primeiro lugar porque ele tem vergonha é... em segundo lugar porque é um desconforto..."

Observa-se pelos relatos que apesar dos esforços o tema ainda traz constrangimentos para quem recebe orientações e também para quem as providencia, o que pode acarretar em interferências quanto ao desenvolvimento do trabalho de orientação dos usuários e por consequência interferir com a qualidade das amostras de escarro enviadas para análise.

\section{Sobre o resultado dos processos de capacitação na prática dos profissionais de saúde}

\section{Perfil dos usuários do PNCT entrevistados}

As entrevistas com usuários do PNCT foram realizadas com questões abertas e os mesmos colocaram sua opinião sobre a realização do exame de escarro e sobre a importância dos mesmos, cujos dados são apresentados através das tabelas 19 e 20.

Dos 29 usuários do PNCT entrevistados, $18(62,1 \%)$ usuários eram do sexo masculino e $11(37,9 \%)$ usuários do sexo feminino, em sua maioria entre 20 e 40 anos, e com I Grau incompleto como nível de escolaridade, o que encontra-se em conformidade com estudos epidemiológicos (Brasil 2002d, RAVAGLIONE 2003, RUFFINO NETTO 2001).

Tabela 19: Número de usuários do serviço de saúde entrevistado em relação a idade citada. São Paulo, 2004.

\begin{tabular}{l|cc}
\hline Idade em anos & $\begin{array}{c}\text { Número de usuários } \\
\text { entrevistados }\end{array}$ & \% acumulada \\
\hline De 10 a 19 & $2(6,9 \%)$ & 6,9 \\
De 20 a 29 & $8(27,6 \%)$ & 34,5 \\
De 30 a 39 & $9(31 \%)$ & 65,5 \\
De 40 a 49 & $4(13,8 \%)$ & 79,3 \\
De 50 anos e + & $6(20,7 \%)$ & 100 \\
\hline & & $\mathbf{1 0 0 \%}$ \\
\hline
\end{tabular}


Quando destaca-se o nível de escolaridade da população assistida -58,6\% apresenta, o I Grau Incompleto, percebe-se o quanto é importante investir no desenvolvimento de habilidades interpessoais favorecendo o estabelecimento de um processo de comunicação mais efetivo, o que ocorre quando consideramos a congruência entre a comunicação verbal, a não-verbal e o contexto em que ambas ocorrem, pois, são características desta população a necessidade do uso de técnicas de comunicação que favoreçam a compreensão (TAYLOR 1992, SILVA 2002).

Tabela 20: Número de usuários do serviço de saúde entrevistados em relação ao grau de

\begin{tabular}{l|cc}
\hline escolaridade citado & \\
\hline Nível de escolaridade & $\begin{array}{c}\text { Número de usuários } \\
\text { entrevistados }\end{array}$ & \% acumulada \\
\hline I Grau incompleto & $17(58,6 \%)$ & 58,6 \\
I Grau completo & $2(6,9 \%)$ & 65,5 \\
II Grau incompleto & $2(6,9 \%)$ & 72,4 \\
II Grau completo & $4(13,8 \%)$ & 86,2 \\
III Grau incompleto & $1(3,4 \%)$ & 89,6 \\
III Grau completo & $1(3,4 \%)$ & 93,0 \\
Sem escolaridade & $2(7,0 \%)$ & 100 \\
\hline & $\mathbf{2 9}(\mathbf{1 0 0 \%})$ & $\mathbf{1 0 0 \%}$ \\
\hline
\end{tabular}

\section{Conhecimento e opinião dos usuários do PNCT sobre a colheita da amostra de escarro}

Só foi possível entrevistar usuários de $12(44,4 \%)$ serviços de saúde, dos 27 (100\%) visitados. Destes 12 serviços, em $6(22,2 \%)$ também foi realizada a observação da prática dos profissionais durante a orientação do usuário para a colheita da amostra de escarro. Ocorreu a observação da prática da orientação dos usuários para a colheita da amostra de escarro em $3(11,1 \%)$ serviços onde não foi possível a realização das entrevistas com os usuários.

Vale lembrar que não foi possível entrevistar usuários em todos os serviços de saúde visitados pois, em alguns serviços, no dia da visita para a coleta de dados 
não compareceram clientes para atendimento no PNCT, ou mesmo, ocorreram algumas dificuldades como: os profissionais dos serviços realizarem o atendimento para somente após atender ao pesquisador, ou mesmo não realizarem agendamento de clientes para o dia da visita do pesquisador, independente do fato de terem sido orientados sobre o delineamento do estudo.

Conhecer a opinião do usuário sobre a colheita da amostra de escarro e sobre a importância da baciloscopia, foi utilizado para estudar a prática dos profissionais. É importante saber como as informações veiculadas durante o atendimento dos usuários são sedimentadas e utilizadas pelos mesmos, somando subsídios para o planejamento de projetos educativos no preparo dos profissionais de saúde.

Durante as entrevistas realizadas com os usuários, quando questionados sobre como haviam descoberto que estavam com tuberculose pulmonar, percebeu-se que alguns destes citavam voluntariamente a colheita da amostra de escarro como um exame para diagnosticar a tuberculose e, para outros, o exame de escarro só foi lembrado quando estimulado pelo pesquisador.

Tabela 21: Número de usuários conforme o tipo de citação sobre o exame de escarro. São Paulo, 2004.

\begin{tabular}{l|c}
\hline Citação do exame de escarro & Número de usuários \\
\hline Citação espontânea & $24(82,7 \%)$ \\
Citação estimulada & $5(17,3 \%)$ \\
\hline Total & $\mathbf{2 9}(\mathbf{1 0 0 \%})$ \\
\hline
\end{tabular}

A maioria dos usuários identificou o exame de escarro como importante para o diagnóstico com exceção de 5 usuários $(17,3 \%)$ que necessitaram ser estimulados para colocar o exame de escarro como um item necessário para o diagnóstico da tuberculose pulmonar conforme demonstrado na tabela 21 .

A orientação sobre o que é a baciloscopia de escarro justifica a importância da colheita de uma boa amostra, inclusive esclarecendo a sua importância para o controle de tratamento, desta forma, espera-se que o usuário do PNCT a identifique 
como uma das mais importantes alternativas para diagnóstico e controle de tratamento.

Conhecer a opinião do usuário do PNCT sobre a colheita da amostra de escarro tornou-se primordial pois, a forma como o mesmo percebe esta colheita influencia a forma como realiza a mesma.

Nas orientações que são realizadas aos usuários é de extrema importância que se destaque a necessidade do exame de escarro para o diagnóstico e controle do tratamento da tuberculose, assim, foi solicitado aos usuários que relatassem a importância do exame de escarro na opinião deles, ou seja, qual a utilidade do exame. Estas respostas são apresentadas no quadro a seguir em forma de temas e, optou-se por esta forma de apresentação para destacar o modo como os usuários referiram-se ao exame de escarro e como os mesmos foram interpretados:

Quadro 12: Frequência de temas citados pelos usuários do PNCT sobre a importância e utilidade do exame de escarro. São Paulo, 2004.

\begin{tabular}{|l|c|}
\hline Temas sobre a importância e utilidade do exame de escarro & $\begin{array}{c}\text { Número de } \\
\text { citações }\end{array}$ \\
\hline $\begin{array}{l}\text { Pesquisa do exame, "prá" dar resultado sim ou não, "prá descobrir } \\
\text { tuberculose }\end{array}$ & $15(51,7 \%)$ \\
\hline Nada; não sei & $7(24,1 \%)$ \\
\hline $\begin{array}{l}\text { "Prá" controle e saber se está diminuindo o grau, "prá" ver se a } \\
\text { gente tá melhor, para diagnóstico e controle do tratamento }\end{array}$ & $5(17,2 \%)$ \\
\hline $\begin{array}{l}\text { "Prá" descobrir se tem alguma doença, "prá" cuidar da melhoria da } \\
\text { saúde, "prá" gente se cuidar "prá" saber se o pulmão está } \\
\text { respirando }\end{array}$ & $4(13,8 \%)$ \\
\hline "Prá" saber o vírus da TB & $4(13,8 \%)$ \\
\hline
\end{tabular}

Dos 29 usuários entrevistados, $15(51,7 \%)$ relacionou o exame de escarro com diagnóstico da tuberculose, porém, parecem não relacionar com a presença de microorganismos no escarro (Quadro 12).

Relacionar o exame com a descoberta de doença, ajudando a cuidar da saúde e manter funções do pulmão aparece em 4 respostas, 13,8\% dos entrevistados. Estes 
relatos não relacionam o exame especificamente para o diagnóstico e controle da tuberculose, deixando o tema em aberto para "doenças" do pulmão.

A relação com o controle da doença, ou seja, acompanhamento do "grau" da doença, melhora do quadro aparece em 5 respostas, portanto 17,2\% dos entrevistados, subentende-se que as solicitações mensais para a colheita das amostras de controle de tratamento poderão ser mais toleradas pelos usuários se este apreender a importância deste controle para o restabelecimento de sua saúde. Estes 5 usuários também relataram a importância do exame de escarro no diagnóstico da tuberculose (Quadro 12).

O destaque da descoberta de microorganismos no escarro relacionados à tuberculose aparece em 4 respostas, portanto $13,8 \%$ dos entrevistados, embora estes usuários não tenham se referido ao controle de tratamento. Quando relacionam o exame com a detecção da presença de microorganismos causadores da tuberculose, mesmo que denominados vírus, talvez também possam apresentar maior tolerância aos pedidos mensais de baciloscopia de escarro por entenderem que só apresentarão melhora se deixarem de ser encontrados microorganismos no escarro, o que é a maneira de controlar o seu tratamento. A orientação do usuário deve ser correta, o mesmo deve relacionar tratamento medicamentoso, cura e agente causador uma bactéria e não um vírus, a apreensão destes conhecimentos pode facilitar a agregação de outros mais como o risco da auto-medicação, prevenção de doença causadas por vírus por não apresentarem cura, entre outros.

A respeito da opinião dos usuários sobre a realização da colheita da amostra de escarro, percebe-se ainda atitudes negativas, porém já mescladas à sua aplicação como diagnóstico e controle de tratamento, como demonstra o quadro 13, quadro este elaborado com a frequência que o tema apareceu no relato dos usuários do PNCT.

Comparando as frequências de citações dos temas sobre a opinião dos usuários a respeito da colheita das amostras de escarro, 19 (65,5\%) citações são favoráveis a colheita da amostra contra $11(37,9 \%)$ citações desfavoráveis. O quadro conduz a uma avaliação positiva do tema, visto ser uma dificuldade a adesão dos 
usuários e a colaboração dos mesmos para o sucesso da colheita e portanto da baciloscopia (Quadro 13).

Quadro 13: Opinião dos usuários do PNCT entrevistados sobre a colheita da amostra de escarro. São Paulo, 2004.

\begin{tabular}{|l|c|}
\hline \multicolumn{1}{|c|}{ Opinião sobre a colheita do escarro } & $\mathbf{N}^{\circ}$ de Usuários \\
\hline Importante para diagnóstico & $6(20,7 \%)$ \\
\hline Acho bom; bom para prevenir doença & $6(20,7 \%)$ \\
\hline $\begin{array}{l}\text { Muito estranho, nojento; muito ruim de fazer, eu não gosto; } \\
\text { nojento mas necessário; muito nojento; muito ruim, horrível }\end{array}$ & $6(20,7 \%)$ \\
\hline $\begin{array}{l}\text { Um pouquinho chato; chato mas necessário; cansativo; se não } \\
\text { precisasse seria melhor }\end{array}$ & $5(17,2 \%)$ \\
\hline $\begin{array}{l}\text { Importante para saber se estou melhorando } \\
\text { Normal; normal tem que fazer mesmo }\end{array}$ & $4(13,7 \%)$ \\
\hline
\end{tabular}

A importância da colheita da amostra de escarro também foi tema citado pelos usuários, sendo que $4(13,7 \%)$ usuários relacionaram a importância da colheita a melhora do quadro, possivelmente pensando no controle de tratamento. Dos 9 usuários entrevistados, $6(20,7 \%)$ relacionou a importância da colheita da amostra de escarro ao diagnóstico da tuberculose.

No quadro 14 são apresentadas as formas relatadas pelos usuários do PNCT sobre como foram orientados a colher a amostra de escarro.

Pelas respostas obtidas, 55,2\% dos respondentes, ou seja, 16 usuários citaram a necessidade de forçar a tosse, relacionando a colheita do exame a esforço, isto porque parece que a idéia central neste caso seria a necessidade de ser colhida a amostra de escarro proveniente da árvore brônquica, daí a necessidade de tossir, porém, aos respondentes isto não parece claro, acreditam que precisam conseguir o escarro mas se este estiver nas vias aéreas superiores e for eliminado, muito provavelmente será encaminhado para o laboratório e não será uma amostra de boa qualidade para avaliação (BRASIL 2002, SES 2002). 
Quadro 14: Frequência das formas relatadas como orientação recebida dos profissionais de saúde para colher a amostra de escarro. São Paulo, 2004.

\begin{tabular}{|l|l|}
\hline \multicolumn{1}{|c|}{$\begin{array}{c}\text { Formas relatadas como orientação para colher a amostra de } \\
\text { escarro }\end{array}$} & Freqüiência \\
\hline Forçar a tosse, forçar o peito, tossir bastante "prá" conseguir & $16(55,2 \%)$ \\
\hline Colher à noite e de manhã & $14(48,3 \%)$ \\
\hline Colher em jejum & $14(48,3 \%)$ \\
\hline $\begin{array}{l}\text { Escarrar dentro do pote, não colocar o dedo dentro do pote, colocar } \\
\text { o pote na geladeira, fechar muito bem o pote }\end{array}$ & $8(27,6 \%)$ \\
\hline $\begin{array}{l}\text { Escovar os dentes sem pasta, lavar a boca com água, escovar os os } \\
\text { dentes }\end{array}$ & $6(20,7 \%)$ \\
\hline $\begin{array}{l}\text { Respirar 3 vezes e encher o pulmão para tossir, inspirar e tossir, } \\
\text { respirar fundo, segurar a respiração }\end{array}$ & $5(17,2 \%)$ \\
\hline Não serve cuspe e secreção nasal só do pulmão; não saliva, escarro & $4(13,8 \%)$ \\
\hline Inalação com água quente; batidas nas costas & $1(3,4 \%)$ \\
\hline Escrever nos potinhos & $1(3,4 \%)$ \\
\hline
\end{tabular}

Outra frequência bastante significativa foi a orientação de colher uma amostra de manhã e uma à noite, presentes em $48,3 \%$ das respostas, ou seja 14 usuários. Atualmente recomenda-se duas amostras de escarro (BRSIL 2002, SES 2002) para o diagnóstico da tuberculose, uma no momento em que o usuário está no serviço e a outra no domicílio. A recomendação anterior, eram de 3 amostras de escarro para diagnóstico e solicitava-se ao usuário que colhesse uma amostra no serviço de saúde, uma à noite e uma pela manhã para já entregar estas duas últimas o mais rápido possível. O fato do usuário referir que é solicitado ao mesmo colher uma amostra à noite e uma pela manhã sugere ou que ainda estão sendo solicitadas 3 amostras para diagnóstico ou que não está sendo realizada a colheita da amostra no serviço de saúde como preconizado (BRSIL 2002, SES 2002). Nos ambulatórios especializados no atendimento de DST/AIDS, são solicitadas 3 amostras, 2 baciloscopias e uma cultura, como rotina, porém este procedimento foi citado como recebido por usuários de serviços de saúde que não dos serviços de atendimento em DST/AIDS. 
Colher a amostra em jejum foi citado em 48,3\% das respostas, de 14 usuários. O Manual de Orientação sugere que o usuário seja orientado a colher pela manhã em jejum pois, de um modo geral, é comum o acúmulo de secreção das vias aéreas inferiores na região dos brônquios após um período prolongado na posição horizontal (SES 2002), e também o fato de estar em jejum seria uma possibilidade de reduzir náuseas e vômitos, além de garantir que a amostra permaneça livre de resíduos resíduos alimentares, o que poderia interferir na qualidade do exame.

Estar em jejum para colher a amostra de escarro é uma sugestão, porém, não significa que o usuário não possa colher a amostra de outra forma, já que, respeitando-se as orientações de estar com a região de orofaringe livre de resíduos alimentares, e o fato de a amostra colhida permanecer em local fresco, livre do calor e da luz solar, podendo também ser mantida sob refrigeração, esta pode ser colhida no horário mais conveniente ao usuário, como por exemplo, no horário em que mais tosse ou que mais elimine secreção, sem a necessidade de tornar a colheita um incomodo pelo esforço a ser despendido para colher a amostra em horário determinado.

Durante a realização de uma entrevista, uma usuária de 60 anos presenteou o pesquisador com o seguinte depoimento:

“Às vezes de manhã eu não tenho catarro, aí eu uso a bombinha para conseguir o catarro. Eu lavo a boca, porque não pode tomar nem água antes e escarro no potinho. Às vezes eu preciso tossir e preciso forçar muito, às vezes eu afogo com o catarro. Eu tenho mais catarro à tarde, mas os médicos pedem para colher de manhã!"

A colheita de escarro, definitivamente não é uma atividade prazerosa, mas, também não deve ser sofrível, considerando que precisamos solicitar amostras durante o tratamento para o controle do mesmo e o sucesso na colheita torna-se a cada mês de tratamento mais difícil, pela melhora do quadro infeccioso e inflamatório do tecido pulmonar e diminuição da presença da secreção pulmonar. 
Cuidados assépticos no manuseio do pote de coleta, conservação da amostra e cuidados com o transporte da mesma foram citados por 8 usuários, 27,6\% dos mesmos, itens de extrema importância para a qualidade do resultado da baciloscopia e no entanto, não foi citado com a frequiência desejada.

Observações sobre a limpeza da boca antes da colheita esteve presente em $20,7 \%$ das entrevistas realizadas com 6 usuários e aqui cabe a mesma observação realizada sobre a necessidade da amostra ser colhida ou não em jejum.

Técnicas que facilitam a colheita da amostra como o uso da inspiração forçada e retenção do ar nos pulmões para imprimir maior pressão na contração do diafragma para uma tosse efetiva foram citadas por 5 usuários ou 17,2\% dos entrevistados, porém, pela forma como relataram estas técnicas não pareceu claro que haviam compreendido as mesmas com o propósito a que se prestam e sim como mais cuidados a serem seguidos para obtenção da amostra de escarro.

A compreensão de que a amostra deve vir da árvore brônquica e não da região de orofaringe foi citação de apenas $13,8 \%$ dos entrevistados, ou seja, 4 usuários. Percebeu-se que os usuários até entendiam que era necessária a secreção mucosa e não saliva mas não pareceu que os mesmos entendessem porque a secreção deveria vir do pulmão e não do nariz ou boca.

Técnicas de facilitação da colheita da amostra por fluidificação da secreção brônquica foi citação de apenas um usuário, 3,4\% dos respondentes o que pode mostrar que outros recursos poderiam ser utilizados para tornar a colheita menos impeditiva para os mesmos.

Apenas um usuário, 3,4\% dos respondentes, referiu que foi orientado a "escrever" no potinho, ou seja, identificar o mesmo o que vai contra as orientações do Manual de Orientação (SES 2002) que assim como as normas do PNCT (BRASIL 2002) recomendam que o pote entregue ao usuário deva estar identificado inclusive discriminando que amostra será colhida, se segunda amostra de diagnóstico ou primeira, segunda, etc amostras de controle de tratamento.

Manusear o frasco de colheita do material para identificação depois da colheita da amostra de escarro também fere cuidados relativos à biossegurança do profissional pois sabe-se que pelo esforço de tosse o usuário não consegue eliminar 
sua secreção dentro do pote de colheita sem eliminar perdigotos e respingos para fora do frasco de colheita. Orientar o usuário a envolver o frasco de colheita com papel também não garante que as bordas e paredes externas do frasco não sejam contaminadas. São cuidados para os quais o profissional deve estar atento.

Os usuários entrevistados foram atendidos por serviços de saúde cujos profissionais de saúde presentes na área do PNCT para atendimento apresentavam as seguintes características apresentadas na tabela 22, levando-se em consideração a participação em treinamentos e conhecimento do Manual de Orientação.

Observa-se que 7 profissionais $(58,3 \%)$ participaram de treinamento porém 2 deles, $16,7 \%$ não conhecem o Manual de Orientação; 5 (41,7\%) profissionais não participaram de treinamento sendo que $3(25 \%)$ deles não conhecem o Manual de Orientação. Dos profissionais que participaram de treinamentos a maioria conhece o Manual de Orientação e dos que não participaram de treinamentos a relação é exatamente contrária, ou seja, existem mais profissionais observados que não conhecem o Manual de Orientação.

Tabela 22: Profissionais de saúde dos serviços onde ocorreu entrevista de usuários do PNCT relacionados à participação em treinamentos e conhecimento do Manual de Orientação. São Paulo, 2004.

\begin{tabular}{l|c}
\hline \multicolumn{1}{c|}{$\begin{array}{c}\text { Participação em treinamentos e conhecimento do } \\
\text { manual }\end{array}$} & $\begin{array}{c}\mathbf{N}^{\circ} \text { de } \\
\text { profissionais }\end{array}$ \\
\hline Participaram de treinamento e conheciam o manual & $5(41,6 \%)$ \\
Participaram de treinamento e não conheciam o manual & $2(16,7 \%)$ \\
Não participaram de treinamento e conheciam o manual & $2(16,7 \%)$ \\
Não participaram de treinamento e não conheciam o manual & $3(25 \%)$ \\
Total & $\mathbf{1 2 ( 1 0 0 \% )}$ \\
\hline
\end{tabular}




\section{Comparando a prática e o relato dos profissionais de saúde com o relato dos usuários do PNCT}

Serão discutidos a realização ou não dos itens do roteiro de observação da prática dos profissionais de saúde, relacionando os resultados aos dados obtidos através dos relatos dos usuários do PNCT sobre a forma como foram orientados a colher a amostra de escarro e sobre como realmente realizam a colheita da amostra de escarro.

As porcentagens discutidas foram calculadas sobre o total de observações realizadas.

\section{Explica a importância do exame para o paciente}

Foram observados dois profissionais $(7,14 \%)$, que não participaram de treinamentos e não conheciam o Manual de Orientação, orientando usuários para a colheita da amostra de escarro para o diagnóstico da tuberculose, e, nenhum deles explicou aos usuários a importância do exame antes de iniciar a orientação. Somente 4 profissionais $(14,3 \%)$ da amostra apresentou conhecimento classificado como satisfatório para a definição e importância da baciloscopia e $71,4 \%$ apresentou conhecimento satisfatório somente para a definição de baciloscopia, o que pode explicar a ausência de orientação do tema para os usuários. Dos usuários, apesar do resultado das observações, 51,7\% relacionou a amostra de escarro ao diagnóstico da tuberculose, $17,2 \%$ relacionou a baciloscopia ao acompanhamento do tratamento e $13,8 \%$ se referiu a um microorganismo causando a doença.

Somente dois profissionais, que conheciam o Manual de Orientação e participaram de treinamento, referiram que solicitam saber do usuário o que ele sabe sobre o exame de escarro antes de iniciar a orientação, explicam a importância para descobrir o bacilo e explicam sobre a tuberculose, o que esteve de acordo com o resultado da observação da prática realizada.

Percebe-se a grande dificuldade de aceitação do exame para ambas as partes, profissional e usuário. Desde o princípio do acompanhamento do usuário, não existe destaque para a orientação sobre a baciloscopia especificamente, nem tampouco para 
a sua importância, afirmação esta que pode ser comprovada com o relato dos usuários.

\section{Procura saber do usuário como o mesmo colhe a amostra de escarro}

Nas $7(100 \%)$ observações realizadas para a orientação de usuários sobre a colheita da amostra de escarro para controle de tratamento, em apenas uma delas $(14,3 \%)$ o profissional de saúde solicitou saber do usuário como ele colhia a amostra de escarro antes de iniciar o procedimento de orientação. Ao serem solicitados a responder como orientam os usuários a colher a amostra, somente dois profissionais que participaram de treinamentos e conheciam o Manual de Orientação citaram que antes de iniciar a orientação perguntavam ao usuário o que sabiam sobre a tuberculose e a baciloscopia. Não há necessidade de re-orientar o indivíduo que já realiza a colheita conforme se preconiza, porém, não existe este cuidado e respeito ao indivíduo. Um dos profissionais de saúde que primeiro procurou saber o conhecimento do usuário sobre a tuberculose e a baciloscopia, procurando deixar claro ao usuário as inadequações, para somente depois orientar o usuário sobre a forma correta da colheita, referiu ter participado do treinamento na FSP USP em 2002 e conhecer o Manual de Orientação.

\section{Explica a importância da baciloscopia para o controle do tratamento}

Somente $1(14,3 \%)$ profissional, que não participou de treinamentos mas conhecia o Manual de Orientação, explicou ao usuário a importância da baciloscopia para o controle de tratamento, os outros $6(85,7 \%)$ não explicaram.

Quanto às respostas dos profissionais sobre como orientam os usuários, dois $(7,14 \%)$ profissionais referem explicar a importância da baciloscopia ao mesmos, e estes profissionais conhecem o Manual de Orientação e participaram de treinamentos. Reforça-se que somente 1 (14,3\%) dos profissionais de saúde apresentou conhecimento satisfatório sobre a importância da baciloscopia para o controle de tratamento. Fica mais difícil colaborar ou se esforçar para uma colheita 
de melhor qualidade quando não se compreende os motivos pelos quais necessita-se fazê-la.

O relato dos usuários confere com a prática dos profissionais conforme já discutido, 4 usuários $(13,7 \%)$ da amostra relacionou a baciloscopia à melhora do quadro, em outras palavras, controle de tratamento.

\section{Orienta o usuário lavar a boca ou bochechar com água antes de expectorar explicando a necessidade do procedimento}

Para surpresa do pesquisador, não foi observado nenhum profissional orientando o usuário a lavar a boca ou bochechar com água antes de expectorar, bem como explicando a necessidade de eliminar resíduos de alimento e de pasta de dentes antes de colher o escarro, porém, $64,3 \%$ dos usuários entrevistados sobre como foram orientados a colher a amostra de escarro citaram a higiene da boca para a colheita do escarro, e este foi o segundo item mais citado. Também foi o quarto tema mais citado pelos profissionais como orientação realizada aos usuários. Talvez a presença do pesquisador observando tenha inibido as ações dos profissionais, é um fator já considerado nas pesquisas de campo (POLIT e HUNGLER 1995).

\section{Orientação do usuário para inspiração profunda e retenção do ar nos pulmões}

A orientação de inspirar profundamente e reter o ar nos pulmões foi realizada por 6 profissionais observados, $66,6 \%$ da amostra, porém só foi citada como orientação recebida por $17,2 \%$ dos usuários entrevistados. Talvez, o fato de não ser enfatizado a necessidade do esforço muscular, dificulte a memorização do procedimento. A mecânica e utilidade do procedimento necessitam ser evidenciadas nas orientações. Este tema foi o segundo mais citado pelos profissionais que referiram não conhecer o Manual de Orientação, como orientação realizada aos usuários, e o sexto mais citado pelos profissionais que conheciam o manual de orientação. 


\section{Realização do esforço de tosse}

Realizar o esforço de tosse após ter permanecido alguns segundos com o ar retido nos pulmões foi observado na orientação de 3 profissionais ou $33,4 \%$ da amostra, sendo que os outros 6 profissionais, 66,6\% da amostra não realiza esta orientação embora esta tenha sido a orientação mais citada como recebida por $55,2 \%$ dos usuários entrevistados. Foi um tema também muito citado pelos profissionais como orientação realizada aos usuários. A relação da colheita do escarro com o esforço de tosse é imediata pelo usuário do serviço de saúde, tosse e escarro estão intimamente relacionados no imaginário popular, mas precisa ser devidamente realizada para não tornar-se um esforço em vão.

\section{Demonstração do procedimento com o frasco de colheita}

A demonstração de como utilizar o frasco de colheita durante a realização da orientação e a quantidade de secreção a ser colhida só foi observado ser realizado por um profissional de saúde, $11,1 \%$ da amostra, sendo um profissional que referiu ter participado de treinamento e conhecer o Manual de Orientação. Os outros 8 profissionais, $88,9 \%$ da amostra, não realizou a demonstração da técnica com o uso do frasco de colheita do escarro.

Demonstrar e utilizar gestos ajuda a fixar informações, complementa e reforça orientações (STEFANELLI 1993, SILVA 1996) e estudo sobre a comunicação não-verbal anterior revela que a exploração da mesma é deficitária no atendimento do usuário do PNCT (MAZZAIA 2000) e como percebe-se, continua sendo.

\section{Boa amostra proveniente da árvore brônquica}

Existe a necessidade de orientar o usuário a colher uma amostra de escarro proveniente da árvore brônquica, utilizando uma linguagem de mais fácil compreensão, proveniente da "região mais profunda e não da garganta", buscando-se a colheita de uma boa amostra de escarro (BRASIL 2002d), porém esta orientação só foi observada sendo realizada por $3(33,3 \%)$ profissionais, o restante não realizou a orientação. A necessidade de colher o escarro, "colher o que vier do pulmão e não 
saliva, cuspe", foi a sétima citação dos usuários, estando presente em $18,3 \%$ das respostas dos usuários, o que coincide com a frequência em que foi observado ser orientado pelo grupo de profissionais, porém foi o tema mais citado como orientação realizada aos usuários pelos profissionais de saúde entrevistados que não conheciam o manual de orientação, e o terceiro mais citado pelos profissionais que conheciam o manual de orientação. A qualidade da baciloscopia é inteiramente dependente da qualidade da amostra colhida, parece que esta informação é conhecida dos profissionais porém pouco praticada, embora extremamente necessária, daí as queixas dos laboratórios sobre a qualidade das amostras.

\section{Repetição da inspiração forçada, retenção do ar e tosse}

O procedimento de inspirar profundamente, reter $\mathrm{o}$ ar nos pulmões e realizar um esforço de tosse deve ser repetido por 3 vezes para se obter a quantidade de secreção adequada - de 5 a $10 \mathrm{ml}$ de escarro, porém somente um profissional, 11,1\% da amostra realizou a orientação. Nenhum usuário do PNCT, quando entrevistado, referiu a técnica como preconizada, referiram-se a respirar três vezes, encher o pulmão de ar e tossir, mas não relacionam com a necessidade de se obter uma boa amostra de escarro. $\mathrm{O}$ relato dos usuários coincide com o relato dos profissionais sobre como orientam os usuários, os mesmos referem-se a respirar 3 vezes, respirar fundo 3 vezes, tossir 3 vezes. A questão sobre repetir determinado procedimento por 3 vezes ficou retido na memória dos usuários mas a aplicação do mesmo não. Isto pode demonstrar que não houve compreensão da técnica de colheita do escarro em sua totalidade.

\section{Fechar o frasco herméticamente e transportá-lo com a tampa sempre para cima}

Somente 4 profissionais $(44,4 \%)$ realizaram a orientação de fechar muito bem o frasco e transportá-lo com a tampa para cima evitando derramamento do material biológico, contaminação excessiva do frasco e até mesmo perda do material para análise. Conforme relato dos profissionais do laboratório, que será apresentado, as condições de transporte e conservação das amostras ainda permanece como um 
problema a ser sanado. Somente um profissional de saúde dos quatro acima citados participou de treinamento, todos os outros não participaram e todos negaram conhecimento sobre o Manual de Orientação. A orientação de fechar bem o frasco foi citada por $50 \%$ da amostra de profissionais entrevistados. $\mathrm{O}$ transporte da amostra com a tampa para cima é pouco lembrada, citada por apenas $3(10,7 \%)$ profissionais. O conhecimento do Manual de Orientação ou participação em treinamentos não influiu para o atendimento deste tema. Nenhum usuário reportou-se ao tema.

\section{Orientação do envolvimento do frasco de colheita em papel ou plástico para transporte até o serviço de saúde}

Seis profissionais $(66,7 \%)$ realizaram a orientação dos usuários do PNCT para embrulharem o frasco de colheita para transporte, destes, três conhecem o Manual de Orientação, dois participaram de treinamentos e, os outros três que não realizaram esta orientação não conhecem o Manual de Orientação, 2 não participaram de treinamento. Este tema foi muito citado como orientação realizada pelos profissionais aos usuários, coincidindo com a observação. É um hábito dos usuários envolver os frascos de colheita de exames para transporte, aliás, comentando a experiência de receber as amostras dos usuários, os mesmos parecem constrangidos quando solicitado aos mesmos que desembrulhem os frascos para que sejam recebidos. É como se fosse necessário esconder aquilo que portam, afinal, diz respeito a excreta.

\section{Orientação do usuário para lavagem das mãos após a colheita do escarro}

Somente um profissional $(11,1 \%)$ que não participou de treinamentos e não conhece o manual orientou o usuário a lavar as mãos após a colheita do escarro, todos os outros não realizaram a orientação, demonstrando pouco cuidado com as questões de higiene e contaminação na comunidade. A prática não foi citada pelos usuários como orientação recebida e foi citada por 4 profissionais, 14,3\% dos 28 entrevistados como orientação realizada para a colheita da amostra de escarro, dois profissionais $(7,14 \%)$ que participaram de treinamentos e conheciam o Manual de 
Orientação, dois profissionais $(7,14 \%)$ que não conheciam o manual de orientação sendo que um participou de treinamento e o outro não.

\section{Orientação da colheita da amostra no dia de levar para o serviço de saúde}

Um profissional $(11,1 \%)$ realizou a orientação, porém, com a possibilidade de manter a amostra colhida refrigerada até o dia de encaminhamento para o serviço, o usuário pode colher a amostra no período e dia que for mais conveniente para ele. Como já comentado, é necessário facilitar o cumprimento da solicitação para o usuário.

\section{Orientação para a colheita da amostra em ambiente mais ventilado da casa}

Cinco profissionais, $55,5 \%$ das observações acompanhadas, realizaram a orientação do usuário para a colheita da amostra em ambiente ventilado da residência, mostrando preocupação com a contaminação na comunidade. Três destes profissionais $(33,3 \%)$ participaram de treinamentos e um não conhece o Manual de Orientação, os outros dois $(22,2 \%)$ não participaram de treinamento e não conhecem o Manual de Orientação. Esta informação parece estar mais relacionada ao conhecimento sobre a forma de transmissão da doença do que sobre o conhecimento de manuais ou participação em treinamentos.

\section{Valida a compreensão do usuário sobre o procedimento de colheita}

Quatro profissionais $(44,4 \%)$ validam a mensagem da compreensão da técnica de colheita do escarro, dois $(22,2 \%)$ que participaram de treinamentos e conhecem o Manual de Orientação e outros dois (22,2\%) profissionais que não participaram de treinamentos e não conhecem o Manual de Orientação, sendo que um destes às vezes valida e não sempre. É lamentável que se perca uma grande oportunidade de compreender a apreensão dos usuários após o término da atividade de orientação. Validar informações parece não ser uma prática observada nos serviços de saúde. 


\section{Mudança de vocabulário para realização de nova orientação}

Como já discutido, nenhum profissional, modificou a forma de se comunicar com o usuário quando validaram a orientação realizada e identificaram que o usuário não consegue descrever o procedimento de colheita do escarro da forma preconizada. Se não houve compreensão na primeira tentativa de orientação é porque existe a necessidade de modificar a forma de orientação.

\section{Pergunta ao usuário se o mesmo quer fazer perguntas}

Somente três profissionais $(33,3 \%)$ perguntam ao usuário se o mesmo tem dúvida, dois $(22,2 \%)$ que participaram de treinamentos e conhecem o Manual de Orientação e um $(11,1 \%)$ que não participou e não conhece o Manual de Orientação, o restante não utiliza esta prática e portanto não dá oportunidade para que o usuário se coloque, podendo permanecer com dúvidas, comprometendo a qualidade da amostra de escarro a ser colhida.

\section{A prática dos serviços de saúde e a qualidade das amostras de escarro na avaliação dos profissionais de laboratório}

Os quatro laboratórios da rede pública que apresentaram mais de 1500 baciloscopias realizadas no primeiro semestre de 2003 e que identificaram os serviços de saúde que mais solicitavam baciloscopias de escarro, foram os laboratórios que cederam as informações sobre acondicionamento, transporte e qualidade das amostras de escarro enviadas, além de qualificarem o preenchimento das solicitações de exames encaminhadas, informações estas cedidas pelo profissional responsável pelo controle das baciloscopias de escarro.

A princípio, como já citado, foi sugerido pelo pesquisador que os profissionais de laboratório realizassem acompanhamento das amostras de escarro recebidas, por 30 dias, através de impresso constando dados sobre o acondicionamento, transporte, qualidade das amostras de escarro e preenchimento da solicitação de exames, porém, os responsáveis pela realização do controle das baciloscopias de escarro dos laboratórios não aceitaram a proposta e sugeriram 
responder questões sobre os temas em forma de entrevista devido ao acúmulo de atividades. Um dos entrevistados assim se manifestou:

“...ocorreu um aumento expressivo da demanda de baciloscopias de 8 serviços de saúde passou para 80. Só laboratório público realiza as baciloscopias agora."

Como estratégia de controle das ações do PNCT no município de São Paulo, as baciloscopias são realizadas por laboratórios da rede pública, os laboratórios passaram por um processo de treinamento e receberam insumos para o atendimento da demanda da rede de serviços públicos de saúde do Município de São Paulo.

Atendendo à solicitação, as entrevistas foram realizadas com os responsáveis pela realização das baciloscopias de escarro nos quatro laboratórios que avaliavam as amostras de escarro enviadas considerando os itens: acondicionamento, transporte, preenchimento do impresso de solicitação do exame e a qualidade da amostra.

Com relação à classificação das amostras enviadas, de acordo com o Manual de Orientação (SES 2002) divulgado, foram consideradas adequadas as amostras que:

- No acondicionamento encontravam-se bem fechadas, com identificação no corpo do frasco de colheita e embrulhados em sacos plásticos individuais.

- No transporte foram enviadas ao laboratório em caixas plásticas térmicas ou isopor, refrigeradas com gelo reciclável, dispostas de forma a dificultar o derramamento dentro da caixa.

- No preenchimento do pedido de exame mesmos foram devidamente identificados com o nome do serviço de saúde, nome do usuário e endereço completo do mesmo, com data de nascimento, idade e sexo e, principalmente, que fosse discriminada se primeira ou segunda amostra para diagnóstico ou se primeira, segunda ou outra amostra para controle de tratamento. Solicitação de exames enviadas fora da caixa de amostras, em saco plástico lacrado. Pedidos preenchidos para todos os frascos de colheita enviados com secreção. 
- Na qualidade da amostra apresentaram secreção mucosa proveniente da árvore brônquica em quantidade suficiente, no mínimo $5 \mathrm{ml}$.

Esta classificação das amostras foi elaborada também baseando-se na experiência dos profissionais de laboratório que recebem diariamente as amostras, e como resultado temos os dados apresentados no quadro 15.

Percebemos que metade dos itens são classificados como adequados com exceção do item preenchimento da requisição de exame.

Quadro 15: Adequação das amostras de escarro de acordo com acondicionamento, transporte, qualidade da amostra e solicitação de exame, segundo avaliação dos profissionais de laboratórios da rede pública. São Paulo, 2004.

\begin{tabular}{|l|c|c|}
\hline \multicolumn{1}{|c|}{ Itens observados para avaliação } & \multicolumn{2}{c|}{ Adequaç̃o } \\
\cline { 2 - 3 } & Sim & Não \\
\hline Acondicionamento & $2(50 \%)$ & $2(50 \%)$ \\
\hline Transporte & $2(50 \%)$ & $2(50 \%)$ \\
\hline Pedidos de Exame & - & $4(100 \%)$ \\
\hline Qualidade da amostra & $2(50 \%)$ & $2(50 \%)$ \\
\hline
\end{tabular}

Os laboratórios queixaram-se sobre o preenchimento dos pedidos de baciloscopias que não são enviados como preconizado, principalmente com relação à discriminação do tipo de amostra se diagnóstico ou controle de tratamento e o número da amostra. Um dos profissionais refere que $80 \%$ das solicitações de baciloscopias recebidas não apresentam este tipo de informação.

É importante lembrar que as informações constantes do impresso de solicitação das baciloscopias são primordiais para que os laboratórios possam enviar para a Secretaria de Estado da Saúde todos os dados necessários para avaliação do programa, isto no que diz respeito à comprovação diagnóstica e controle de tratamento da tuberculose através do software LABTB.

Os profissionais de laboratórios ainda relataram que são enviados frascos com amostras sem a solicitação de exames, sem o preenchimento do endereço do usuário, 
sem a identificação do usuário e sem a identificação do serviço de saúde solicitante. O quadro 15 mostra que $100 \%$ dos profissionais dos laboratórios referem não ter este item atendido.

Dois laboratórios referiram que as amostras de escarro ainda são transportadas junto à outros tipos de amostras como fezes, sangue, etc, além do que as solicitações de exame também são colocadas dentro da caixa de transporte das amostras, correndo o risco de serem totalmente inutilizadas se envolvidas por secreção orgânica. Um dos profissionais referiu que:

“...é necessário lacrar a caixa de transporte de material biológico e orientar ao motorista do veículo que transporta as caixas que não deve mexer nas caixas. Os motoristas não querem levar muitas caixas..."

Ainda existem serviços de saúde que encaminham as amostras de escarro para o laboratório em caixas de papelão, afirmação esta realizada por um dos profissionais de laboratório entrevistado. Tal afirmativa pôde ser verificada na resposta de um profissional de saúde entrevistado, que referir-se sobre como recebia as amostras, acrescentou alguns dados sobre o acondicionamento das mesmas referindo:

“...pego os potes e coloco arrumadinho na caixa de papelão com divisória para ir pro laboratório..."

Quanto à qualidade das amostras, dois laboratórios referem perceber melhora do atendimento do item, no entanto, dois profissionais de laboratório referiram que ainda recebem muita saliva, secreção nasal e quantidade de secreção muito inferior ao necessário para garantir a qualidade do resultado, o que coincide com os dados colhidos com os profissionais de saúde e usuários do PNCT sobre a técnica para a obtenção da amostra de escarro de boa qualidade.

Considerando a avaliação dos profissionais dos laboratórios ocorreu melhora dos itens acondicionamento, transporte e qualidade da amostra. Já o preenchimento do pedido de baciloscopia continua comprometendo sobremaneira a localização das possíveis fontes de infecção, já que relatam que receberem frascos sem pedidos de exame, ou sem identificação nos frascos e que são positivos à microscopia, 
significando uma fonte de infecção com dificuldades para localização, repercutindo no desenvolvimento do programa como um todo.

A expectativa da DT do CVE e da Coordenação do Programa de Controle da Tuberculose da SMSSP era de que houvesse aumento na quantidade de sintomáticos respiratórios examinados e baciloscopias de escarro realizadas para diagnóstico e controle de tratamento a partir da intervenção educativa realizada em Novembro de 2002 na FSP USP.

Na consulta à Divisão de Tuberculose do CVE da SESSP foi informado que só seria possível disponibilizar dados sobre sintomáticos respiratórios examinados e baciloscopias de escarro, do ano de 2003 e relativos ao primeiro trimestre de 2004 .

Quadro 16: Número de baciloscopias realizadas e sintomáticos respiratórios examinados no Município de São Paulo nos quatro trimestres de 2003 e no primeiro trimestre de 2004. São Paulo, 2004.

\begin{tabular}{|l|c|c|c|c|c|}
\hline \multicolumn{1}{|c|}{ Trimestres } & $\begin{array}{c}2003 \\
1^{\circ} \text { Trimestre }\end{array}$ & $\begin{array}{c}2003 \\
2^{\circ} \text { Trimestre }\end{array}$ & $\begin{array}{c}2003 \\
3^{\circ} \text { Trimestre }\end{array}$ & $\begin{array}{c}2003 \\
4^{\circ} \text { Trimestre }\end{array}$ & $\begin{array}{c}2004 \\
{ }^{\circ} \text { Trimestre }\end{array}$ \\
\hline $\begin{array}{l}\text { Total } \\
\text { Baciloscopias } \\
\text { Realizadas }\end{array}$ & 18754 & 21688 & 20166 & 17968 & 18259 \\
\hline $\begin{array}{l}\text { Sintomáticos } \\
\text { Respiratório } \\
\text { Examinados }\end{array}$ & 10176 & 12341 & 11572 & 10066 & 10829 \\
\hline $\begin{array}{l}\text { Baciloscopias de } \\
\text { Controle }\end{array}$ & 1907 & 2248 & 2099 & 1891 & 1760 \\
\hline
\end{tabular}

Fonte: LAB-TB dados até 10/07/2004

Os dados mostram que nos $2^{\circ}$ e $3^{\circ}$ trimestres de 2003 ocorreu um aumento no número de baciloscopias realizadas, sintomáticos respiratórios examinados e baciloscopias de controle de tratamento, sendo reduzido este número no $4^{\circ}$ trimestre de 2003 que ainda é menor que o $1^{\circ}$ trimestre de 2003. A ocorrência de doenças do aparelho respiratório são maiores entre o $2^{\circ}$ e $3^{\circ}$ trimestres e desta forma, podem ter contribuído para o aumento de investigações quanto à possibilidade de um 
diagnóstico de tuberculose, porém, comparando o primeiro trimestre de 2003 ao primeiro trimestre de 2004 percebe-se uma discreta redução de 2,6\% no número de baciloscopias totais realizadas bem como com relação às baciloscopias para controle de tratamento, que sofreu uma redução de $7,7 \%$. Curioso é o número de sintomáticos respiratórios examinados no primeiro trimestre de 2004, o número é maior que no primeiro trimestre de 2003, porém as baciloscopias totais e para controle de tratamento são menores, como demonstrado.

A dificuldade para a colheita da amostra de escarro aumenta de acordo com o tempo de tratamento e portanto o incentivo para que o usuário colabore e realize a tentativa da colheita de uma boa amostra de escarro é fundamental para que seja possível a cura comprovada da tuberculose pulmonar.

A divulgação do Manual de Orientação e o projeto educativo realizado na FSP USP em 2002, podem ser considerados como variáveis que interferiram nos dados obtidos sobre as bacilocopias de escarro no ano de 2003, porém, um ano após os esforços de treinamento e divulgação do material, o número de baciloscopias solicitadas, principalmente para o controle de tratamento, começa a diminuir, não se mantendo como em 2003.

Profissional sensibilizado e motivado aumenta a possibilidade de usuários sensibilizados e motivados (BERTOLOZZI 1998).

JAMARILLO (2001), em um estudo sobre a evolução do impacto na avaliação de sintomáticos respiratórios, após campanha publicitária educativa sobre tuberculose, realizada em Cali, na Colômbia, com a duração de 6 semanas, campanha veiculda pela televisão, rádio e imprensa, resultou em $64 \%$ de aumento de baciloscopias realizadas e $52 \%$ de aumento de casos confirmados como bacilíferos, porém, os efeitos da campanha foram curtos, ou seja, no momento em que se interrompeu a transmissão televisiva e radiofônica os números de baciloscopias e diagnósticos diminuíram. Ficou demonstrado que a socialização de informações sobre os principais sintomas da tuberculose pulmonar e sobre os procedimentos diagnósticos podem aumentar o número de diagnósticos diminuindo os riscos de contaminação da população exposta. 
No caso dos dados sobre as baciloscopias para o Município de São Paulo, também é observado um declínio no número das mesmas, um ano após um projeto educativo como intervenção para o aumento no número de baciloscopias, principalmente para controle de tratamento. Os dados demonstraram que iniciativas deste vulto necessitam ser incorporadas, talvez, como rotina estabelecida nas Coordenações do PCT não só como iniciativas do nível estadual, mas também do nível municipal.

Durante a coleta de dados, alguns profissionais assim se manifestaram sobre os treinamentos que haviam participado sobre tuberculose:

“...participei de umas reuniões, mas... foi aqui mesmo na unidade...”

“...participei de um treinamento e foi aqui na UVES, veio um pessoa falar com a gente..."

A percepção de que é possível que sejamos um elo importante de uma corrente de ações envolvendo vários níveis de governo, talvez possa interferir nas opções realizadas pelos profissionais responsáveis pelo atendimento do usuário do PNCT. 
5. Conclusões

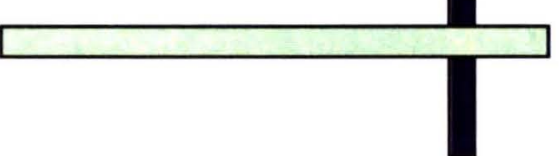


De acordo com os objetivos específicos traçados para este estudo, destaca-se a seguir os resultados mais significativos.

Sobre o preparo dos profissionais de saúde para as atividades do PNCT observou-se que $57,1 \%$ dos profissionais de saúde entrevistados haviam participado de treinamentos sobre tuberculose, sendo que $50 \%$ destes participaram de treinamentos há menos de 1 ano, porém, dos 28 profissionais entrevistados, $57,1 \%$ desconheciam o Manual de Orientação. Os materiais de consulta, muitas vezes a própria documentação do Programa de Saúde, são pouco explorados pelos profissionais. Dos 27 serviços de saúde visitados, em apenas $13(48,2 \%)$ foi encontrado o Manual de Orientação. Nas 5 regiões de saúde com maior incidência de casos de tuberculose no Município de São Paulo foram encontrados 6 Manuais de Orientação, 4 destes em serviços de saúde de uma só Subprefeitura. Em um serviço de saúde, dois auxiliares de enfermagem participaram do projeto educativo da FSP USP em 2002 mas o serviço não possuía o Manual de Orientação. O Manual de Orientação foi avaliado como adequado para consulta e esclarecimentos pelos profissionais de sáude entrevistados.

Os profissionais de saúde que participaram de treinamentos e que conheciam o Manual de Orientação apresentaram melhores resultados quanto ao conhecimento sobre baciloscopia e sua importância para o controle de tratamento da tuberculose, porém, ainda é bem menor a citação da importância da baciloscopia para o controle de tratamento da tuberculose pulmonar. Isto se reflete no conteúdo das falas dos usuários que também demonstraram desconhecimento sobre o controle de tratamento através da baciloscopia do escarro.

Destaca-se que as atividades de capacitação de profissionais de saúde para o PNCT são consideradas medidas administrativas de biossegurança no combate à tuberculose.

Ainda com relação à medidas administrativas de biossegurança no controle da tuberculose, observou-se aumento na porcentagem de profissionais de enfermagem e Enfermeiros realizando pedidos de baciloscopias e preenchimento de impressos, zorroborando com PNCT que recomenda que qualquer profissional, à simples 
suspeita de tuberculose, realize a solicitação da baciloscopia do escarro, com o intuito de identificação mais rápida possível das fontes de infecção. O tempo de espera para o resultado de baciloscopias apresentou melhora comparando-se aos dados coletados em 2002 com 55,6\% dos serviços de saúde citando receber o resultado, quando positivo, no mesmo dia. Ainda encontramos serviços de saúde recebendo resultados de baciloscopias em até 7 dias ou mais contrariando metas da Coordenação do PCT da SSMSP. A prática do rodízio de profissionais para atendimento dos usuários do PNCT foi encontrada em $22,2 \%$ das unidades de saúde, prática que deve ser utilizada com critério, considerando-se a necessidade do preparo de profissionais para o atendimento dos usuários do PNCT e estabelecimento do vínculo do usuário ao programa.

Com relação à adoção de medidas ambientais de biossegurança, 59,3\% dos serviços de saúde foram classificados como inadequados quanto ao local reservado para o atendimento dos usuários do PNCT. Como locais reservados para a colheita das amostras de escarro nos serviços de saúde, detectou-se que $44,4 \%$ dos serviços de saúde utilizavam partes externas da unidade para a colheita, porém, $51,8 \%$ dos serviços ainda utilizavam banheiro de usuários ou salas internas dos serviços de saúde. Se cuidados relativos à dispersão das correntes de ar não forem tomados, existe o risco de manutenção dos Núcleos de Wells nos ambientes da unidade, favorecendo a transmissão da tuberculose.

Contrariando a normatização do PNCT, foram observados $3(11,1 \%)$ serviços de saúde que não colhiam a primeira amostra de escarro na unidade, quando da suspeita do diagnóstico de tuberculose, encaminhando o usuário para colher a primeira amostra de escarro no domicílio.

As orientações pertinentes a cuidados preconizados com relação à biossegurança ainda não foram incorporadas pelos profissionais de saúde, necessitando-se investimentos quanto ao tema. Apesar da grande divulgação da necessidade do uso de precauções padrão, $25 \%$ da amostra de profissionais de saúde entrevistados não utilizam luvas no recebimento da amostra de escarro; ainda não existe total adesão quanto à orientação do usuário para cuidados como: colher a amostra em local ventilado, lavar as mãos após o término do acondicionamento da 
amostra de escarro e utilizar lenços de papel para tossir e descartar secreção respiratória.

Assim como ao usuário é necessário justificar alguns cuidados orientados, ao profissional isto deve ser enfatizado com determinada frequência. Os profissionais que referiram conhecer o Manual de Orientação e participar de treinamentos apresentaram melhores resultados com relação à observação dos itens de biossegurança.

A técnica referida como orientada ao usuário do PNCT para a colheita da amostra de escarro, pelos profissionais de saúde, mostrou-se em desacordo com recomendações do PNCT e do Manual de Orientação.

Embora só tenham sido observados 2 profissionais de saúde, que participaram de treinamentos e conheciam o Manual de Orientação, realizando orientações dos usuários do PNCT para a colheita das amostras de escarro, estes realizaram orientações mais adequadas ao PNCT. Por outro lado, práticas em desacordo ao PNCT foram mais frequentes no grupo de profissionais que não conheciam o Manual de Orientação ou que não participaram de treinamento e desconheciam o Manual de Orientação.

Os profissionais de saúde não utilizam as técnicas de comunicação terapêutica de validação nem de clarificação, em busca da comunicação efetiva, porém observou-se que atenção especial foi dispensada ao usuário já que a maioria dos profissionais reportaram-se ao usuário pelo nome, olharam para o mesmo ao solicitarem informações e ao serem solicitados, procuraram utilizar linguagem de fácil compreensão, ou seja, observou-se respeito ao usuário (SILVA 2002). Nesta avaliação acredita-se que deve ser levada em consideração a presença do pesquisador que acaba por interferir nas relações que se estabelecem no momento do atendimento ao usuário.

Dos profissionais entrevistados, $35,7 \%$ percebiam sua participação na colheita da amostra de escarro nas orientações que realizavam. A percepção da participação na colheita da amostra de escarro através do relacionamento e comunicação estabelecida com o usuário esteve mais presente no conteúdo da fala de profissionais de saúde que trabalhavam em AE, ambulatórios de DST/AIDS e PSF. Os tipos de 
serviços de saúde discriminados desenvolvem programas de atendimento preparando seus profissionais para o acolhimento dos usuários e, provavelmente, estes conhecimentos apreendidos em treinamentos específicos são utilizados no atendimento ao usuário do PNCT.

Dos 29 usuários do PNCT entrevistados 65,5\% demonstram-se favoráveis à colheita da amostra de escarro e 37,9\% demonstraram-se desfavoráveis para o procedimento. Foi observado que os profissionais de saúde ainda se referem à amostra de escarro utilizando palavras que demonstravam atitudes negativas, o que pode influenciar a percepção e a colheita do escarro pelo usuário do PNCT. Como já citado os usuários ainda não relacionam a importância do exame de escarro no controle do tratamento da tuberculose pulmonar.

Forçar a tosse e o peito, colher à noite e de manhã e colher em jejum, foram os procedimentos mais citados pelos usuários como orientação recebida pelos profissionais de saúde para a colheita da amostra de escarro, porém não se percebe nos relatos o conhecimento sobre a necessidade da realização de determinados procedimentos, além disso não foram os itens referidos com maior frequência pelos profissionais de saúde nem tampouco observados no acompanhamento da prática destes profissionais. Enfatiza-se a necessidade de orientações mais voltadas para a necessidade do usuário e não tão vinculadas aos procedimentos a serem cumpridos.

Ocorreu melhora do acondicionamento, transporte e quanto à qualidade das amostras de escarro enviadas ao laboratório, porém, o preenchimento das solicitações de baciloscopias permanecem sendo realizado sem atender às normas estabelecidas, dificultando o envio de informações para a Divisão de Tuberculose do CVE-SESSP. Existem ainda amostras enviadas sem identificação do frasco, solicitações de baciloscopias sem a devida identificação, não ocorre discriminação do tipo de amostra que está sendo enviada, as amostras são transportadas sem refrigeração e as solicitações de exame ainda são encaminhadas ao laboratório dentro das caixas de transporte juntamente com as amostras. Destaca-se o descuido às recomendações de biossegurança. 
6. Considerações Finais

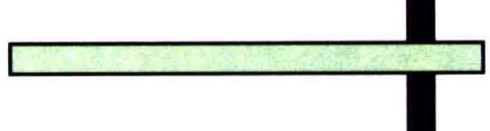


O objeto deste estudo foram as questões do preparo e da prática de profissionais de saúde e dos serviços de saúde relacionadas com a colheita da amostra de escarro, com ênfase na orientação do usuário sobre os procedimentos para a colheita do escarro e na adoção de cuidados necessários para o controle da disseminação da tuberculose nos ambientes de atendimento à saúde quando da obtenção e manipulação das amostras de escarro.

A colheita da amostra de escarro mostra-se essencial para o diagnóstico e para o controle da tuberculose pulmonar por ser o procedimento diagnóstico de eleição, respeitando preceitos internacionais.

Para que a amostra de escarro seja colhida e encaminhada aos laboratórios de análise em condições adequadas, todo cuidado deve ser tomado não só com relação a colheita, mas ao transporte e conservação da mesma, além do que, sua procedência deve ser bem conhecida para que os serviços de saúde possam identificar e ir em busca das fontes de infecção do $M$. Tuberculosis para o início imediato do tratamento.

Os profissionais de saúde devem estar preparados e comprometidos com as atividades do PNCT e para tanto necessitam participar de processos educativos, bem como ter acesso a materiais de consulta para esclarecimento de dúvidas e adequação de suas ações aos procedimentos preconizados. A possibilidade de aprimoramento, quer seja participando de projetos educativos ou tendo acesso a material de consulta de fácil assimilação, demonstra respeito aos profissionais o que reflete na forma como a população usuária é atendida.

Observou-se que, apesar da pequena amostra de serviços de saúde e das pequenas diferenças entre profissionais que participaram ou não de treinamentos e conheciam ou não o Manual de Orientação, elas existiram e precisam ser valorizadas como tal.

$\mathrm{O}$ tema relacionamento interpessoal deve ser destacado nas iniciativas de atualização dos profissionais de saúde pelos gestores do sistema, pois, a forma como o usuário do serviço de saúde é abordado influencia o atendimento ou não das solicitações realizadas pelos profissionais de saúde, além de contribuir para o 
desenvolvimento pessoal não só do usuário mas também do profissional de saúde que $o$ atende.

Não basta somente propiciar momentos de atualização, reciclagens, sensibilização, entre outros, é necessário também um trabalho de avaliação destes investimentos, como, conhecer quais profissionais estão participando dos eventos, qual a responsabilidade destes profissionais quando retornam ao serviço de saúde, ou seja, estabelecer-se um banco de dados de recursos humanos capacitados pois, a socialização do conteúdo desenvolvido no serviço de saúde, depende deste profissional.

A solicitação de baciloscopia para todo o indivíduo sintomático respiratório é determinante para o sucesso do programa e portanto, a colheita do escarro, definitivamente deve deixar de ser algo sofrível para as pessoas, necessitamos facilitar para que o indivíduo esforce-se na colheita da amostra de escarro e, necessitamos torná-lo consciente da importância deste esforço.

O acompanhamento das atividades dos serviços de saúde necessitam deixar de ser somente através de planilhas e números pleiteando-se métodos que se aproximem da realidade de atuação de cada serviço, aproximando-se da prática dos profissionais, da relação que se estabelece com os usuários do PNCT pois, a prática dos profissionais de saúde e o resultado dela, é permeada pela percepção e interpretação deste profissional. O gestor local necessita ser sensibilizado para tal acompanhamento.

"Quem pensa certo está cansado de saber que as palavras a que falta a corporeidade do exemplo pouco ou nada valem. Pensar certo é fazer certo"

Paulo Freire (2000)

Aproximar-se do ideal deveria ser o intuito dos profissionais de saúde que optam por exercer suas atividades nos serviços públicos de saúde, onde sabe-se que, por uma série de motivos, nem sempre existem as condições adequadas para o desenvolvimento do trabalho e atendimento das necessidades das pessoas que procuram o serviço. Porém, se existe a intenção de fazer o certo, como cita Freire 
(2000), isto deve transformar-se em ações, para que não se percam as iniciativas e investimentos no decorrer do tempo.

“...o medo de amar é o medo de ser livre para sempre estar onde o justo estiver... o medo de amar é não arriscar esperando que façam por nós o que é nosso dever, recusar o poder..."

Beto Guedes 
7. Referências Bibliográficas

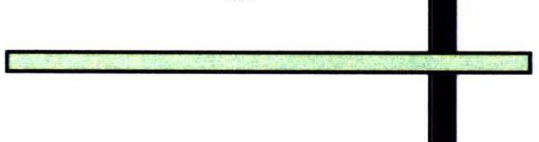




\section{Referências Bibliográficas:}

- American Lung Association - ALA. Tuberculosis and health workers. [on line] 2003. Disponível em http//www.Lungusa.org/site/pp.asp?c=dvluk900E\&b=23041

- Bertolozzi MR A adesão ao programa de controle da tuberculose no distrito sanitário do Butantã, São Paulo. São Paulo; 1998. [Tese de Doutorado Faculdade de Saúde Pública da Universidade de São Paulo].

- Bowman GS; Thompson DR; Sutton TW Nurse's atittudes towards the nursing process. J. Adv. Nurs. 1986; 8(2):125-9.

- Boylard EA, Tablan OC, Williams WW, Pearson ML, Shapiro N, Deitchman SD et al. Guideline for Infection Control in Health Care Personnel - Central of Desease Control. Trad. de CR Pereira. São Paulo: APECIH; 1998

- Brasil. Decreto lei n.7.498, de 25 de Junho de 1986. Dispõe sobre a regulamentação do exercício da Enfermagem e dá outras providencias. Diário Oficial da União, Brasília, 26 Jun 1986. Seção I, p. 9273-75.

- Brasil. Instituto para o Desenvolvimento da Saúde. Universidade de São Paulo. Ministério da Saúde. Manual de Enfermagem: Programa Saúde da Família. $1^{\text {a }}$ ed. Brasília; 2001

- Brasil. Ministério da Saúde. Secretaria de políticas de Saúde. Departamento de Atenção Básica. Manual Técnico para o controle da Tuberculose: Cadernos de Atenção Básica, 6a ed. Brasília; 2002.

- Brasil. Ministério da Saúde. Portaria $\mathrm{n}^{\circ}$ 1474, de 21.8.2002: dispõe sobre as alterações quanto aos requisitos necessários para o pagamento do Incentivo para 
o Controle da Tuberculose na Atenção Básica de Saúde. Diário Oficial da Nação, Brasília, 21 ago. 2002b. Seção 1.

- Brasil. Ministério da Saúde. Fundação Nacional de Saúde. Tuberculose: guia de vigilância epidemiológica. $1^{\text {a }}$ ed. Brasília; 2002c

- Brasil. Ministério da Saúde. Fundação Nacional de Saúde. Centro de Referência Prof. Hélio Fraga. Sociedade Brasileira de Pneumologia e Tisiologia. Controle da Tuberculose: uma proposta de integração ensino-serviço. $5^{\circ}$ ed. Rio de Janeiro; 2002d.

- Campinas LLSL Conhecimentos e opiniões de usuários sobre o valor do exame de escarro, de um serviço de saúde do município de São Paulo visando a qualidade das amostras para o diagnóstico da tuberculose pulmonar pelo método bacteriológico. São Paulo; 1999. [Dissertação de Mestrado - Faculdade de Saúde Pública da USP].

- Candeias N, Marcondes RS Diagnóstico em saúde: um modelo para analisar as relações entre atitudes e práticas na área da Saúde Pública. Revista S. Pública. $1979 ; 13: 62-8$.

- Capuano DA Busca ativa de casos de tuberculose pulmonar em uma unidade de atendimento em farmacodependência do Município de São Paulo. Campinas; 2001. [Dissertação de Mestrado. FCM. UNICAMP.]

- Cox T, Griffiths A, González ER Research on Work-Related Stress. Institute of Work, Health and Organisations, United Kingdom, April 2000.

- D'Amorin MA A medida na teoria da ação racional. In: Pasquali L. Teoria e métodos de medida em ciências sociais do comportamento. Brasília: INEP; 1996. 
- Daniel LF. Atitudes interpessoais em enfermagem. São Paulo: EPU; 1983.

- Declaração de Alma Ata. Disponível em www.saude.gov.br

- Declaração de Ottawa disponível em www.saude.gov.br

- Diáz AP Educação Ambiental como Projeto. Barcelona: Editorial Horsori; 1995.

- Diniz TMRG O estudo de caso: suas implicações metodológicas na pesquisa em serviço social. In: Martinelli ML Pesquisa Qualitativa: um instigante desafio. São Paulo: Veras Editora; 1999

- Freire P Pedagogia da Autonomia: saberes necessários à prática educativa. São Paulo: Paz e Terra; 2000.

- Galesi VM, Almeida MMMB, Santos LAR Tuberculosis case-findig campaign, são Paulo, Brazil. The International Journal of Tuberculosis and Lung Disease, n 11, v.5, p.S91 nov. 2001 supp 1.

- Green LW e col. Health education planning - A diagnostic approach. Palo Alto, Ca:Mayfield, 1980.

- Harries NJ, Hargreaves NJ, Gausi F, Kwanjana JH, Solaniponi FM. Preventing tuberculosis among health workers in Malawi. Bull World Health Organization 2002; 80: 526-31.

- ILO 1986, Psychosocial Factors At Work: Recognition and Control, Report of the Joint ILO/WHO Committee on Occupational Health, $9^{\text {th }}$ Session, Geneva, 18-24/09/84, Occupational Safety and Health Series $n^{\circ} 56$. 
- Jamarillo E. The impact of media-based health education on tuberculosis diagnosis in Cali, Colombia. Health Policy and Planning 2001; 16:68-73.

- Kurcgant P, Castilho V, Leite M.M.J Capacitação do profissional de saúde no âmbito da formação e da educação continuada. Rev.Esc.Enf.USP. 1994; 28(3): p.215-6, dez.1994.

- Lane STM Estudo sobre o significado de adjetivos utilizados nas escalas do diferencial semântico de C. Osgood. Rev Psicol Normal Patol 1969; 15:267-94.

- Martin F. et alii Depression and Burnout in Hopital Health Care Professionals. Int. J. Occup. Environ Health. Vol.3, n³, jul.sep.1997.

- Mazzaia MC Conhecimentos, atitudes e práticas do pessoal de enfermagem visando a qualidade e amostras de escarro para a baciloscopia no diagnóstico da tuberculose pulmonar. São Paulo, 2000. [Dissertação de Mestrado - Faculdade de Saúde Pública da USP].

- Mazzaia MC, Campinas LSL, Matsumoto NF, Biagolini REM, Ferraz SMP, Arpiani SO O uso de pré e pós-teste na avaliação do incremento de conhecimento adquirido em treinamento de profissionais da rede básica de serviços de saúde para o Programa Nacional de Controle da Tuberculose. In: Anais do VII Congresso Brasileiro de Saúde Coletiva ; 2002 jul 29-ago 2; Brasília, Brasil. Brasília: Associação Brasileira de Pós-Graduação em Saúde Coletiva; 2002b

- Mazzaia MC, Campinas LSL, Matsumoto NF, Biagolini REM, Ferraz SMP, Arpiani SO A realidade das unidades de saúde quanto a coleta de amostras de escarro: a situação do município e região metropolitana de São Paulo. In: Anais do VIII Congresso Paulista de Saúde Pública - re-vendo teorias e práticas ; 
2002 out; Ribeirão Preto, Brasil. Ribeirão Preto: Associação Pulista de Saúde Pública; 2002b

- Mendes IAC Enfoque humanístico à comunicação em enfermagem. São Paulo: Sarvier, 1994.

- Miranda CF, Miranda ML Construindo a relação de ajuda. Belo Horizonte: Crescer;1983.

- Mizukami MGN Ensino: as abordagens do processo. São Paulo: EPU, 1986

- Moysés MAA, Geraldi JW, Collares CAL As aventuras do conhecer: da transmissão à interlocução. Educação e Sociedade.2002; XXIII(78):

- Niero R Emprego do Método bacteriológico nos programas de controle da tuberculose. Rev Saúde Pública 1977; 11:416-26.

- Niero R; Derntl AM. Dificultades identificadas por profissionales de salud durante la realización de los procedimientos establecidos en el progama de control de tuberculosis pulmonar para el examen microscópico de esputo. In: Libro de resumenes de la Union Latinoamericana de Sociedades de Tisiologia y Enfermidades Respiratórias; 1993; Lima. p.260.

- Niero R; Derntl AM; Guardado YM. Razões de recusa de amostras de escarro para a pesquisa de BAAR por um laboratório regional de Saúde Pública São Paulo - Brasil. LAES HAES 1996; 103:122-30.

- Niero R; Derntl AM. Formulário de pedido de baciloscopia e informe de resultados. Um novo modelo. In: Programa do $2^{\circ}$ Congresso Brasileiro de SaúdeColetiva; 1989 a; São Paulo p.80. 
- Niero R; Derntl AM Análise de desempenho do pessoal de Enfermagem na realização de procedimentos do Programa de Controle da Tuberculose visando a qualidade das amostras de escarro para microscopia direta de BAAR. Estudo I. In: Anais do $2^{\circ}$ Sim- pósio Brasileiro em Micobactérias; 1989b; São Paulo. SãoPaulo: Instituto Biológico; 1989 b. p.2.

- Pereira CAA. O diferencial semântico: uma técnica de medida nas ciências sociais. São Paulo: Ática; 1986.

- Piovesan A Percepção cultural dos fatos sociais: suas implicações no campo da saúde pública. Rev Saúde Pública 1970; 4: 85-97.

- Polit DF, Hungler BP. Fundamentos da pesquisa em enfermagem. Porto Alegre: Artes Médicas; 1995.

- Ravaglione MC. The TB Epidemic from 1992 to 2002. Tuberculosis 2003; 83: 4-14.

- Rouillon A. Discussão de problemas sobre a organização de um tratamento eficaz para doentes tuberculosos. [artigo traduzido por Marília Belluomini do Bol. Uni. Inter. 1972; 47 ].

- Rosa S. S. Construtivismo e Mudança. $7^{a}$ ed. São Paulo: Cortez; 2000

- Ruffino Neto A. Programa de Controle da Tuberculose no Brasil: situação atual e novas perspectivas. Inf. Epidemiológico SUS 2001; 10:129-38.

- Santos EAV. Biossegurança: conhecimentos, acidentes e cobertura vacinal entre enfermeiras. São Paulo, 2003. [Dissertação de Mestrado - Universidade Federal de São Paulo]. 
- [SES] Secretaria de Estado da Saúde. Centro de Vigilância Epidemiológica "Prof. Alexandre Vranjac". Divisão de tuberculose. Disponível em:<http//www.cve.saúde.gov.br/htm/Tb_c_es.htm.>

- Secretaria de Estado da Saúde (SES). Centro de Vigilância Epidemiológica "Prof. Alexandre Vranjac". Tuberculose: recomendações para redução do risco de transmissão em serviços de saúde. $2^{\text {a }}$ ed. São Paulo; 2003

- Secretaria de Estado da Saúde. Centro de Vigilância Epidemiológica "Prof. Alexandre Vranjac”. Divisão de Tuberculose. Manual de Orientação para Coleta de Amostras de Escarro e outros Materiais para Baciloscopia e Cultura para Diagnóstico e Controle da Tuberculose. 1ª ed. São Paulo; 2002.

- Secretaria de Estado da Saúde. Programa Estadual DST-AIDS. Centro de Referência e Treinamento. Biossegurança; 1998 I(1).

- Secretaria da Saúde do Município de São Paulo. Coordenadoria da Vigilância em Saúde. Centro de Controle de Doenças. Coordenação do Programa de controle de Tuberculose. Gerência de Comunicação e Educação da Vigilância em Saúde. Tuberculose: operação apague essa mancha! São Paulo; 2004. [Folheto educativo - Prefeitura do Município de São Paulo]

- Silva MJP Comunicação tem remédio: a comunicação nas relações interpessoais em saúde. São Paulo: Editora Gente; 1996.

- Silva MJP O papel da comunicação na humanização da atenção à saúde. Bioética; 2002 10(2):73-88.

- Souza AMA, Galvão E A, Santos I, Roschke MA Processo Educativo nos Serviços de Saúde. Brasília, OPAS, 1991. 
- Souza M Assistência de Enfermagem em Infectologia. São Paulo: Atheneu, 2000.p11-14; 281-287.

- Stefanelli M.C. Comunicação com o paciente : teoria e ensino. São Paulo: Robe; 1993.

- Smith PG; Moss AR. Epidemiology of Tuberculosis. In: Bloom B R Tuberculosis: pathogenesis, protection ande control. Washington (DC), ASM Press; 1994. p.3-11.

- Tanaka O Y Avaliação da qualidade dos serviços básicos de saúde: o estudo do Distrito de Brasilândia. São Paulo; 1994. [Tese de Livre -Docência Faculdade de Saúde Pública da USP].

- Taylor CM Mereness' Essentials of Psychiatric Nursing. Cleveland: The C.V.Mosby Company; 1992.

- World Health Organization. Global Tuberculosis Control: Surveillance, planning, financing. Report. Geneva; 2002. Disponível em <URL:http://www.who. int/ doc store/gtb/publications/globrep02/contents.html>

- World Health Organization. Global Tuberculosis Control: Surveillance, planning, financing. Report. Geneva; 2003. Disponível em <URL:http://www.who. int/ doc store/gtb/publications/globrep03/contents.html> 
ANEXOS

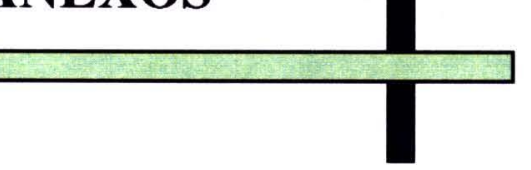




\section{ANEXO 1}

Treinamento para coleta de material para baciloscopia e cultura para diagnóstico e controle de tratamento de tuberculose pulmonar

\section{Pré e pós-teste}

1- Para descobrir casos de TB na comunidade devemos pesquisar:

a) Sintomáticos respiratórios

b) Comunicantes de casos de TB

c) Suspeitos radiológicos

d) Pessoas com condição social e doenças que predisponham a TB

e) Todas as alternativas estão corretas

2- Em relação à coleta de escarro para pesquisa de BK (Bacilo de Koch):

a) devem ser colhidas duas amostras, uma no momento da suspeita e a Segunda no dia seguinte ao despertar

b) pode ser armazenado em geladeira por até 7 dias

c) é um método simples e barato

d) as amostras devem ser encaminhadas de preferência no mesmo dia da coleta para o laboratório

e) todas as alternativas estão corretas

3- O local adequado para coleta de escarro deve ser:

a) no banheiro dos clientes onde é mais privativo

b) na sala de medicações onde o profissional de enfermagem pode acompanhar e orientar

c) na sala de inalação pois se tiver dificuldade fará inalação

d) em local reservado por ser mais privativo

e) em local em que haja troca de volumes de ar ou locar aberto
6- A orientação para a coleta de escarro é:

a) escarrar o quanto puder no pote de coleta

b) respirar fundo, segurar o ar o máximo possível e por fim escarrar no pote de coleta. Repetir este procedimento por 3 vezes se necessário

c) inspirar profundamente, reter 0 ar por alguns instantes, tossir e escarrar no pote de coleta, repetir este procedimento por 3 vezes até atingir a quantidade necessária

d) inspirar profundamente, reter $\mathrm{o}$ ar por alguns instantes, tossir por 3 vezes e escarra no pote a quantidade necessária

e) inspirar profundamente, reter $\mathrm{o}$ ar por alguns instantes, tossir o máximo possível para que se consiga o máximo de secreção e por fem, escarrar no pote de coleta.

7- Na coleta de escarro:

a) todos os clientes com secreção têm muita facilidade de colher a amostra

b) independente de idade e de sexo, todos conseguem colher a amostra

c) mulheres, crianças e portadores de HIV e AIDS têm dificuldade de coletar a amostra

d) quanto mais idoso (a) mais facilidade de colher a amostra

e) com a orientação correta todos conseguem colher a amostra 
4- A boa amostra de escarro é aquela que provém:

a) da árvore brônquica

b) da faringe

c) de aspirações de secreções nasais e pulmonares

d) da faringe, de sevreções nasais e da árvore brônquica

e) da saliva e pulmonar

5- O volume ideal da amostra de escarro é:
a) $3 \mathrm{a} 4 \mathrm{ml}$
b) 2 a $5 \mathrm{ml}$
c) 5 a $10 \mathrm{ml}$
d) $10 \mathrm{a} 20 \mathrm{ml}$
e) $15 \mathrm{a} 20 \mathrm{ml}$

8- A $2^{\text {a }}$ amostra de coleta de escarro deve ocorrer logo ao despertar porque:

a) deve-se ter um período para que seja colhido uma amostra diferente da $1^{\mathrm{a}}$

a) se obtém uma amostra mais abundante pois as secreções pulmonares se acumulam durante a noite

b) a quantidade de tosse é maior do que no restante do dia

c) durante o dia, quando o cliente está ativo, tem que tossir mais para se colher a amostra

d) todas alternativas estão corretas

9- Os bacilos que conseguem atingir os alvéolos e causar infecção pulmonar são: a) os advindos da tosse, fala e espirro do doente
a) as gotículas de Flügger
b) os Núcleos de Wells
c) os das gotículas de Flügger e dos núcleos de Wells
d) Todas as alternativas estão corretas 


\section{ANEXO 2}

Levantamento de dados nas unidades de saúde com relação à coleta de amostra de escarro

1. Qual (is) profissional (ais) que preenche (em) a requisição de coleta de amostra de escarro em sua unidade ?

2. Qual é o local utilizado para a coleta de escarro ?

3. Você já tinha participado de um treinamento de coleta de amostra de escarro? Algum outro profissional da unidade participou anteriormente deste tipo de treinamento ?

4. Há rodízio do pessoal que atende os clientes para a coleta de escarro ?

5. Quanto tempo tem demorado para chegar o resultado de baciloscopia em sua unidade? 


\section{ANEXO 3}

\section{Entrevista}

*Idade: anos Escolaridade: ( ) I Grau

( ) II Grau ( ) III Grau

*Função:
( ) Atendente
( ) Auxiliar de Enfermagem
( ) Técnico de Enfermagem
( ) Visitador Sanitário
( ) Outro. Qual:

Há quanto tempo trabalha na função acima:

*Participou de algum treinamento/reciclagem sobre tuberculose/colheita de amostra de escarro? ( ) $\operatorname{sim}$ ( ) não

Há quanto tempo: (dias, meses, anos)

Que informações recebeu neste treinamento/reciclagem ?

*Como foi para você participar deste treinamento?

*Qual sua opinião sobre o Manual de Orientação para Coleta de Amostras de Escarro e outros Materiais para Baciloscopia e Cultura para Diagnóstico e Controle da Tuberculose?

*O que é baciloscopia de escarro, pesquisa de BK no escarro ou exame de escarro ?

*Qual a importância deste exame ?

*Conte com detalhes como é realizada a orientação do paciente para a colheita da amostra de escarro

*Como você vivencia, vê, percebe a sua participação na colheita da amostra de escarro ? 


\title{
ANEXO 4 \\ Entrevista Profissionais de laboratório - Unidade: Data:
}

1. De acordo com sua experiência de trabalho na área de baciloscopia, como você tem percebido, em relação às amostras de escarro enviadas para a sua unidade:

a) acondicionamento das amostras ?

b) transporte das amostras?

c) preenchimento das requisições das amostras ?

d) A qualidade das amostras de escarro enviadas ?

\begin{abstract}
ANEXO 5
Entrevista com Usuários do Serviço de Saúde - Unidade código:

Idade: $\quad$ Escolaridade: $\quad$ Sexo:
\end{abstract}

1. Vejo que o $\mathrm{Sr}\left({ }^{a}\right)$ leva pote de coleta de exame, que exame o $\mathrm{Sr}\left({ }^{a}\right)$ vai fazer ?

2. O que o $\mathrm{Sr}\left({ }^{(a)}\right.$ pensa/acha sobre colher este exame ?

3. Para o $\mathrm{Sr}\left({ }^{\mathrm{a}}\right)$, para que serve este exame ?

4. Como foi explicado para o $\mathrm{Sr}\left({ }^{a}\right)$ colher este exame ? 


\section{ANEXO 6}

Local:

\section{Roteiro de Observação}

Orienta o paciente a colher a amostra de escarro
( ) $\operatorname{sim}$
( ) não

\section{COMUNICAÇÃO}

1.Recebe o paciente dirigindo-se ao mesmo pelo nome
( ) $\operatorname{sim}$
( ) não
( ) às vezes

2. Olha para o paciente quando se dirige ao mesmo
( ) $\operatorname{sim}$
( ) não
( ) às vezes

3. Olha para o paciente quando este responde às solicitações feitas
( ) $\operatorname{sim}$
( ) não
( ) às vezes

4. Utiliza gestos enquanto orienta o paciente (comunicação não verbal)
( ) $\operatorname{sim}$
( ) não
( ) às vezes

5.Utiliza linguagem de fácil compreensão para o paciente
( ) sim
( ) não
( ) às vezes

6.Quando solicita informações do paciente, espera pela resposta do mesmo
( ) $\operatorname{sim}$
( ) não
( ) às vezes

7. Clarifica os termos utilizados pelo paciente
( ) $\operatorname{sim}$
( ) não
( ) às vezes

8. Valida a compreensão da mensagem enviada e recebida
( ) $\operatorname{sim}$
( ) não
( ) às vezes

\section{ORIENTAÇÃO DO PROCEDIMENTO DE COLHEITA DA AMOSTRA DE ESCARRO}

Colheita da amostra de escarro para diagnóstico da tuberculose pulmonar

1. Explica a importância do exame para o paciente
( ) $\operatorname{sim}$
( ) não

2.Orienta o paciente a lavar a boca ou bochechar com água antes de expectorar
( ) $\operatorname{sim}$
( ) não

3.Explica a necessidade de eliminar resíduos de alimento antes de colher o escarro
( ) $\operatorname{sim}$
( ) não 
4.Explica a necessidade de eliminar resíduos de pasta de dente antes de colher a amostra de escarro
( ) $\operatorname{sim}$
( ) não

5. Orienta o paciente a inspirar profundamente
( ) $\operatorname{sim}$
( ) não

6.Orienta o paciente a reter o ar inspirado por alguns instantes

( ) $\operatorname{sim}$ ( ) não

7.Orienta o paciente a tossir de boca aberta lançando o material proveniente no recipiente plástico após ter retido o ar

( ) $\operatorname{sim} \quad$ ( ) não

8.Demonstra com o frasco plástico adequado a quantidade de material a ser colhida
( ) $\operatorname{sim}$
( ) não

9. Explica a necessidade do escarro ser proveniente de região mais profunda e não da região oro-faringe
( ) $\operatorname{sim}$
( ) não

10. Orienta o paciente a repetir os ítens 5-6 e 7 acima citados por mais duas vezes para se conseguir a quantidade de escarro desejada
( ) $\operatorname{sim}$
( )não

11. Orienta o paciente a fechar o recipiente herméticamente tomando o cuidado de permanecer com o mesmo

sempre com a tampa para cima
( ) $\operatorname{sim}$
( ) não

12.Orienta o paciente a envolver o recipiente plástico em papel limpo para transporte até a unidade de saúde
( ) $\operatorname{sim}$
( ) não

13. Orienta o paciente a lavar as mãos após a colheita do escarro
( ) $\operatorname{sim}$
( ) não

14.Explica a necessidade de lavar as mãos após a colheita de escarro
( ) $\operatorname{sim}$
( ) não

15.Orienta o paciente a colher uma amostra no dia da consulta na unidade e uma no dia seguinte pela manhã
( ) $\operatorname{sim}$
( ) não 
16.Valida a compreensão da mensagem enviada
( ) $\operatorname{sim}$
( ) não (se não passe para o ítem 18)

17. Muda a linguagem quando necessita repetir a orientação
( ) $\operatorname{sim}$
( ) não

18.Procura saber do paciente se ele quer fazer alguma pergunta

( ) $\operatorname{sim} \quad$ ( ) não

Colheita da amostra de escarro - Pacientes em controle de tratamento

1.Procura saber do paciente como o mesmo colhe a amostra de escarro
( ) $\operatorname{sim}$
( ) não
(se não passe para ítem 3)

2.No caso do paciente estar colhendo a amostra de escarro de forma incorreta informa ao paciente sobre

o fato

$\begin{array}{ll}\text { ( ) } \operatorname{sim} \text { ( ) não } & 0\end{array}$

3. Explica para o pacientea importância do exame para o controle do tratamento
( ) sim
( ) não

4.Orienta o paciente a lavar a boca ou bochechar com água antes de expectorar
( ) $\operatorname{sim}$
( ) não

5.Explica a necessidade de eliminar resíduos de alimento antes de colher o escarro
( ) $\operatorname{sim}$
( ) não

6.Explica a necessidade de eliminar resíduos de pasta de dente antes de colher a amostra de escarro
( ) $\operatorname{sim}$
( ) não

7. Orienta o paciente a inspirar profundamente
( ) $\operatorname{sim}$
( ) não

8.Orienta o paciente a reter $\mathrm{o}$ ar inspirado por alguns instantes
( ) $\operatorname{sim}$
( ) não

9.Orienta o paciente a tossir lançando o material proveniente no recipiente plástico após ter retido o ar
( ) $\operatorname{sim}$
( ) não

10.Demonstra com o frasco plástico adequado a quantidade de material a ser colhida
( ) $\operatorname{sim}$
( ) não 
11. Explica a necessidade do escarro ser proveniente de região mais profunda e não da região oro-faringe
( ) $\operatorname{sim}$
( ) não

12. Orienta o paciente a repetir os ítens $7-8$ e 9 acima citados por mais duas vezes para se conseguir a quantidade de escarro desejada
( ) $\operatorname{sim}$
( )não

13.Orienta o paciente a fechar o recipiente herméticamente tomando o cuidado de permanecer com o mesmo sempre com a tampa para cima
( ) $\operatorname{sim}$
( ) não

14.Orienta o paciente a envolver o recipiente plástico em papel limpo para transporte até a unidade de saúde
( ) $\operatorname{sim}$
( ) não

15. Orienta o paciente a lavar as mãos após a colheita do escarro
( ) $\operatorname{sim}$
( ) não

16.Explica a necessidade de lavar as mãos após a colheita de escarro
( ) $\operatorname{sim}$
( ) não

17.Orienta o paciente a colher o escarro sómente no dia de levar a amostra para o posto
( ) $\operatorname{sim}$
( ) não

18.Valida a compreensão da mensagem enviada
( ) $\operatorname{sim}$
( ) não (se não passe para o ítem 20)

19. Muda a linguagem quando necessita repetir a orientação
( ) $\operatorname{sim}$
( ) não

20.Procura saber do paciente se ele quer fazer alguma pergunta
( ) $\operatorname{sim}$
( ) não 
ANEXO 7

\section{Termo de Consentimento Livre e Esclarecido Dados sobre Pesquisa Científica}

Pesquisadora: Maria Cristina Mazzaia - Enfermeira Mestre em Saúde Pública (011) 9371-17-16 Tema: Atendimento no Programa de Controle da Tuberculose

\section{Registro das explicações da pesquisadora aos sujeitos sobre a pesquisa:}

1. O presente estudo tem por objetivo contribuir com o aprimoramento das ações de controle do Programa Nacional de Controle da Tuberculose

2. As informações obtidas serão tratadas com extremo sigilo, preservando-se o anonimato dos respondentes. Não haverá divulgação personalizada das informações.

3. Para a coleta de dados serão preenchidos formulários de escalas, roteiros de observação e serão gravadas entrevistas para posterior avaliação dos dados.

Esclarecimentos dados pelo pesquisador sobre as garantias do sujeito da pesquisa:

1. Acesso, a qualquer tempo, às informações sobre procedimentos, riscos e benefícios relacionados à pesquisa, inclusive para dirimir eventuais dúvidas;

2. Liberdade de retirar seu consentimento a qualquer momento e de deixar de participar do estudo

3. Salvaguarda da confidencialidade, sigilo e privacidade

4. Qualquer questão, dúvida, esclarecimento ou reclamação sobre os aspectos éticos dessa pesquisa, favor entrar em contato com Comitê de Ética em Pesquisas da Secretaria Municipal da saúde de São Paulo - Rua General Jardim, 36 - $2^{\circ}$ andar - tel.: 3218-4043 - email: smscep@ prefeitura.sp.gov.br

Declaro que , após convenientemente esclarecido pelo pesquisador e ter entendido o que me foi explicado, consinto em participar da presente Pesquisa. 